\title{
Retrosynthetic Analysis of $\alpha$-Alkenyl- $\beta$-Diketones: Regio- and Stereoselective Two-Step Synthesis of Highly Arylated Representatives from Acetylenes, Ketones, and Acyl Chlorides
}

Dmitrii A. Shabalin, Elena V. Ivanova, Igor' A. Ushakov, Elena Yu. Schmidt, and Boris A. Trofimov*

A.E. Favorsky Irkutsk Institute of Chemistry, Siberian Branch of the Russian Academy of Sciences, 1 Favorsky St, Irkutsk 664033, Russian Federation

*E-mail: boris_trofimov@irioch.irk.ru

\section{Table of Contents}

${ }^{1} \mathrm{H}$ and ${ }^{13} \mathrm{C}$ NMR Spectra of Ketone 1c................................................................... S2

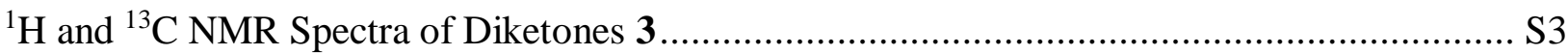

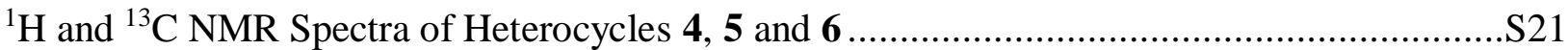

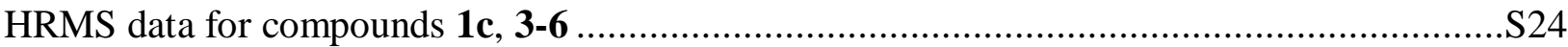


${ }^{1} \mathrm{H}$ and ${ }^{13} \mathrm{C}$ NMR Spectra of Ketone 1c
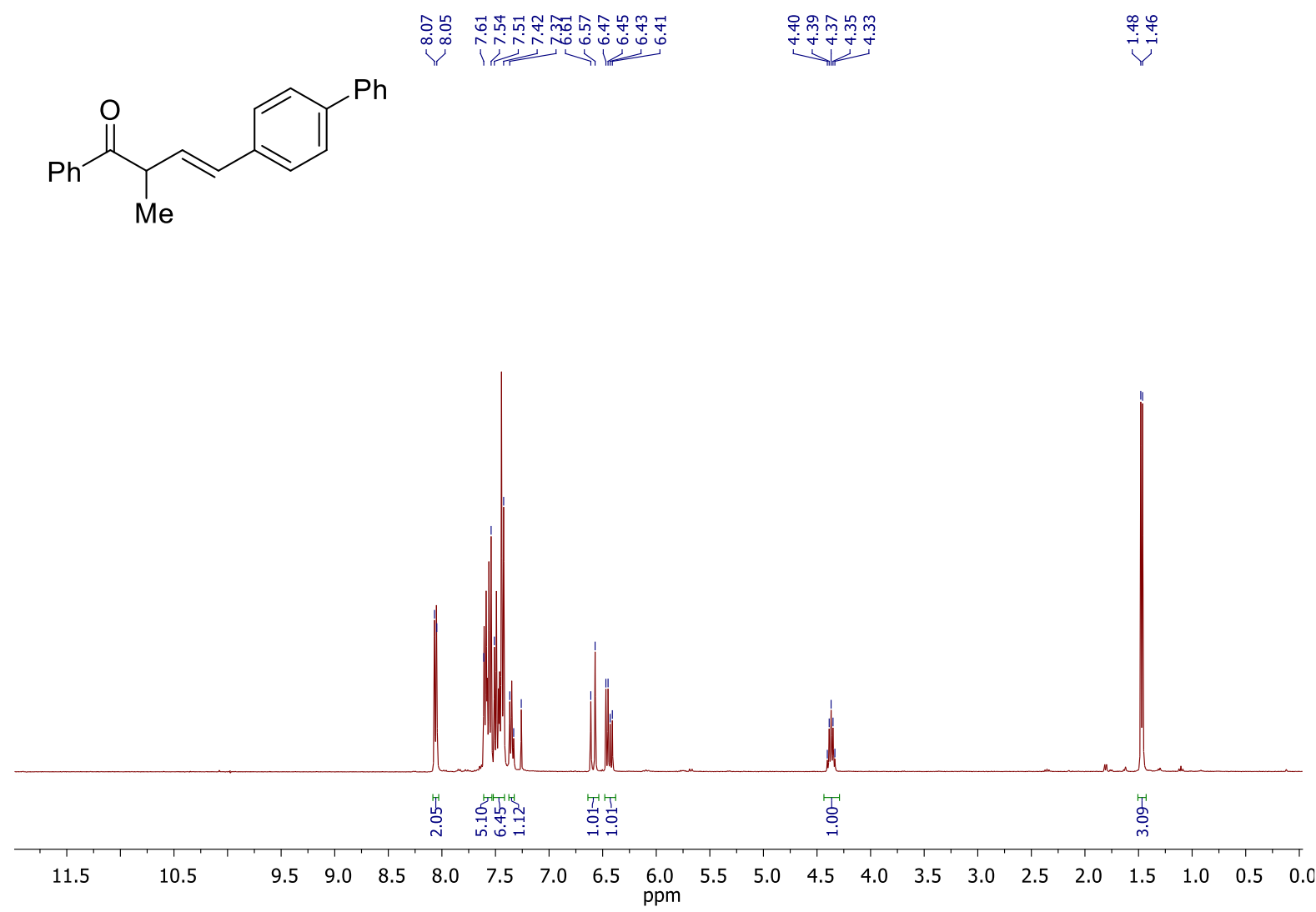

${ }^{1} \mathrm{H}$ NMR spectrum of $1 \mathrm{c}\left(400.1 \mathrm{MHz}, \mathrm{CDCl}_{3}\right)$

\begin{tabular}{|c|c|}
\hline & 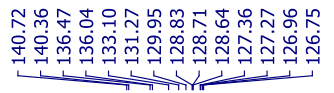 \\
\hline
\end{tabular}

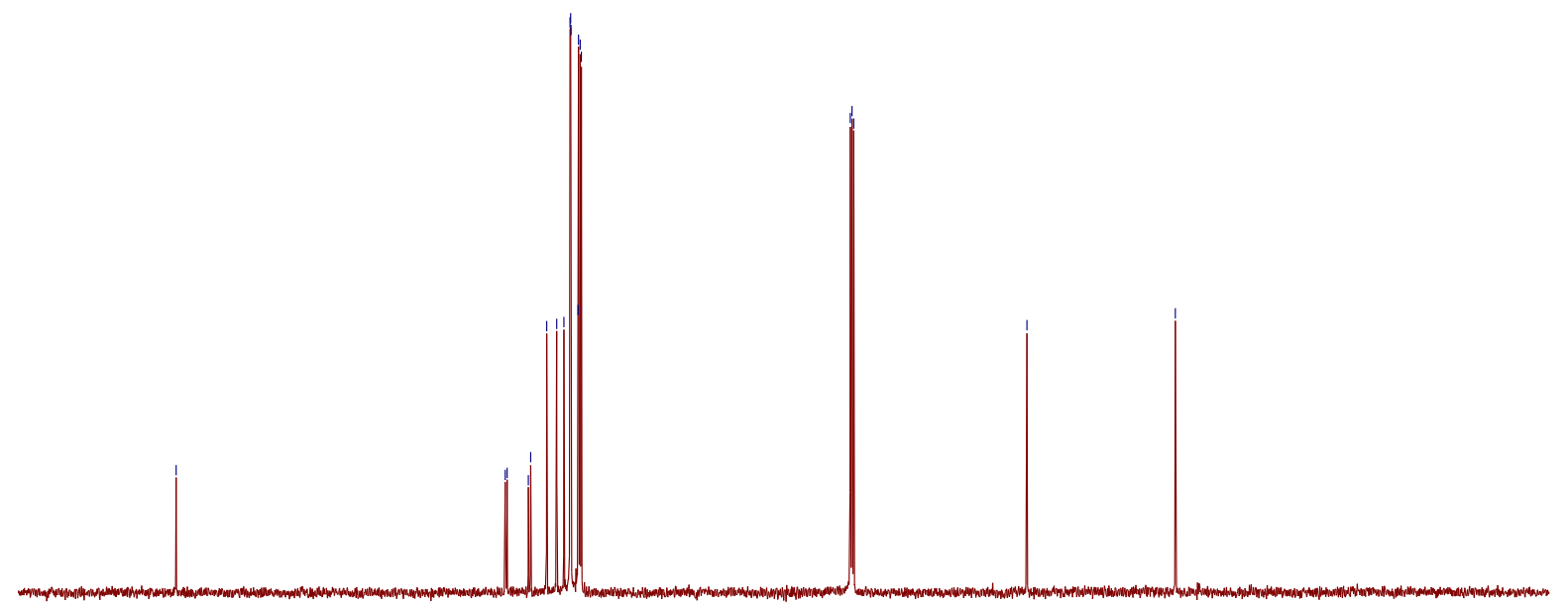

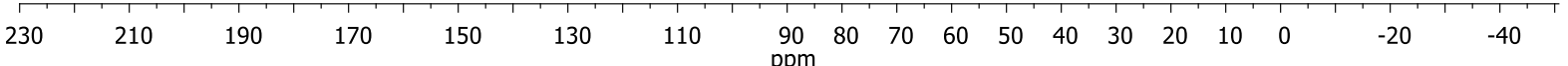

${ }^{13} \mathrm{C}$ NMR spectrum of $\mathbf{1 c}\left(100.6 \mathrm{MHz}, \mathrm{CDCl}_{3}\right)$ 
${ }^{1} \mathrm{H}$ and ${ }^{13} \mathrm{C}$ NMR Spectra of Diketones 3

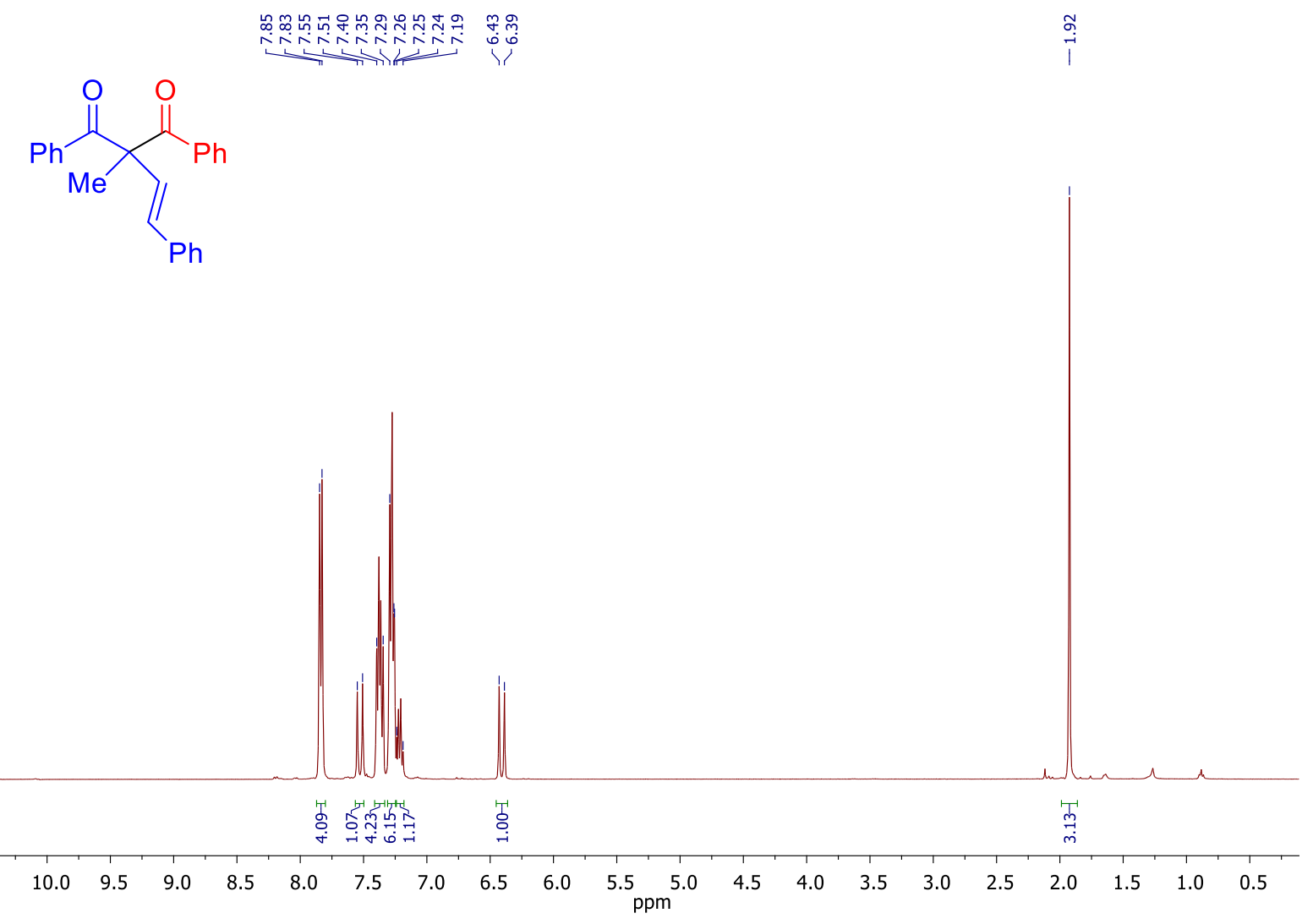

${ }^{1} \mathrm{H}$ NMR spectrum of $\mathbf{3 a a}\left(400.1 \mathrm{MHz}, \mathrm{CDCl}_{3}\right)$

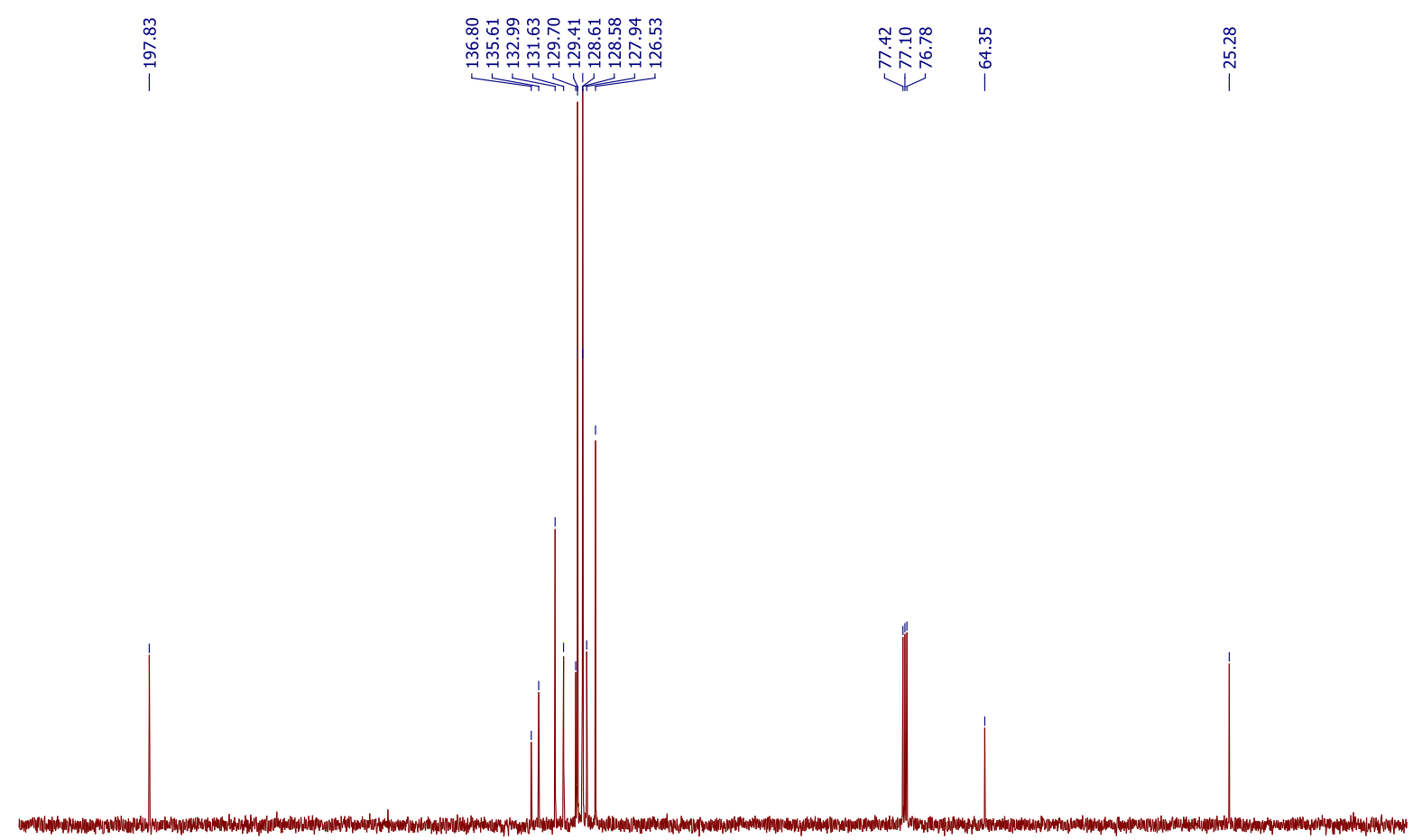

$\begin{array}{lllllllllllllllllllllll}210 & 200 & 190 & 180 & 170 & 160 & 150 & 140 & 130 & 120 & \underset{\mathrm{ppm}}{110} & 100 & 90 & 80 & 70 & 60 & 50 & 40 & 30 & 20 & 10 & 0\end{array}$

${ }^{13} \mathrm{C}$ NMR spectrum of $3 \mathbf{a a}\left(100.6 \mathrm{MHz}, \mathrm{CDCl}_{3}\right)$ 


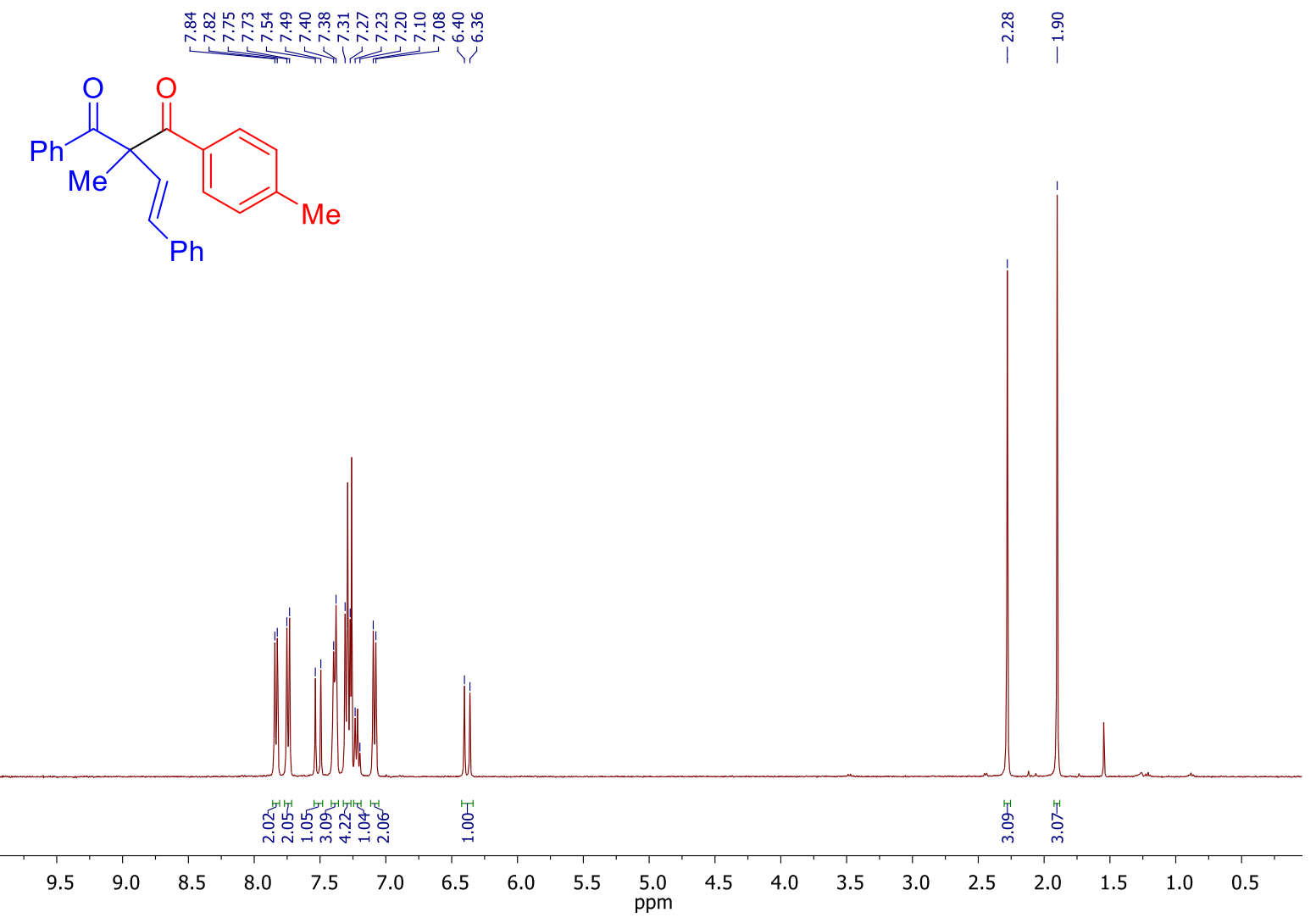

${ }^{1} \mathrm{H}$ NMR spectrum of $\mathbf{3 a b}\left(400.1 \mathrm{MHz}, \mathrm{CDCl}_{3}\right)$

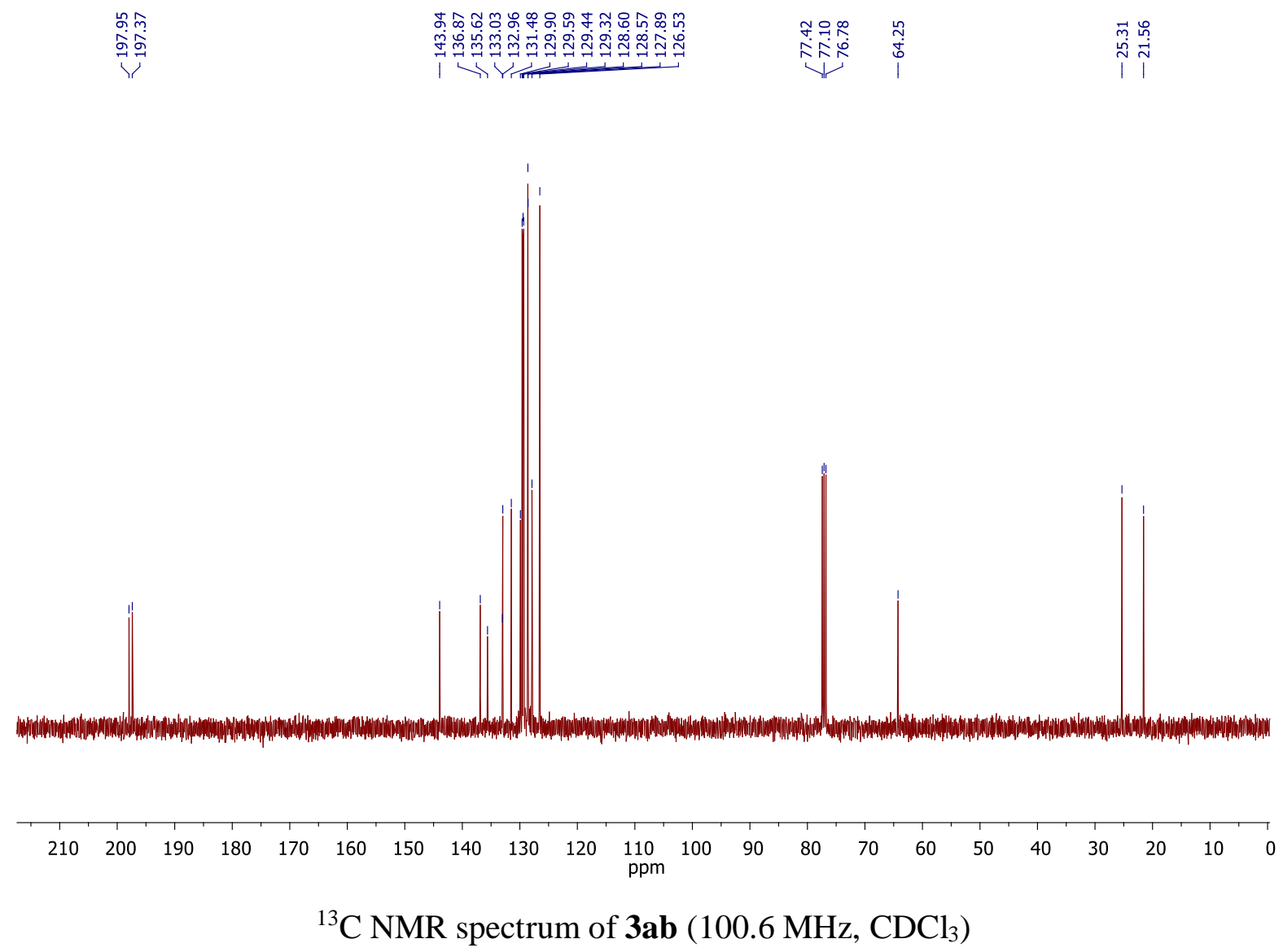




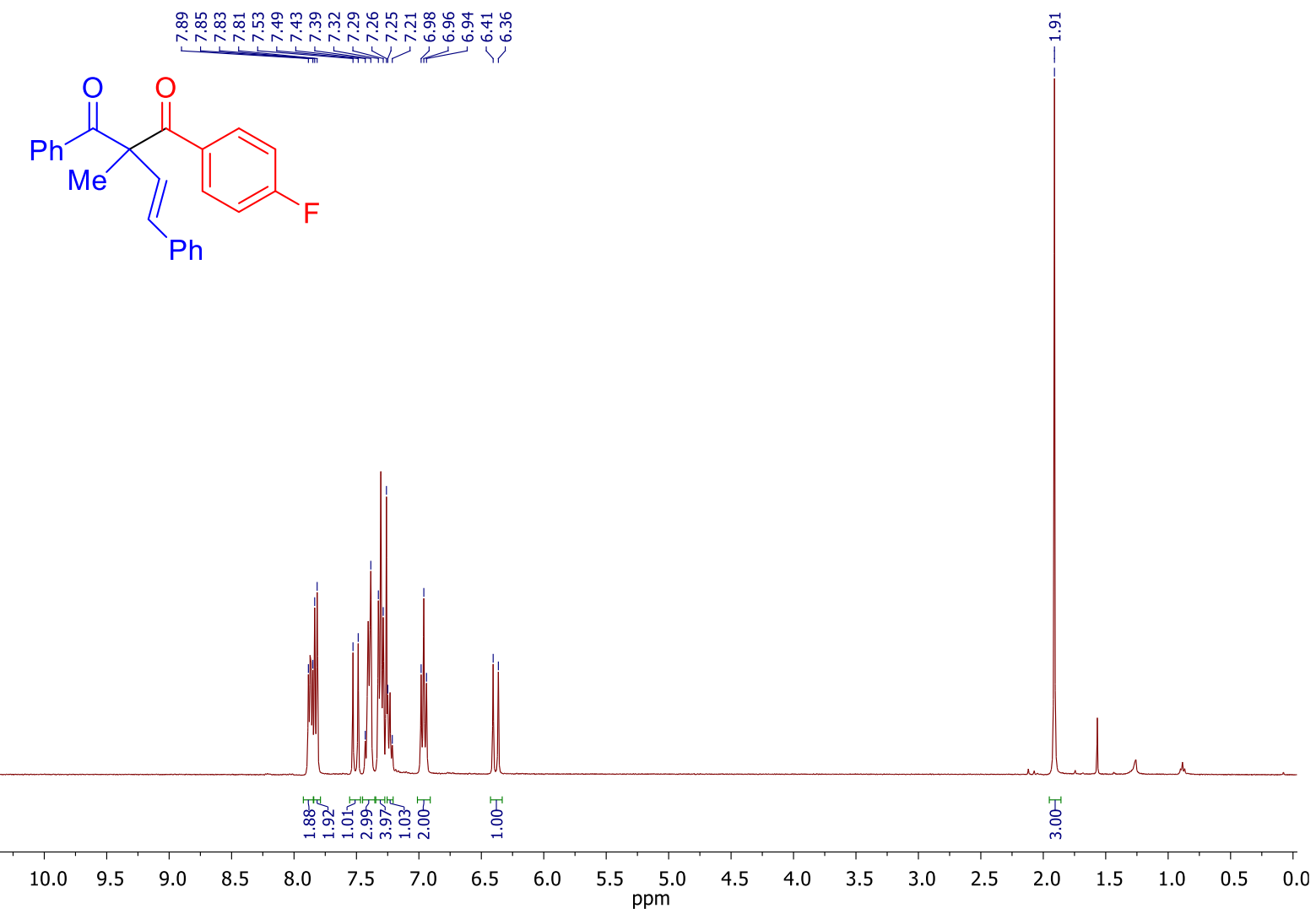

${ }^{1} \mathrm{H}$ NMR spectrum of $\mathbf{3 a c}\left(400.1 \mathrm{MHz}, \mathrm{CDCl}_{3}\right)$

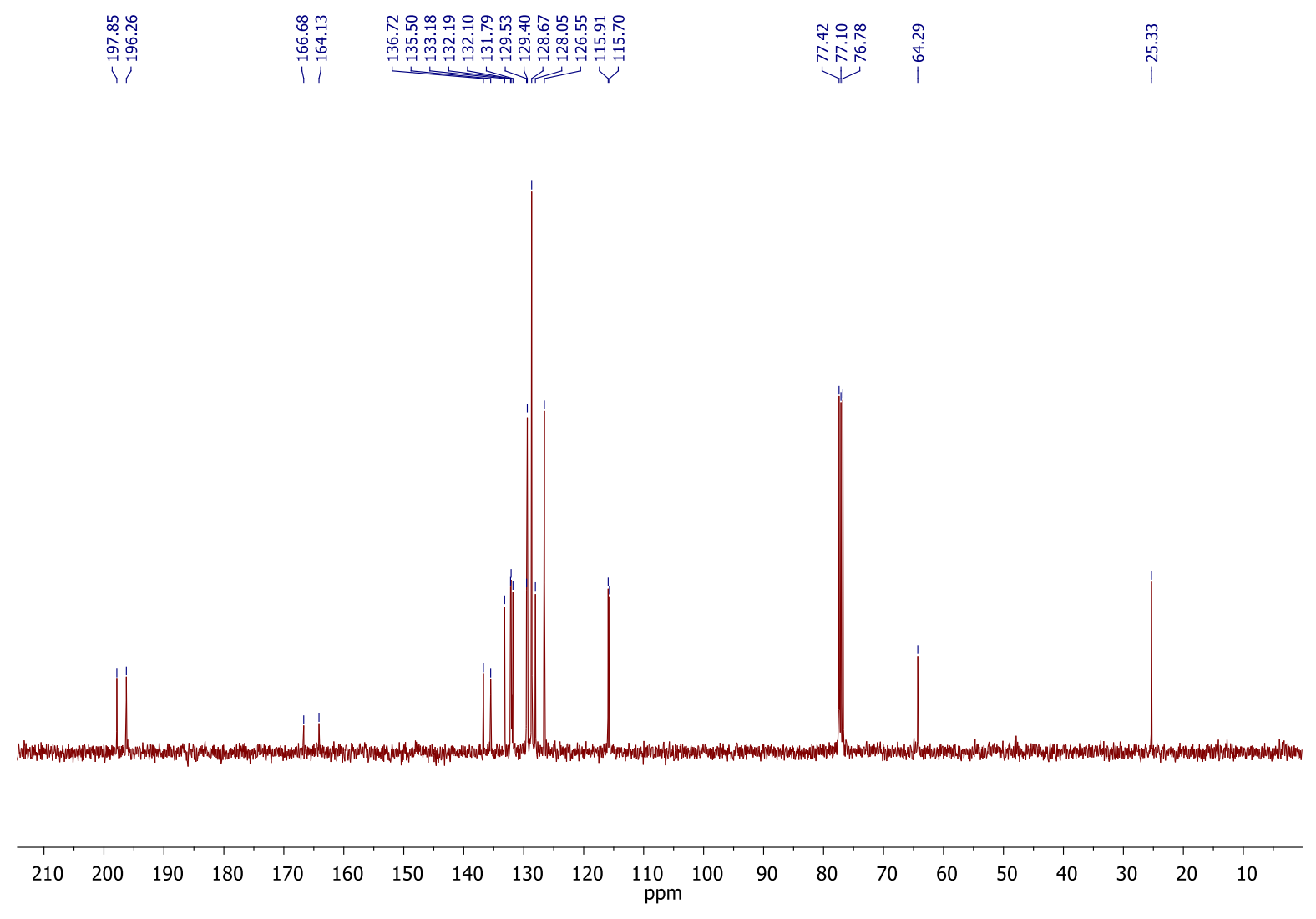

${ }^{13} \mathrm{C}$ NMR spectrum of 3 ac $\left(100.6 \mathrm{MHz}, \mathrm{CDCl}_{3}\right)$ 


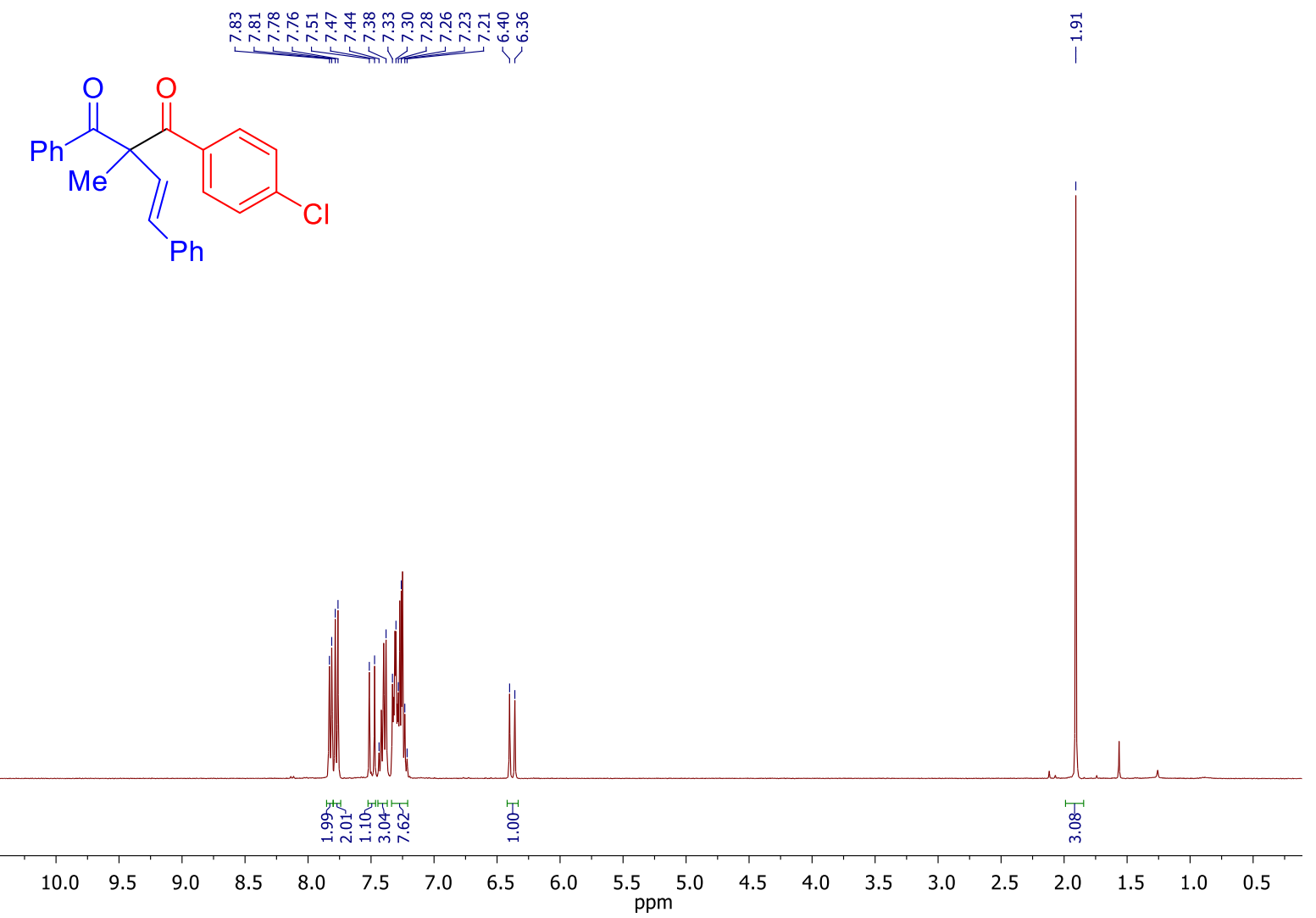

${ }^{1} \mathrm{H}$ NMR spectrum of $\mathbf{3 a d}\left(400.1 \mathrm{MHz}, \mathrm{CDCl}_{3}\right)$

\begin{tabular}{|c|c|c|c|}
\hline 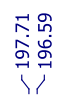 & 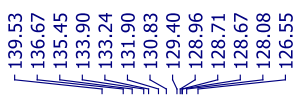 & 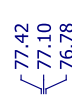 & \begin{tabular}{l}
$\tilde{m}$ \\
\multirow{0}{0}{} \\
1
\end{tabular} \\
\hline
\end{tabular}

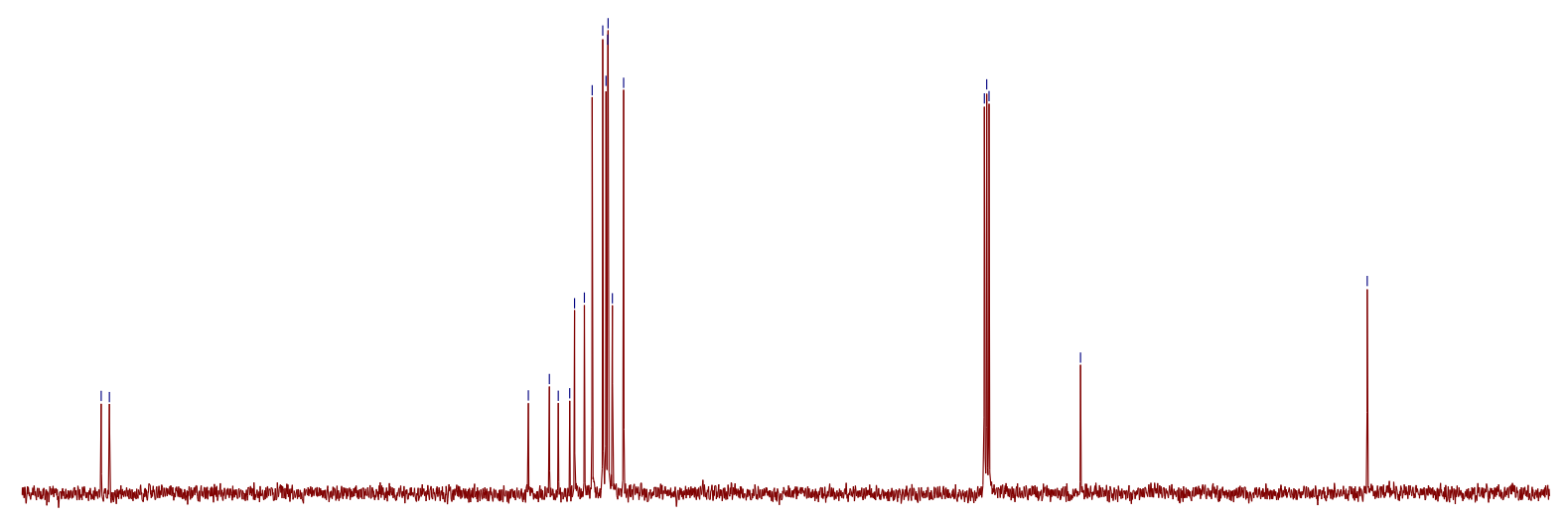

$\begin{array}{lllllllllllllllllllll}200 & 190 & 180 & 170 & 160 & 150 & 140 & 130 & 120 & 110 & 100 & 90 & 80 & 70 & 60 & 50 & 40 & 30 & 20 & 10\end{array}$

${ }^{13} \mathrm{C}$ NMR spectrum of $\mathbf{3 a d}\left(100.6 \mathrm{MHz}, \mathrm{CDCl}_{3}\right)$ 


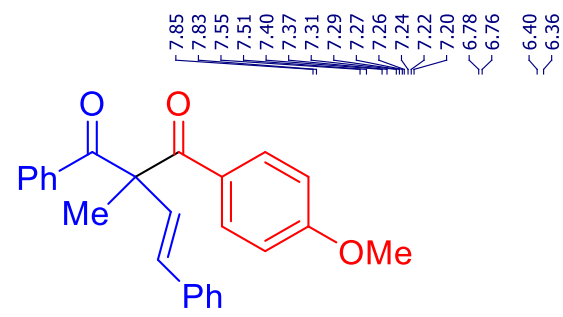

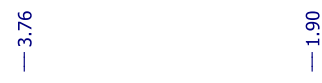

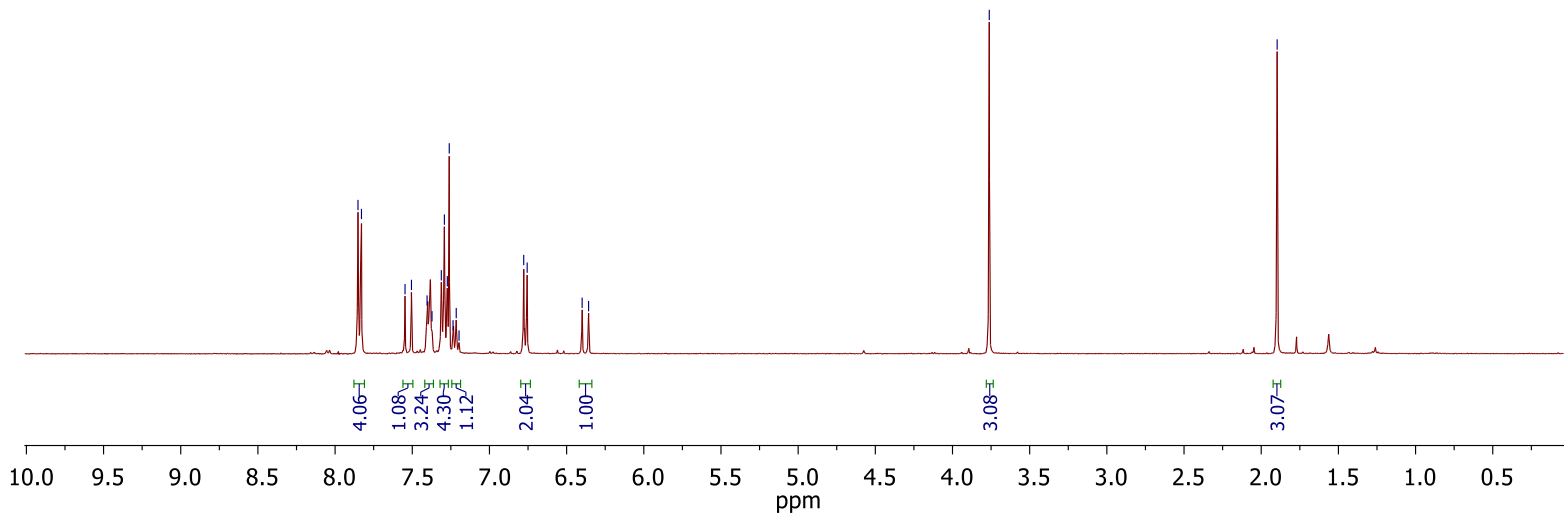

${ }^{1} \mathrm{H}$ NMR spectrum of $\mathbf{3 a e}\left(400.1 \mathrm{MHz}, \mathrm{CDCl}_{3}\right)$

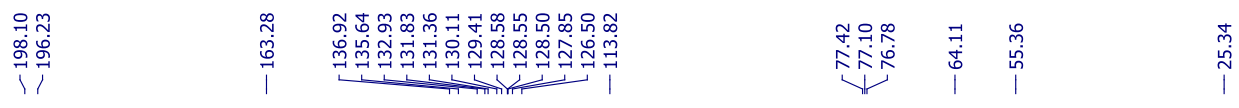

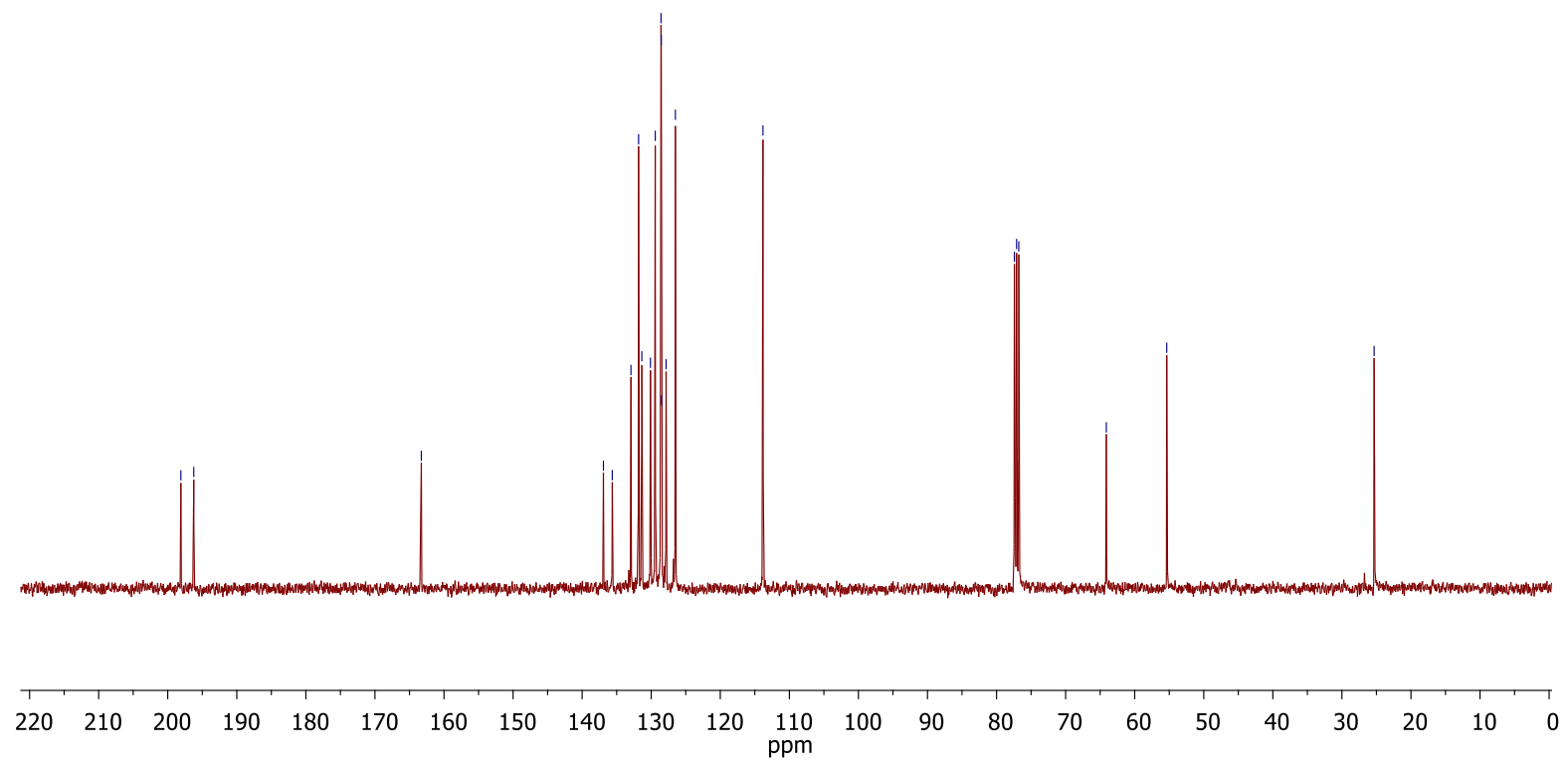

${ }^{13} \mathrm{C}$ NMR spectrum of 3ae (100.6 MHz, $\left.\mathrm{CDCl}_{3}\right)$ 


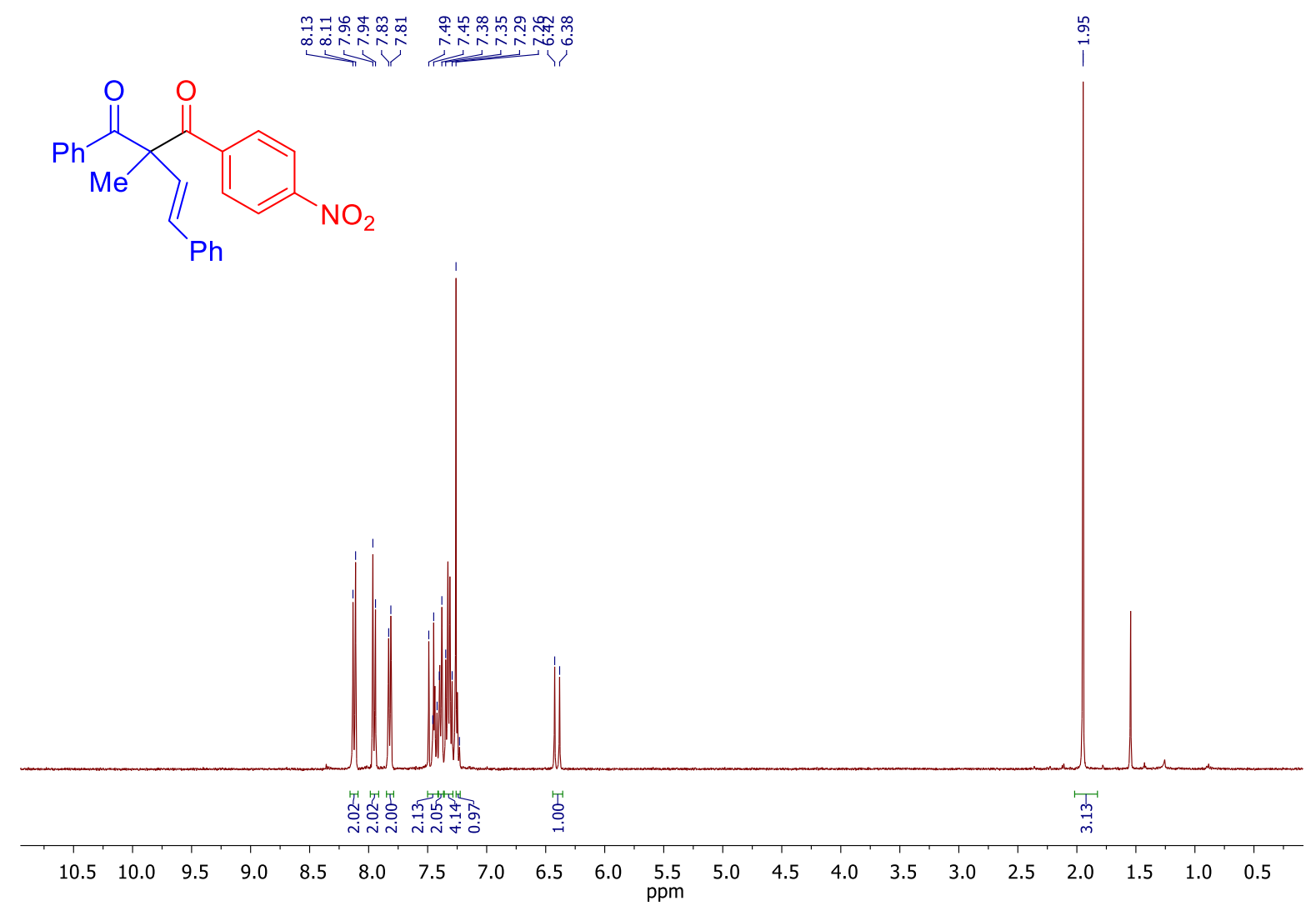

${ }^{1} \mathrm{H}$ NMR spectrum of 3 af $\left(400.1 \mathrm{MHz}, \mathrm{CDCl}_{3}\right)$

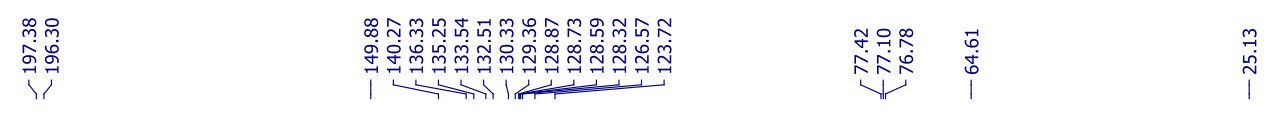

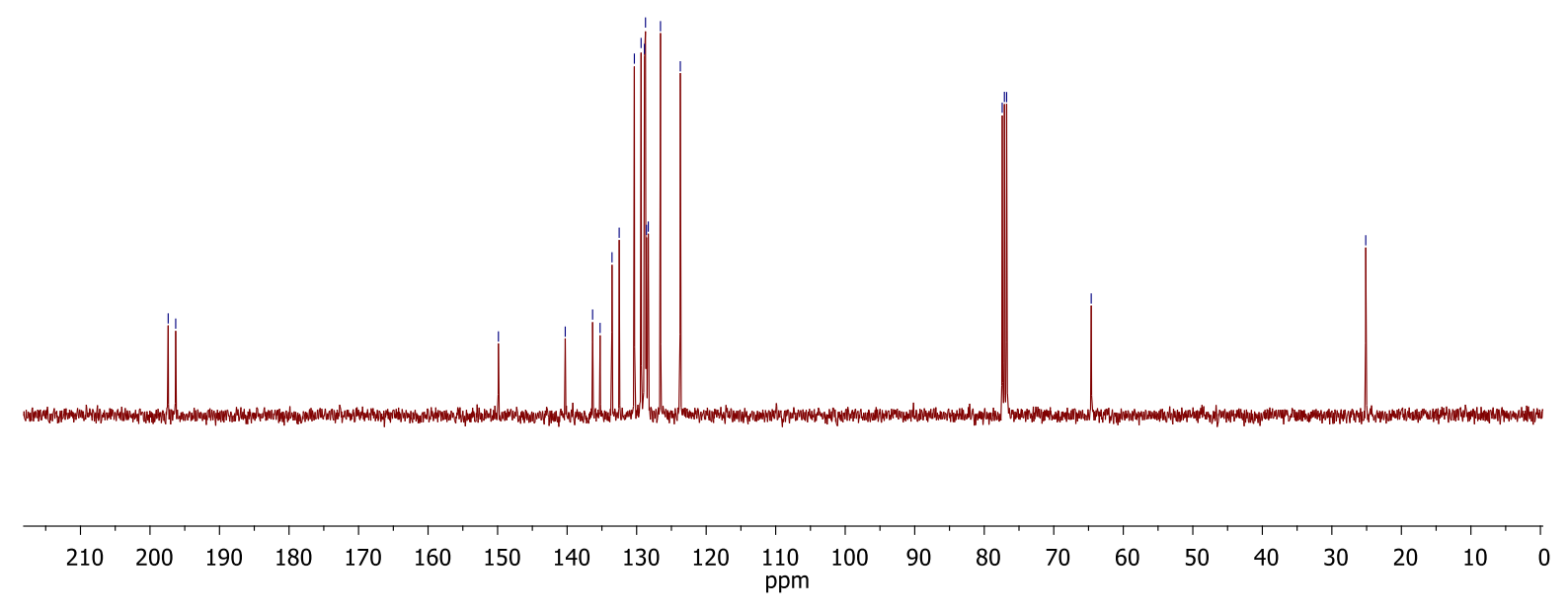

${ }^{13} \mathrm{C}$ NMR spectrum of 3af $\left(100.6 \mathrm{MHz}, \mathrm{CDCl}_{3}\right)$ 


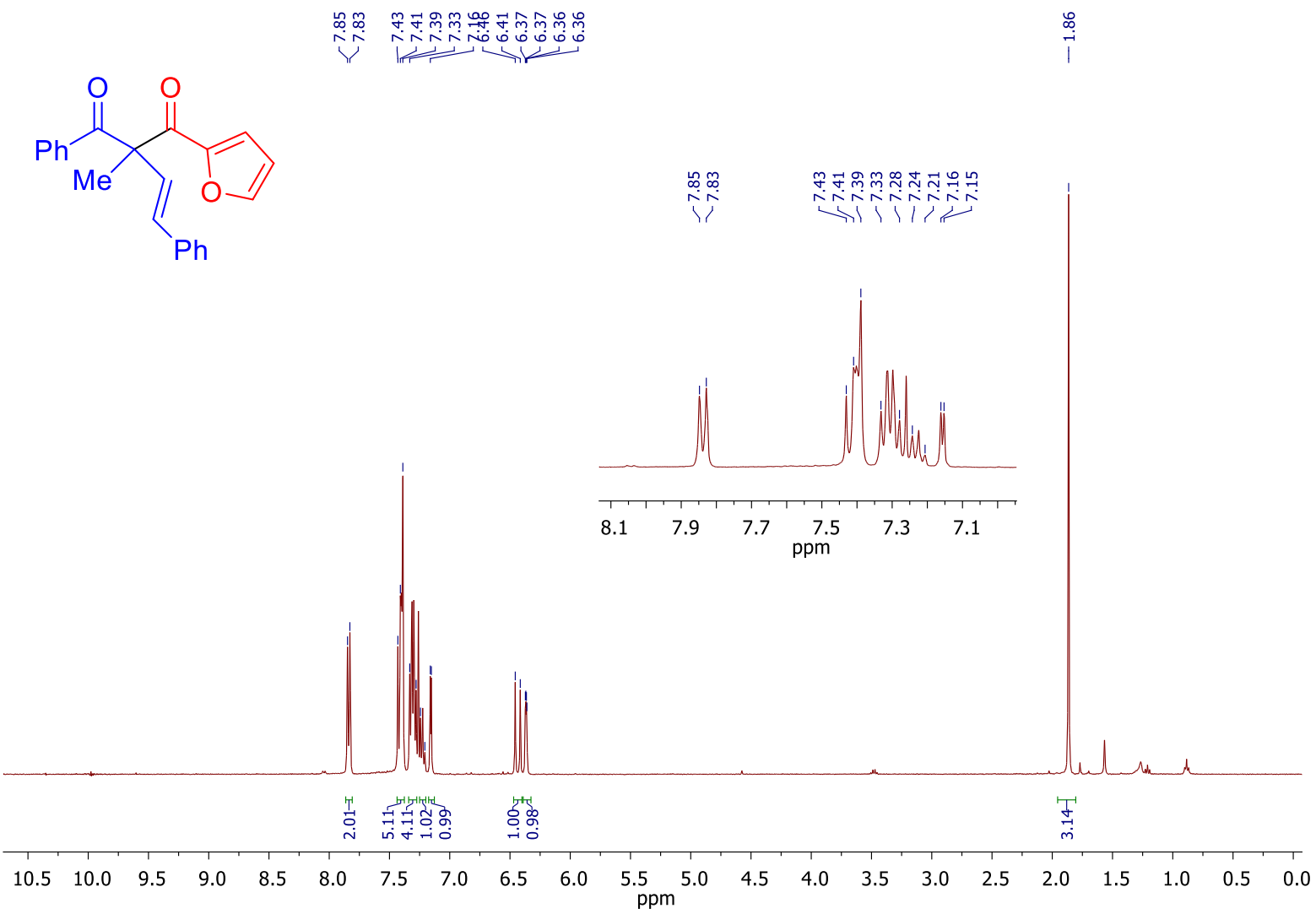

${ }^{1} \mathrm{H}$ NMR spectrum of $\mathbf{3 a g}\left(400.1 \mathrm{MHz}, \mathrm{CDCl}_{3}\right)$

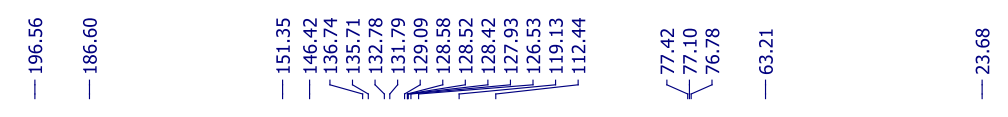
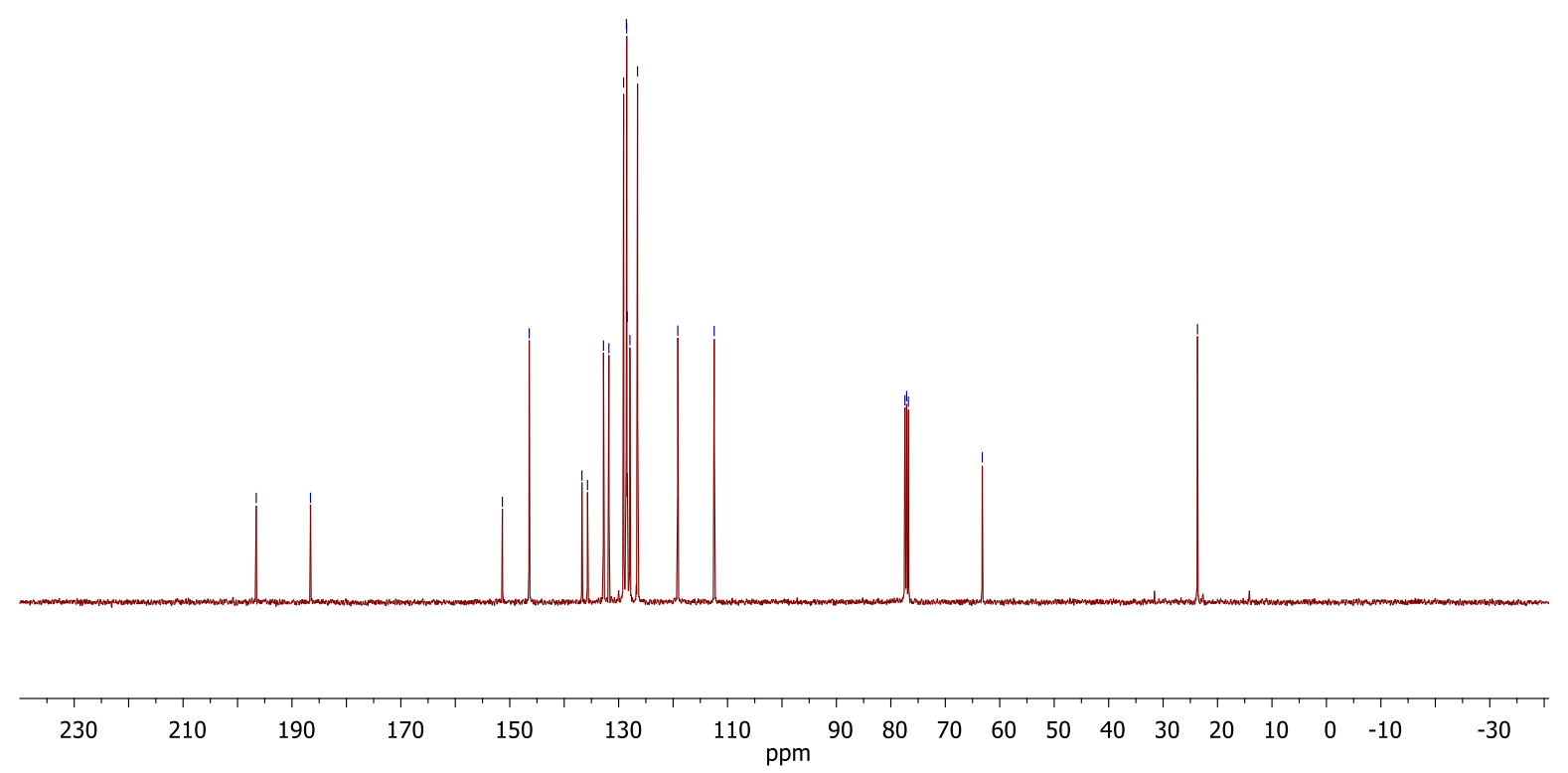

${ }^{13} \mathrm{C}$ NMR spectrum of $\mathbf{3 a g}\left(100.6 \mathrm{MHz}, \mathrm{CDCl}_{3}\right)$ 


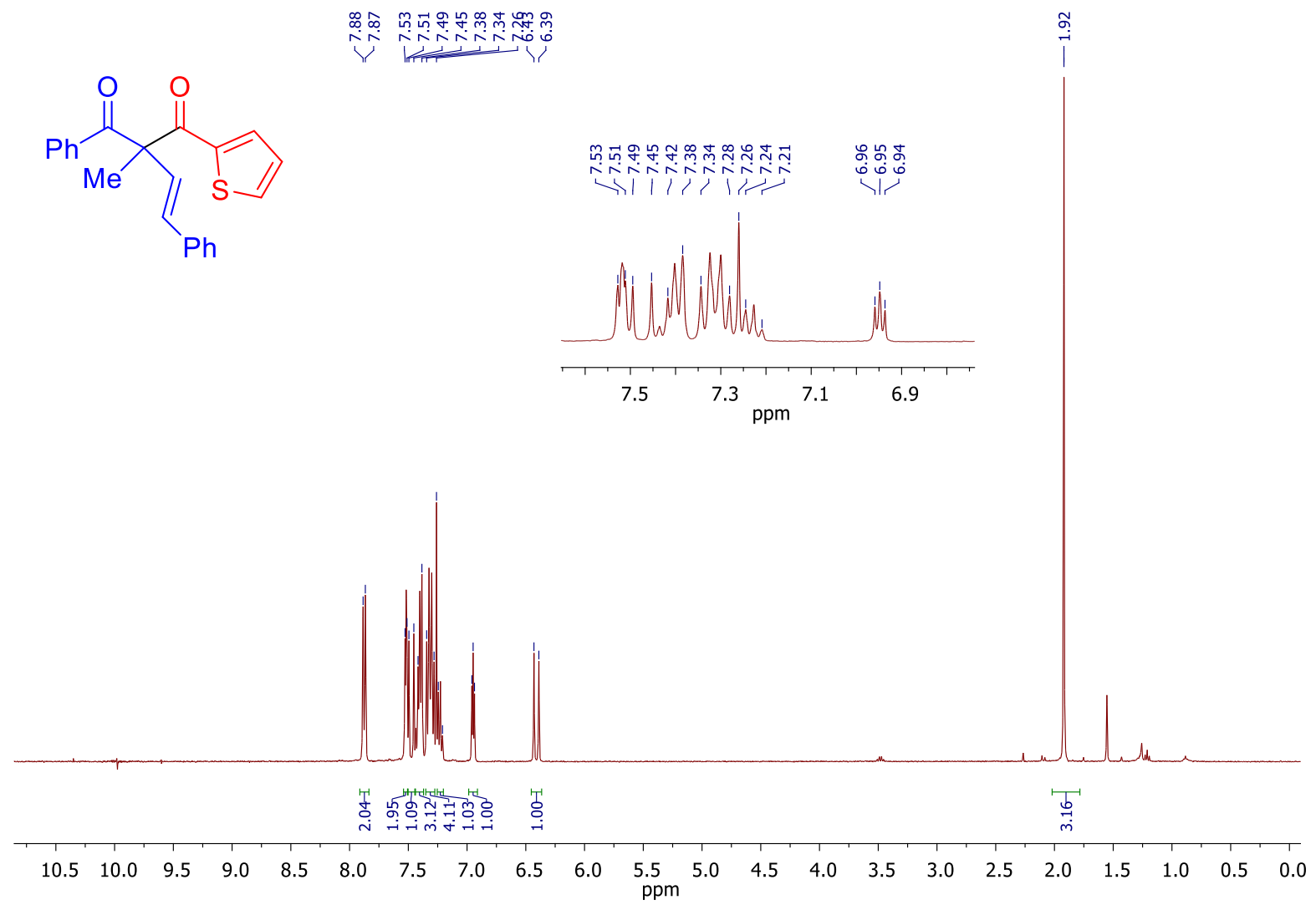

${ }^{1} \mathrm{H} \mathrm{NMR}$ spectrum of $\mathbf{3 a h}\left(400.1 \mathrm{MHz}, \mathrm{CDCl}_{3}\right)$

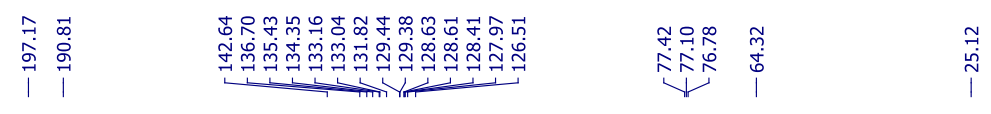
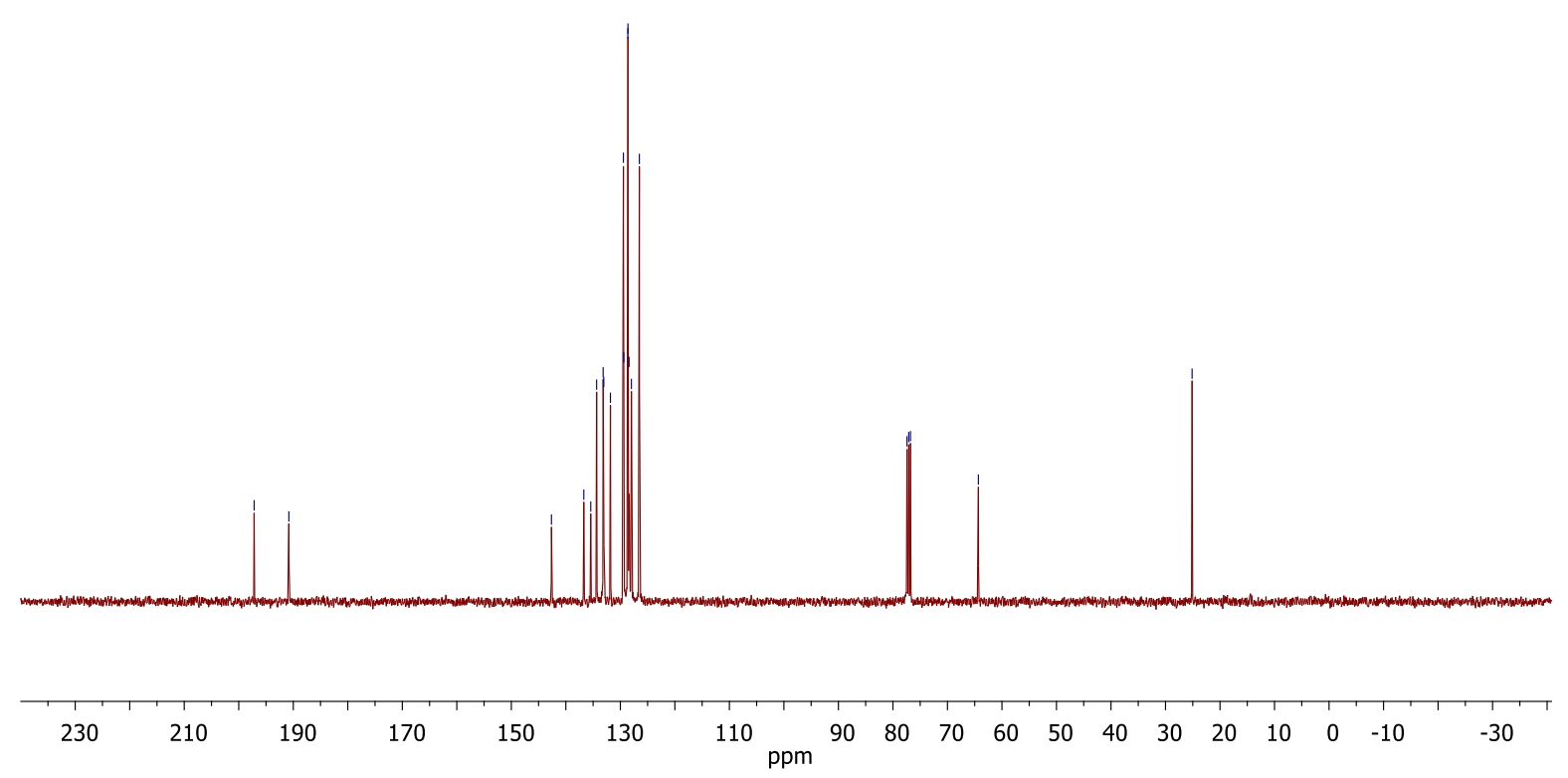

${ }^{13} \mathrm{C}$ NMR spectrum of $\mathbf{3 a h}\left(100.6 \mathrm{MHz}, \mathrm{CDCl}_{3}\right)$ 


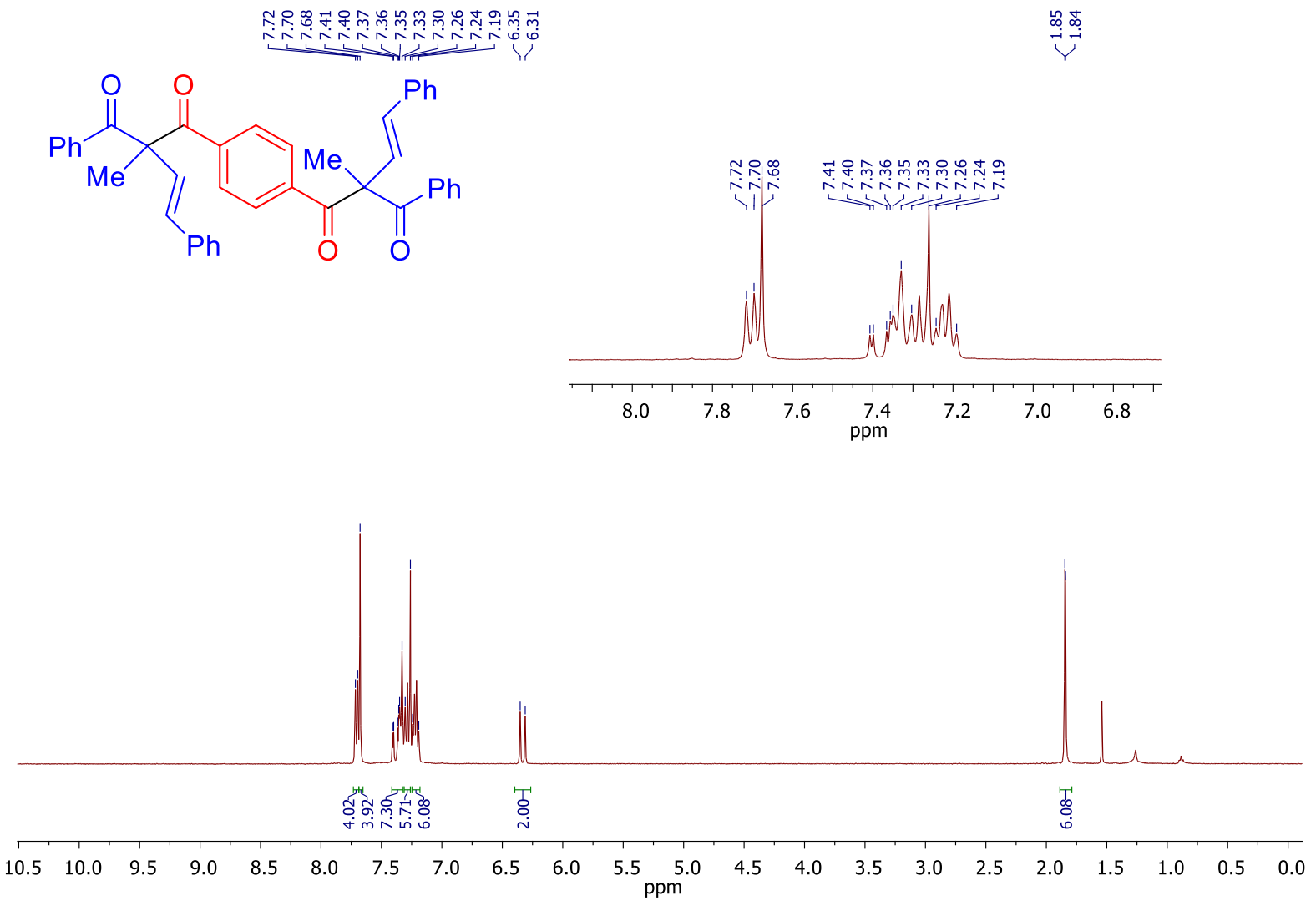

${ }^{1} \mathrm{H}$ NMR spectrum of 3ai $\left(400.1 \mathrm{MHz}, \mathrm{CDCl}_{3}\right)$

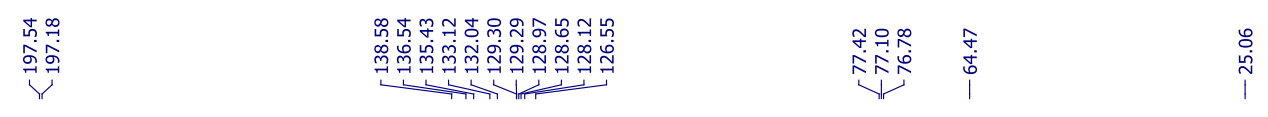

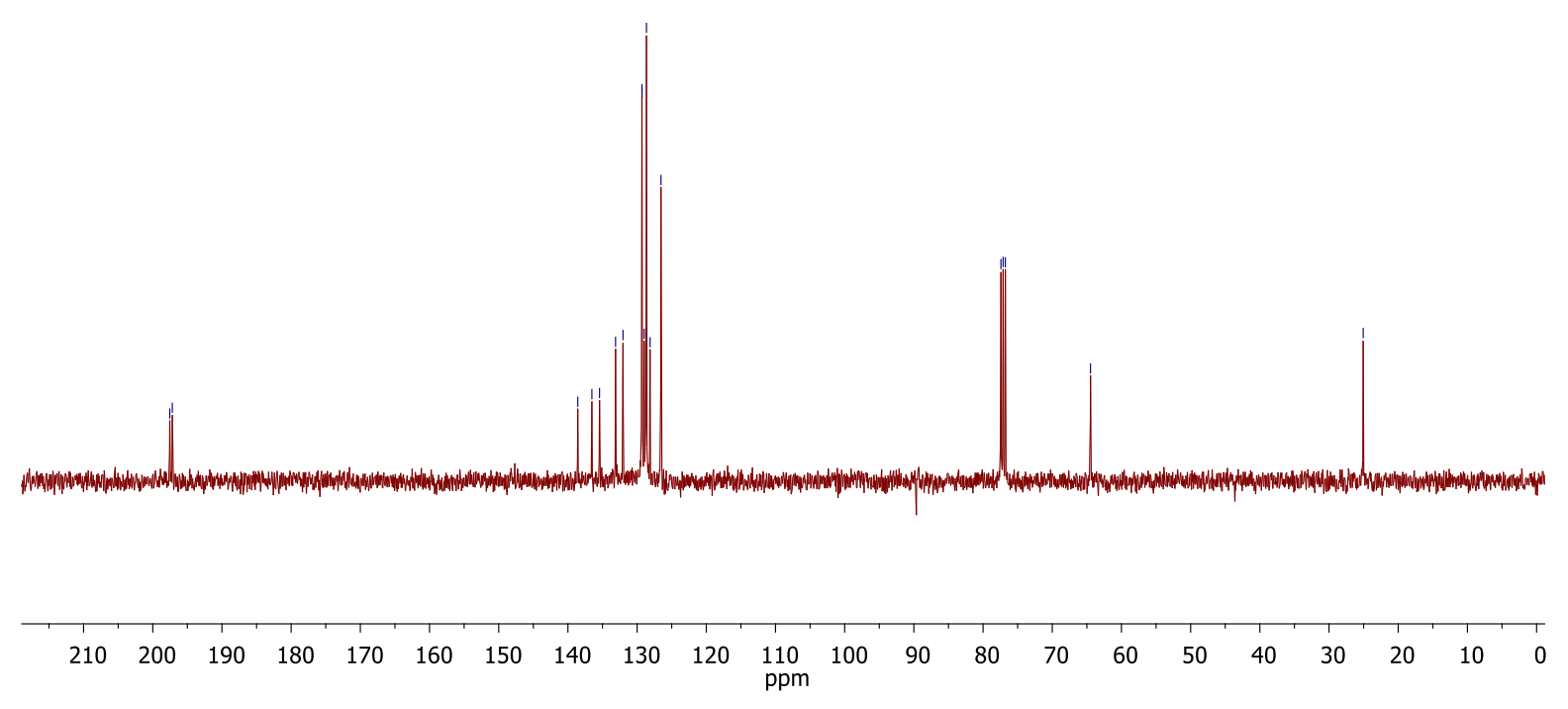

${ }^{13} \mathrm{C}$ NMR spectrum of 3ai $\left(100.6 \mathrm{MHz}, \mathrm{CDCl}_{3}\right)$ 


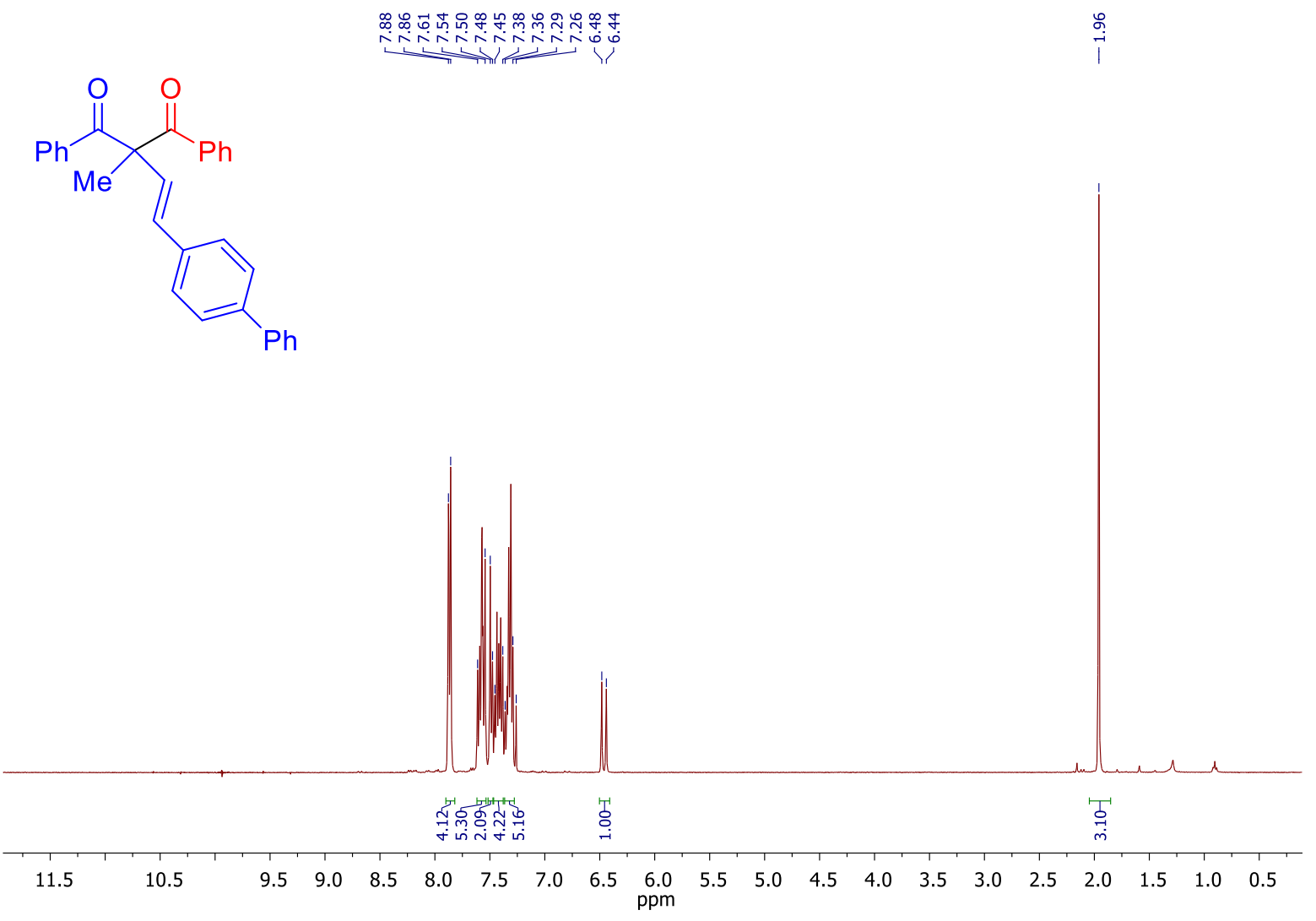

${ }^{1} \mathrm{H}$ NMR spectrum of $\mathbf{3 c a}\left(400.1 \mathrm{MHz}, \mathrm{CDCl}_{3}\right)$

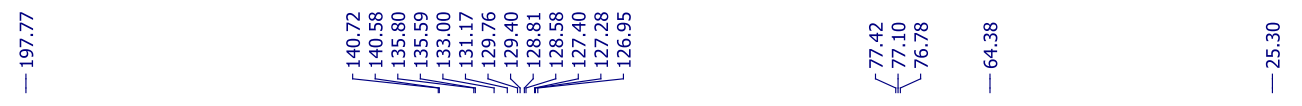

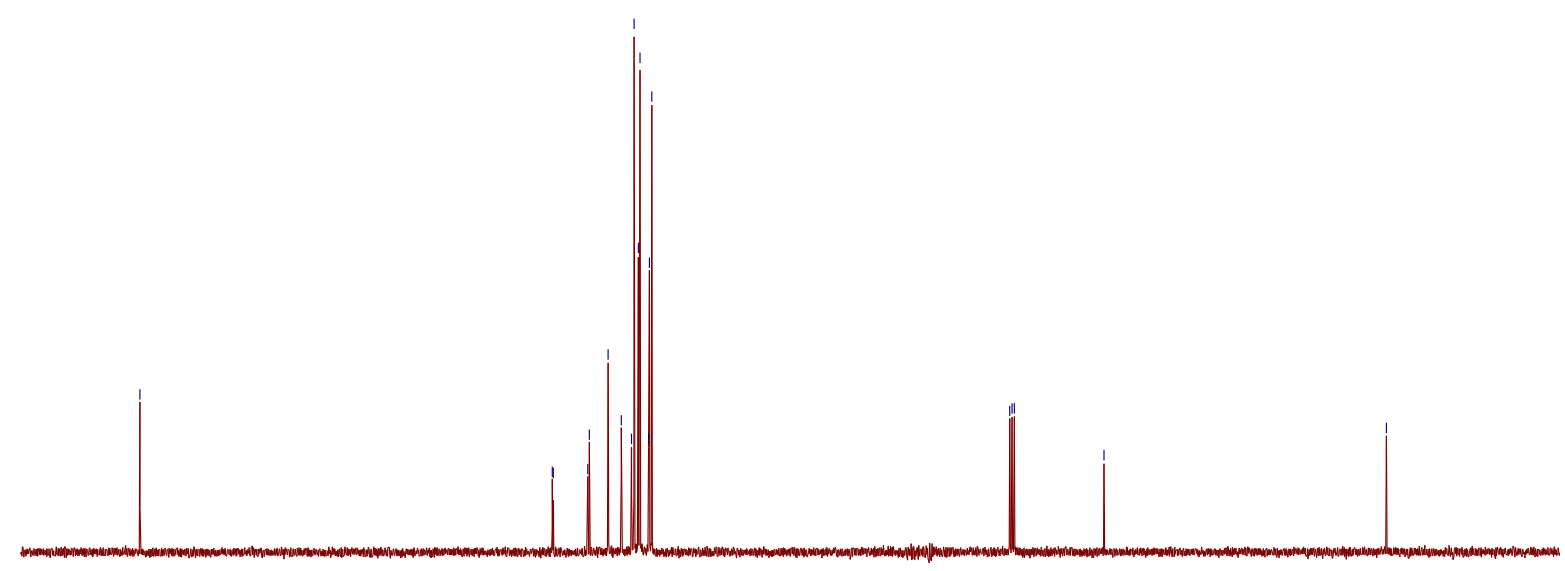

$\begin{array}{lllllllllllllllllllll}210 & 200 & 190 & 180 & 170 & 160 & 150 & 140 & 130 & 120 & 110 & 100 & 90 & 80 & 70 & 60 & 50 & 40 & 30 & 20 & 10\end{array}$

${ }^{13} \mathrm{C}$ NMR spectrum of $\mathbf{3 c a}\left(100.6 \mathrm{MHz}, \mathrm{CDCl}_{3}\right)$ 


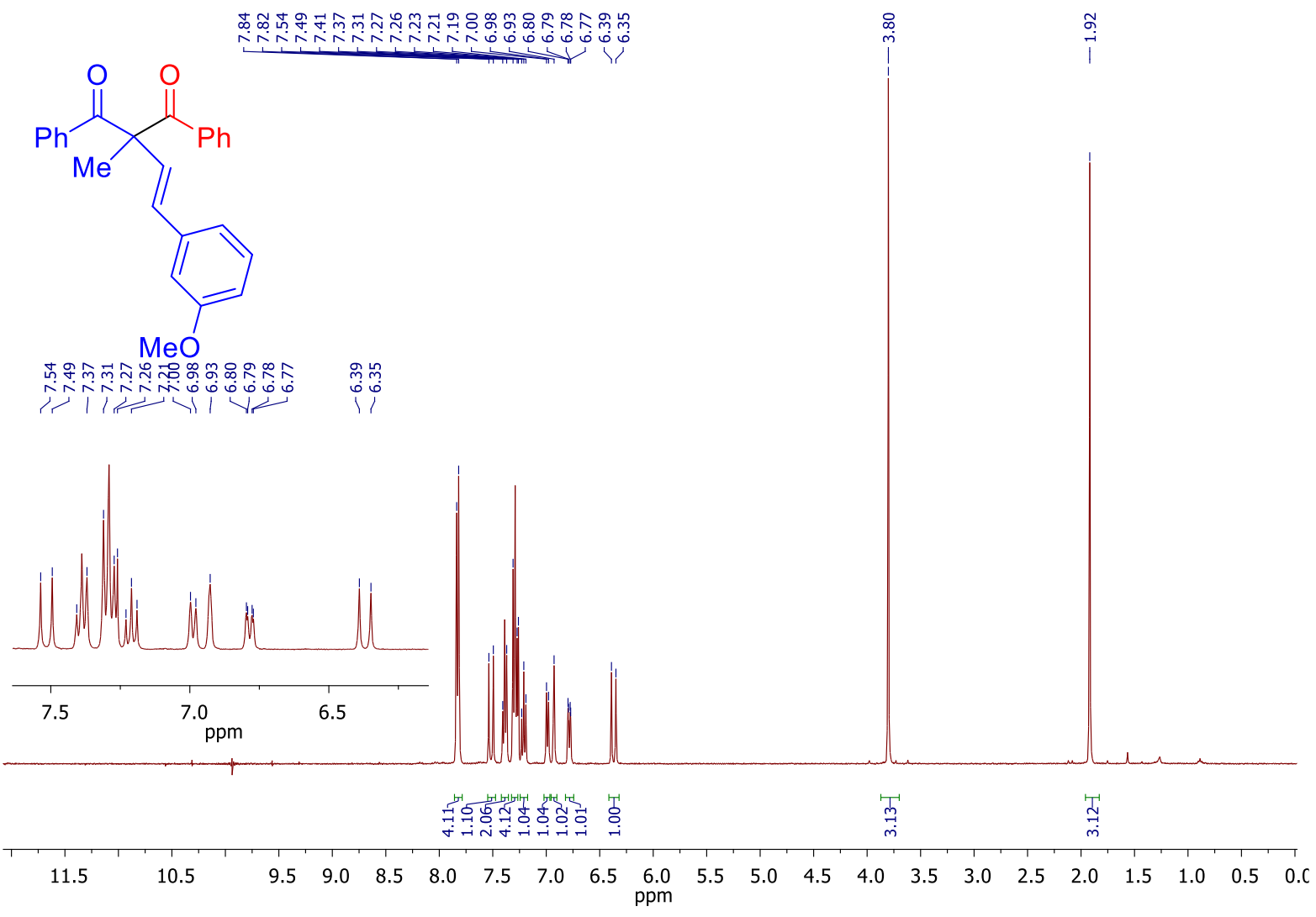

${ }^{1} \mathrm{H}$ NMR spectrum of $\mathbf{3 d a}\left(400.1 \mathrm{MHz}, \mathrm{CDCl}_{3}\right.$ )

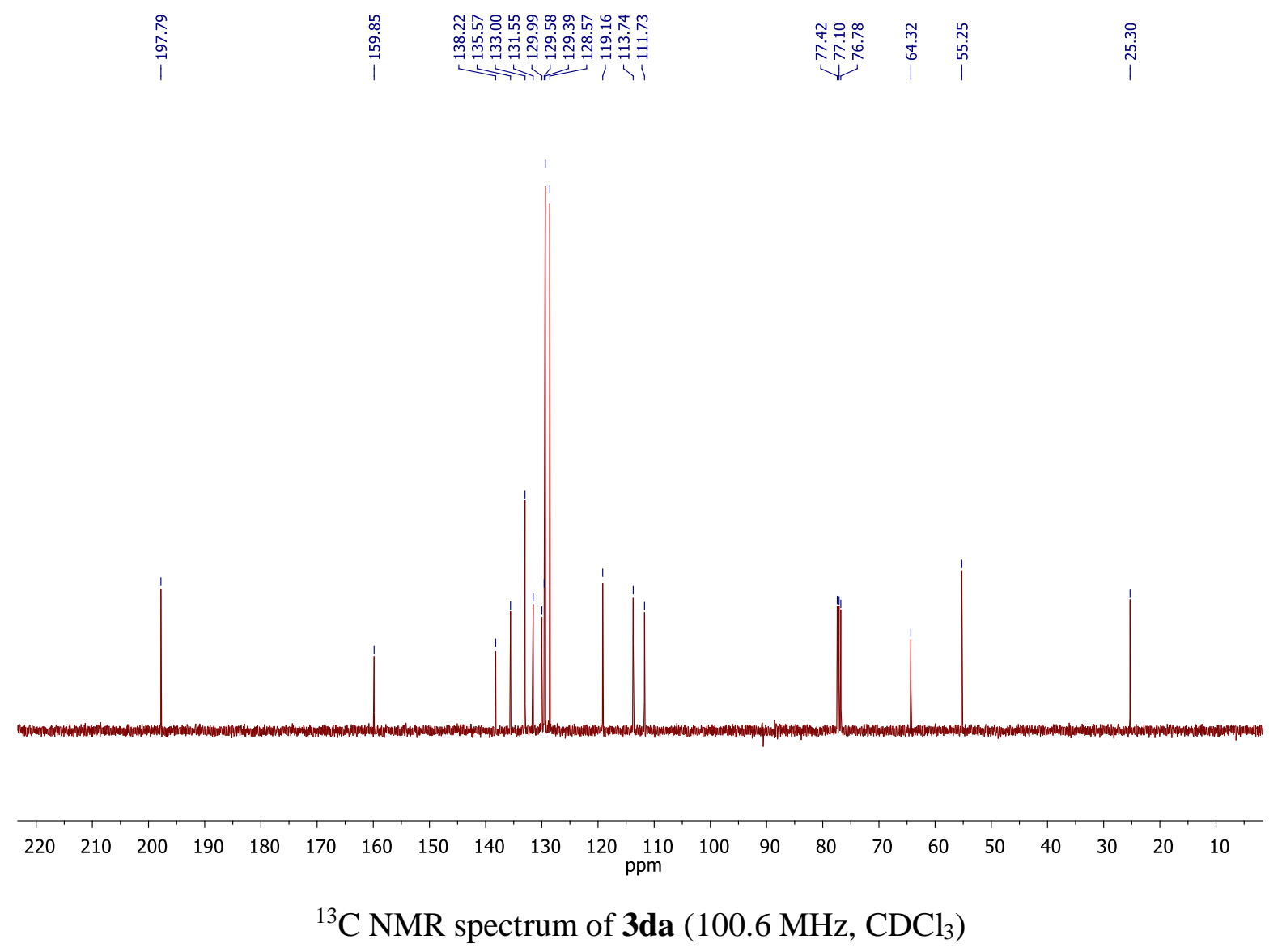




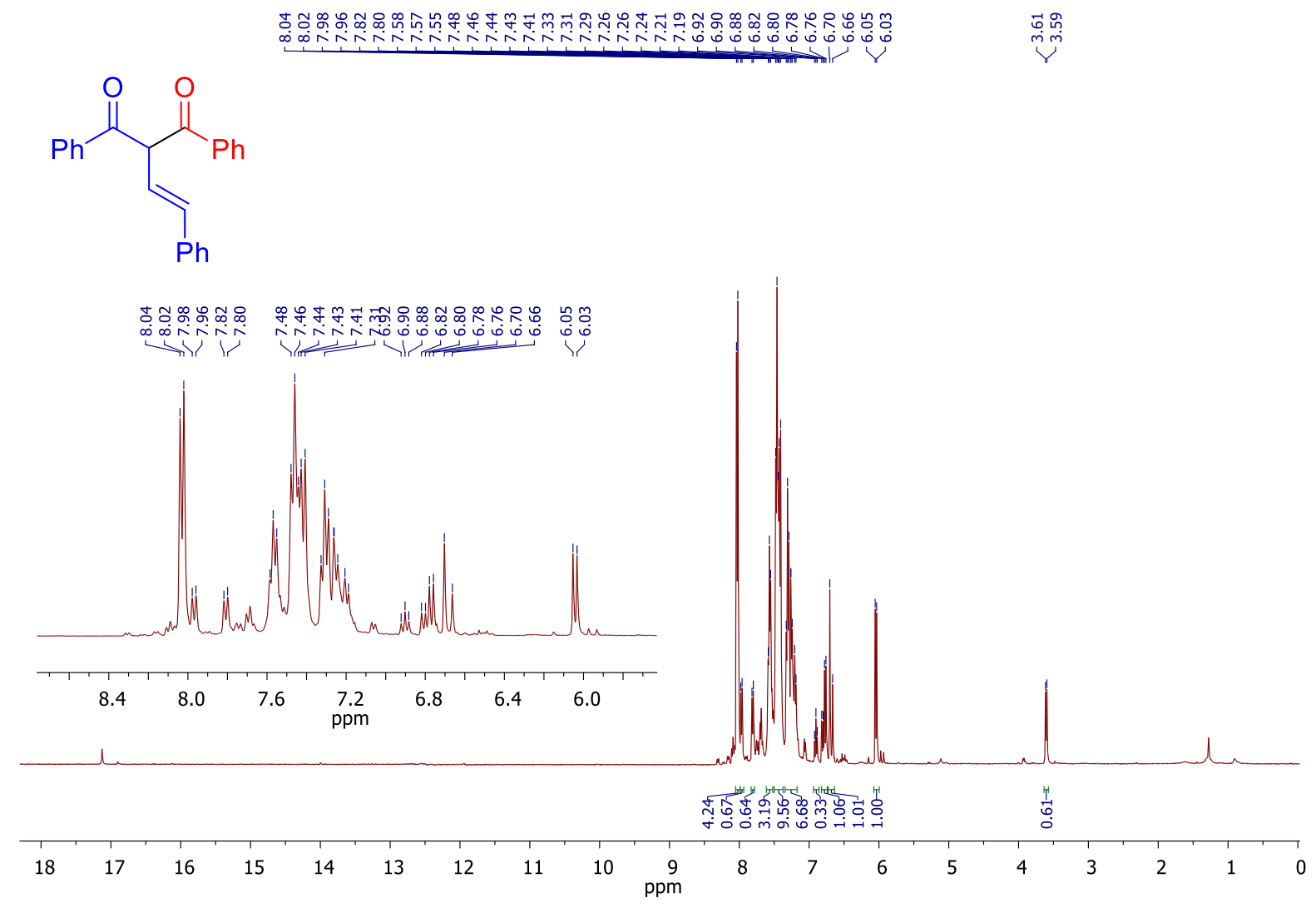

${ }^{1} \mathrm{H}$ NMR spectrum of $\mathbf{3 e a}\left(400.1 \mathrm{MHz}, \mathrm{CDCl}_{3}\right)$
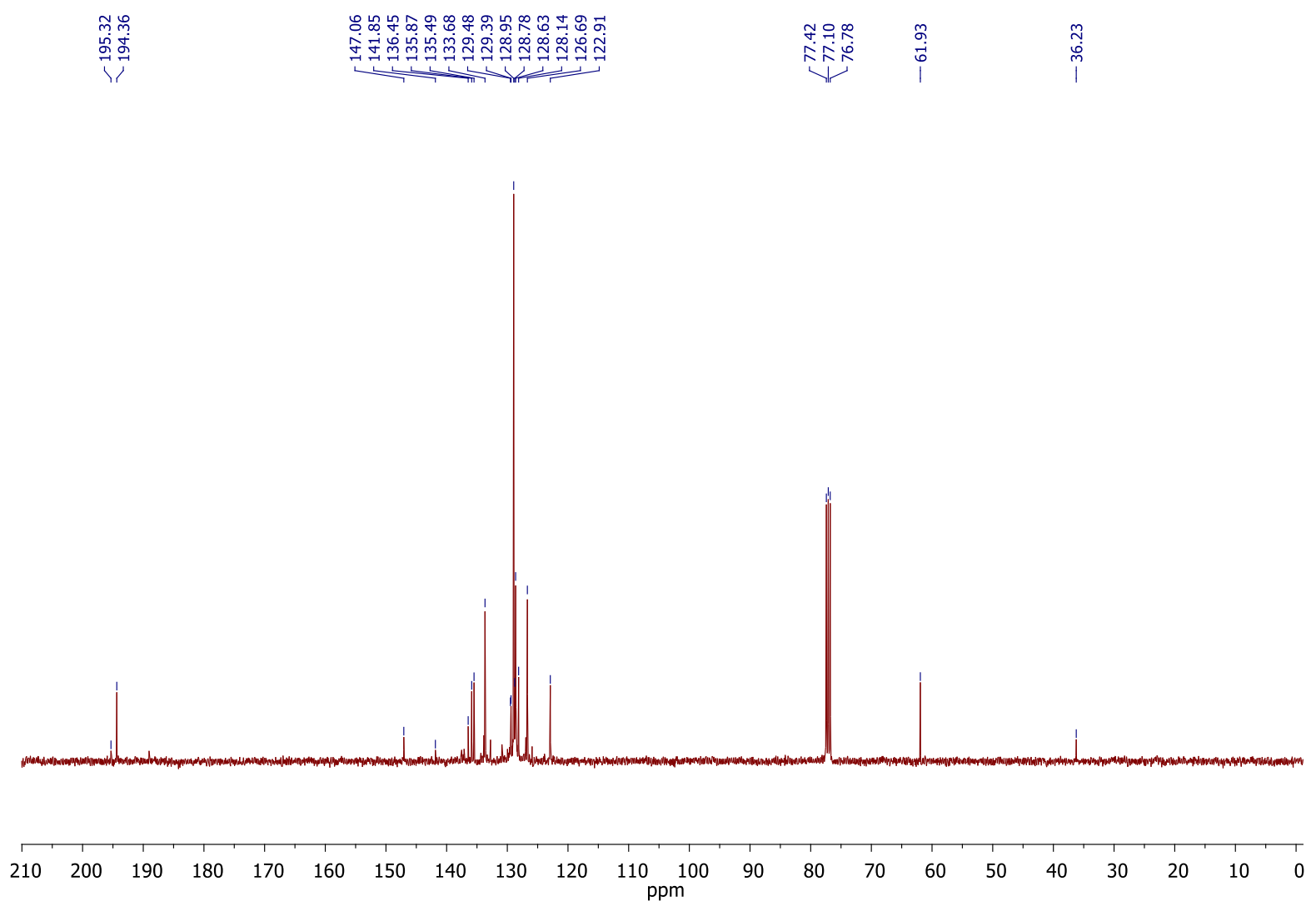

${ }^{13} \mathrm{C}$ NMR spectrum of 3 ea $\left(100.6 \mathrm{MHz}, \mathrm{CDCl}_{3}\right)$ 


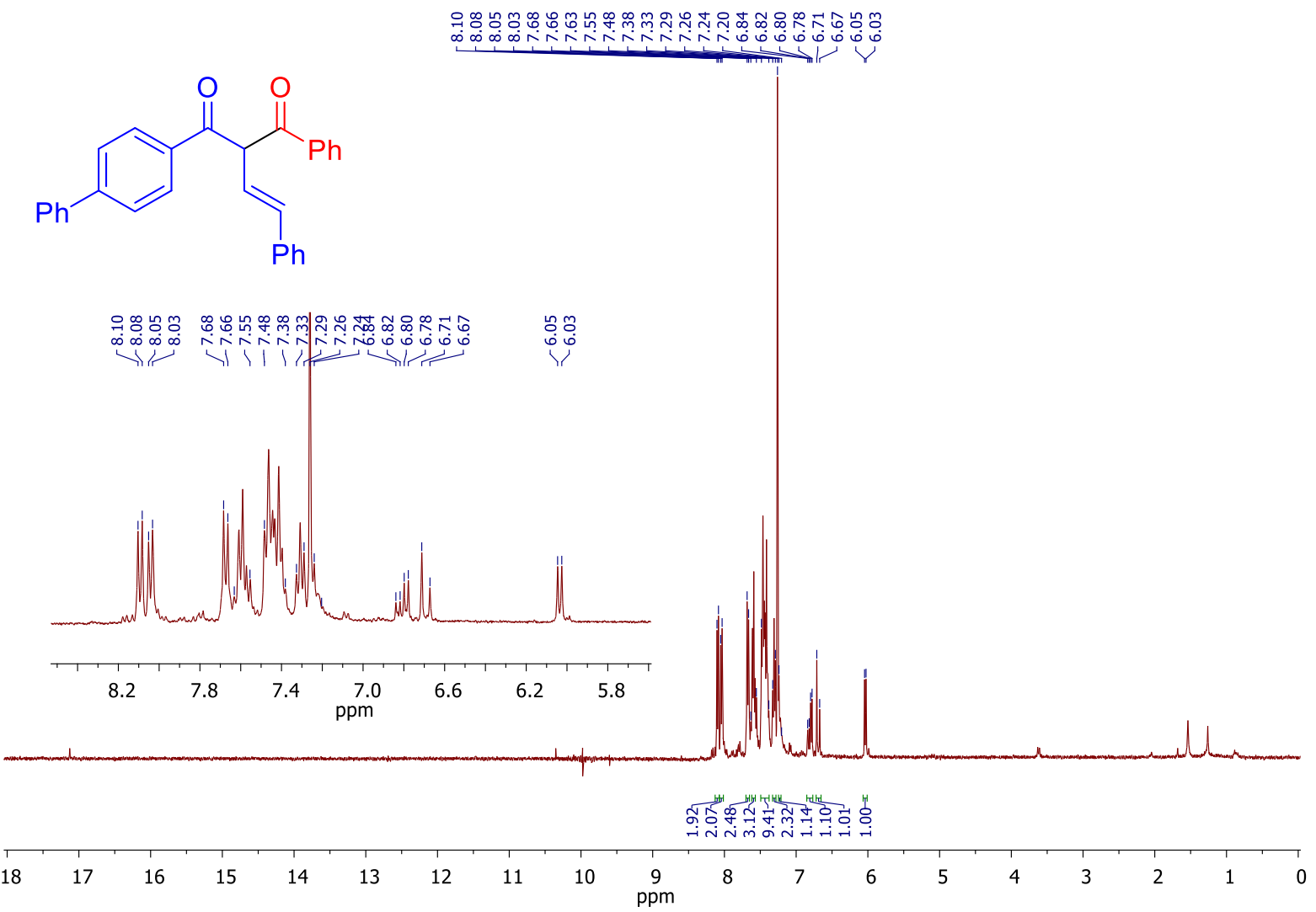

${ }^{1} \mathrm{H}$ NMR spectrum of $\mathbf{3 f a}\left(400.1 \mathrm{MHz}, \mathrm{CDCl}_{3}\right)$

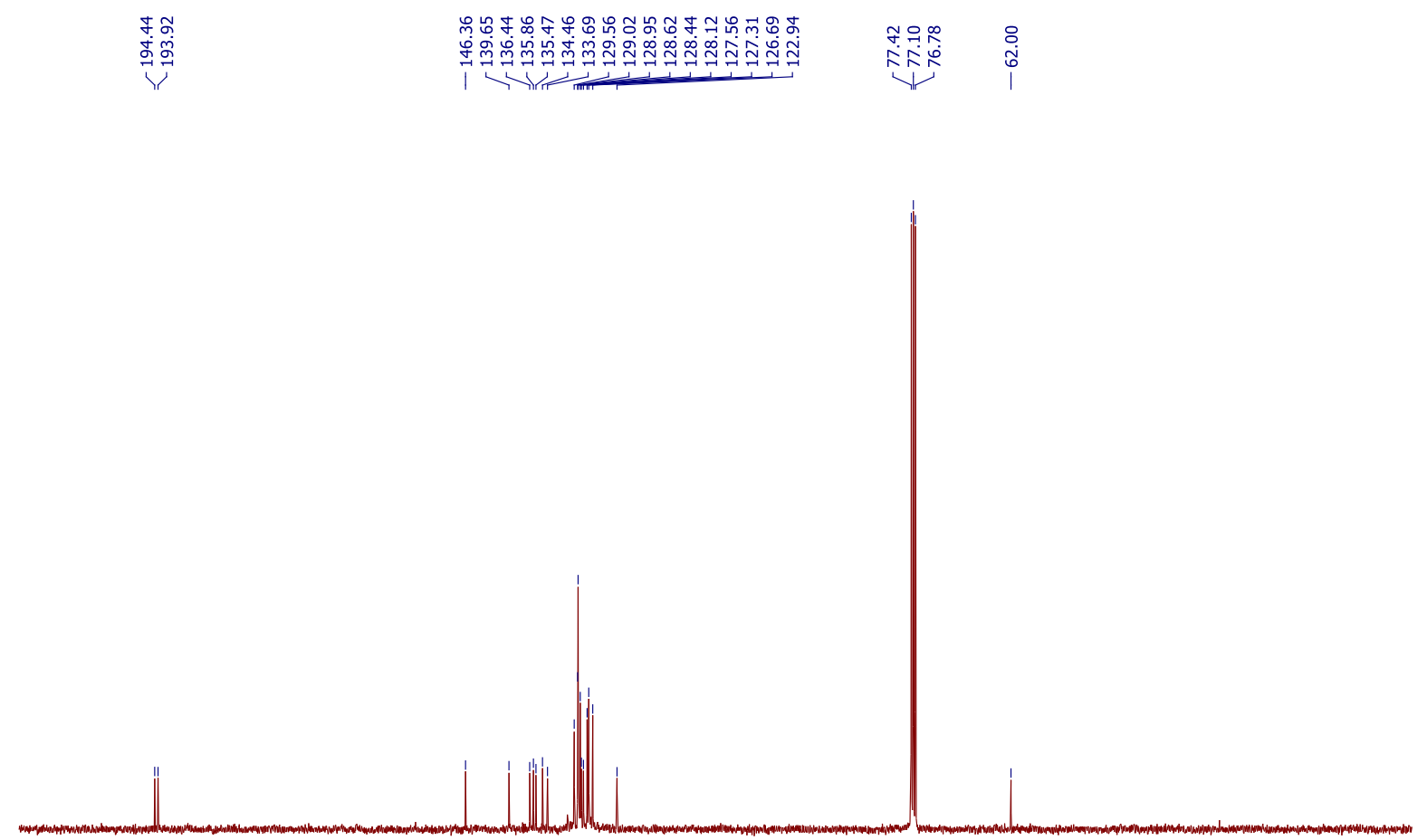

$\begin{array}{lllllllllllllllllllllllll}210 & 200 & 190 & 180 & 170 & 160 & 150 & 140 & 130 & 120 & 110 & 100 & 90 & 80 & 70 & 60 & 50 & 40 & 30 & 20 & 10 & 0\end{array}$

${ }^{13} \mathrm{C}$ NMR spectrum of $\mathbf{3 f a}\left(100.6 \mathrm{MHz}, \mathrm{CDCl}_{3}\right)$ 
<smiles>O=C(c1ccc2ccccc2c1)C(/C=C/c1ccccc1)c1ccccc1</smiles>

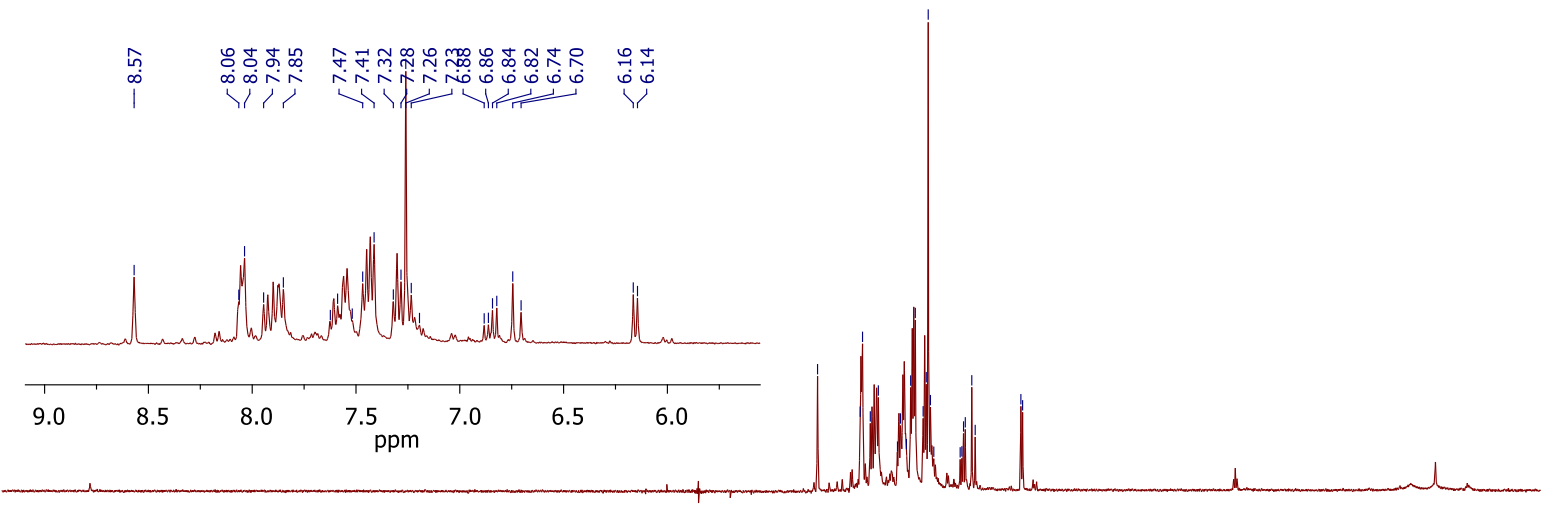

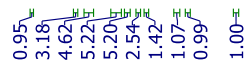

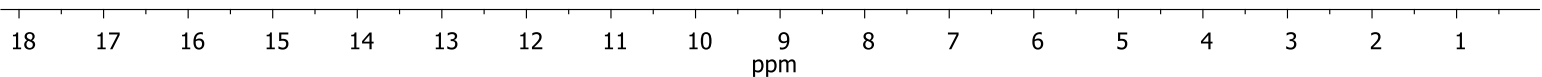

${ }^{1} \mathrm{H}$ NMR spectrum of $\mathbf{3 g a}\left(400.1 \mathrm{MHz}, \mathrm{CDCl}_{3}\right)$

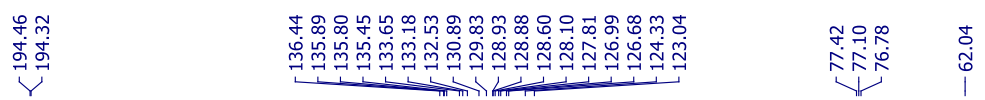

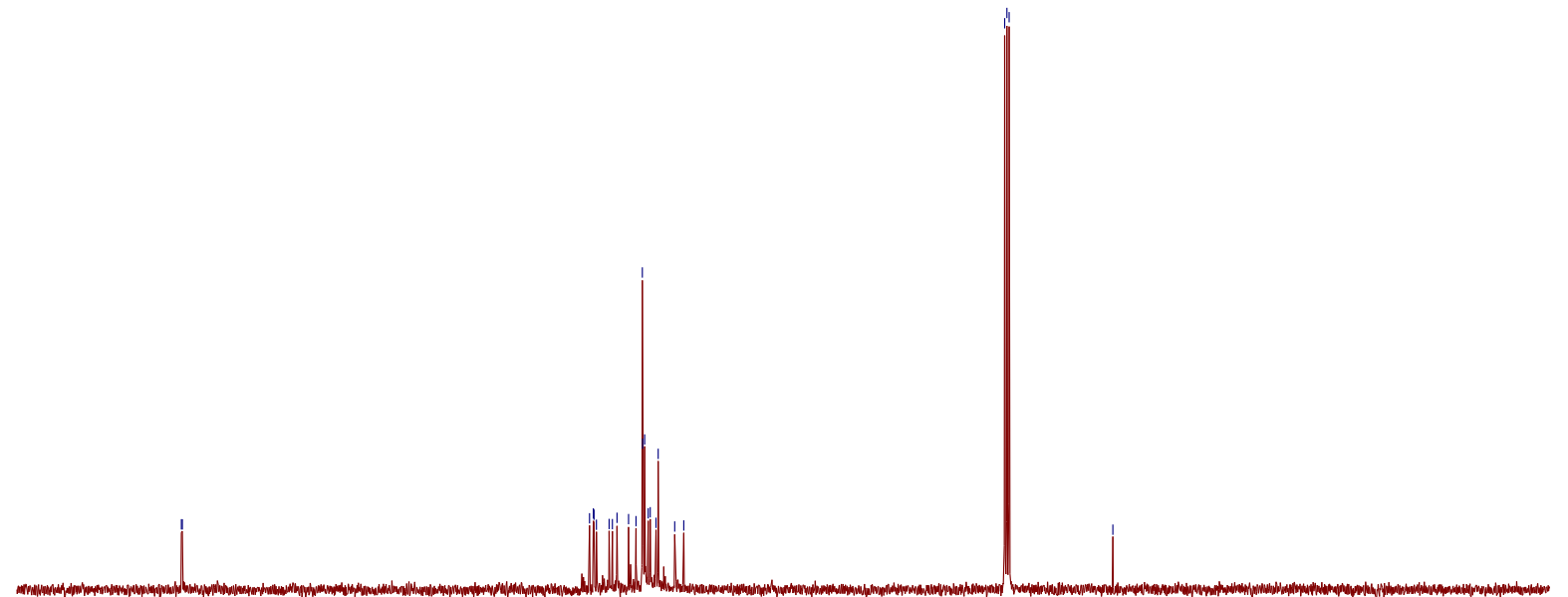

$\begin{array}{lllllllllllllllllllllll}210 & 200 & 190 & 180 & 170 & 160 & 150 & 140 & 130 & 120 & 110 & 100 & 90 & 80 & 70 & 60 & 50 & 40 & 30 & 20 & 10 & 0\end{array}$

${ }^{13} \mathrm{C}$ NMR spectrum of 3 ga $\left(100.6 \mathrm{MHz}, \mathrm{CDCl}_{3}\right)$ 

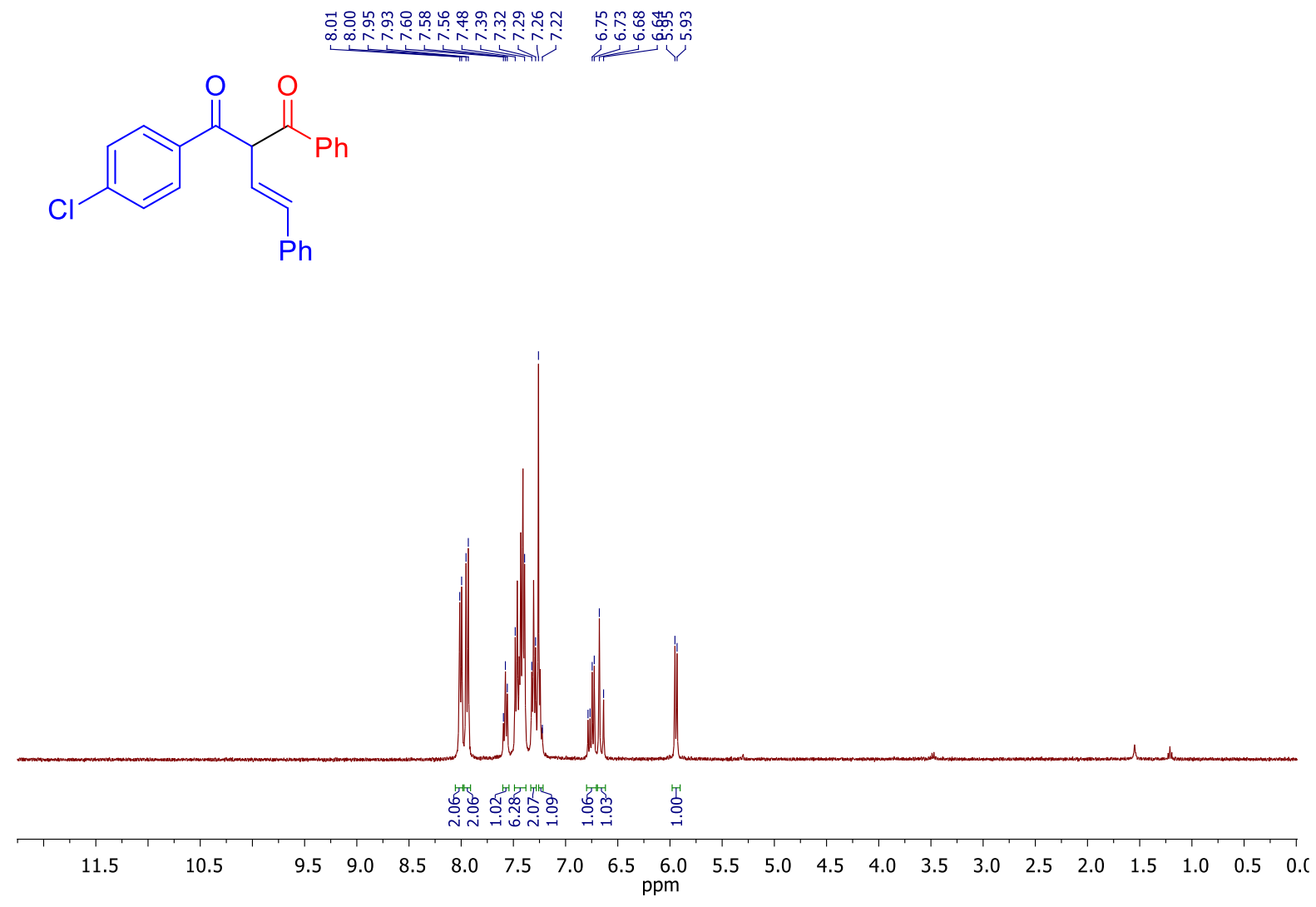

${ }^{1} \mathrm{H}$ NMR spectrum of $\mathbf{3 h a}\left(400.1 \mathrm{MHz}, \mathrm{CDCl}_{3}\right)$

\begin{tabular}{|c|c|c|}
\hline 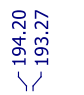 & 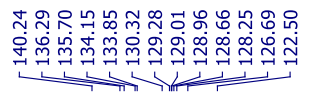 & 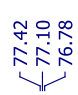 \\
\hline
\end{tabular}
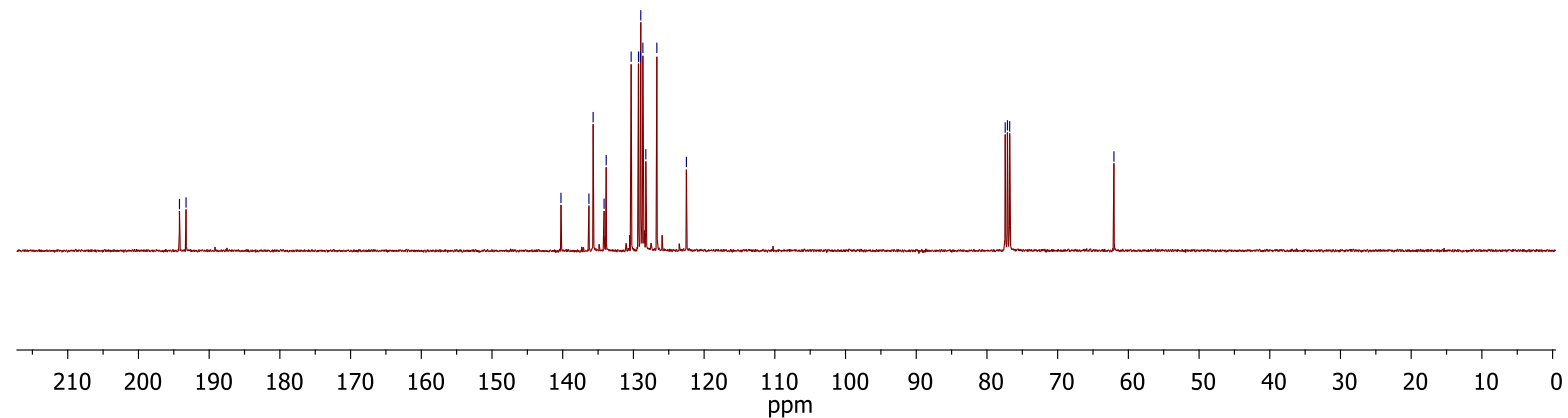

${ }^{13} \mathrm{C}$ NMR spectrum of 3 ha $\left(100.6 \mathrm{MHz}, \mathrm{CDCl}_{3}\right)$ 
<smiles>COc1ccc(C(=O)C(/C=C/c2ccccc2)C(=O)c2ccccc2)cc1</smiles>

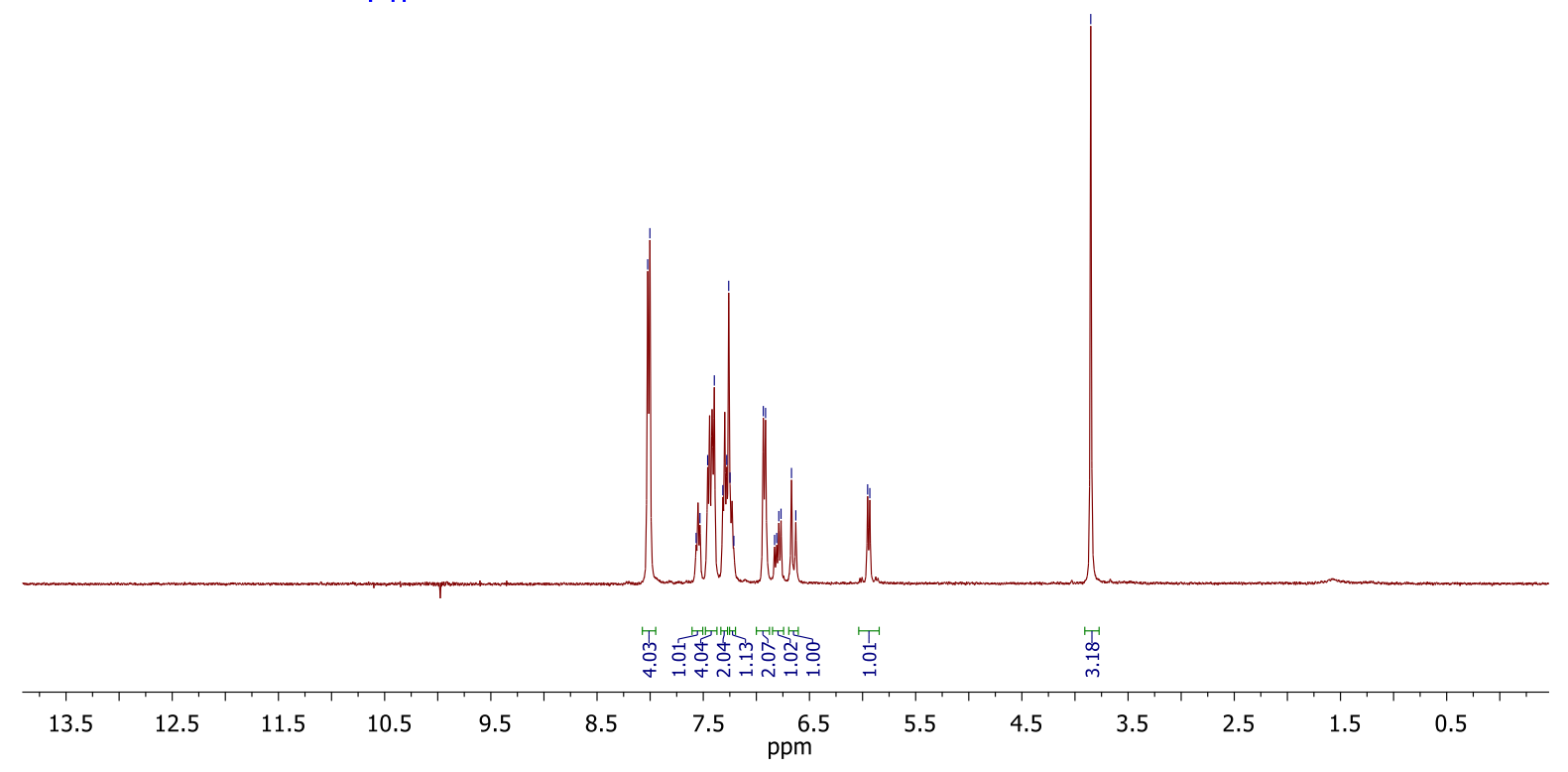

${ }^{1} \mathrm{H}$ NMR spectrum of $3 \mathbf{i a}\left(400.1 \mathrm{MHz}, \mathrm{CDCl}_{3}\right)$

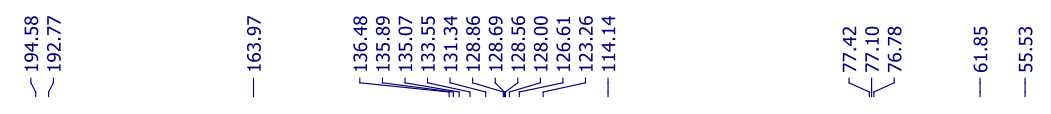

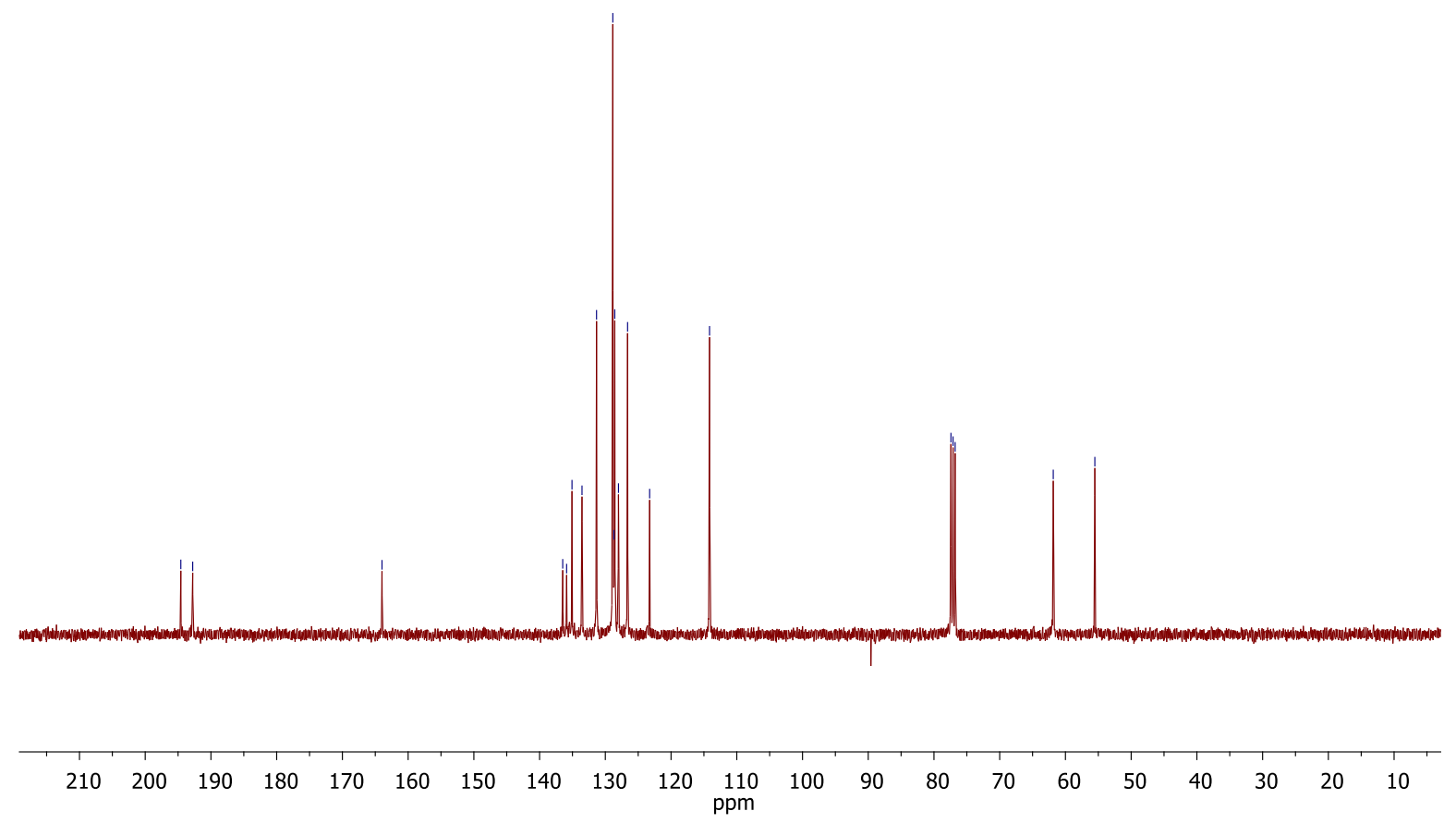

${ }^{13} \mathrm{C}$ NMR spectrum of 3 ia $\left(100.6 \mathrm{MHz}, \mathrm{CDCl}_{3}\right)$ 


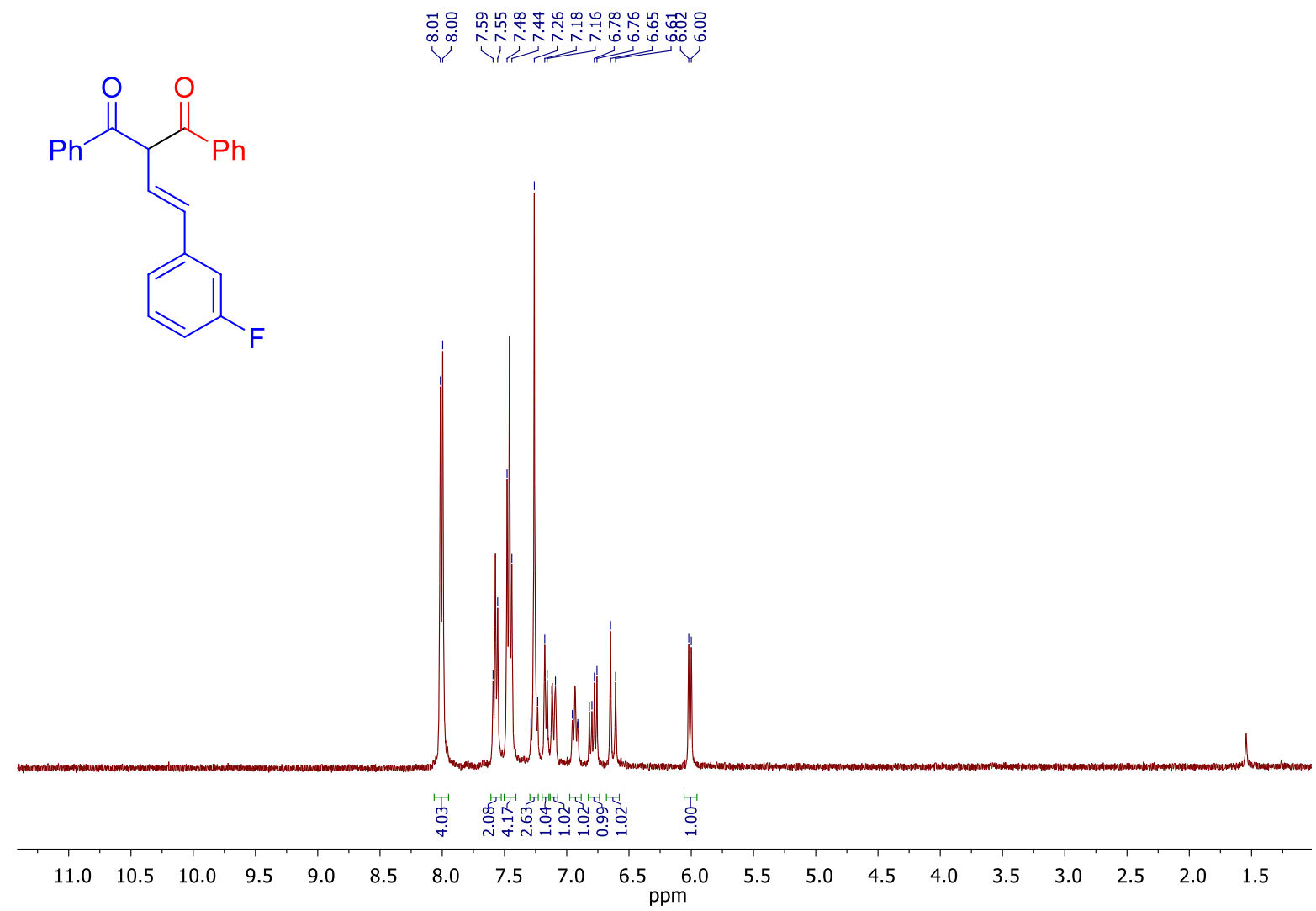

${ }^{1} \mathrm{H} \mathrm{NMR}$ spectrum of $\mathbf{3 j a}\left(400.1 \mathrm{MHz}, \mathrm{CDCl}_{3}\right)$

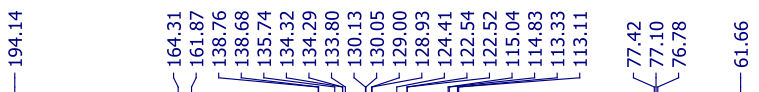

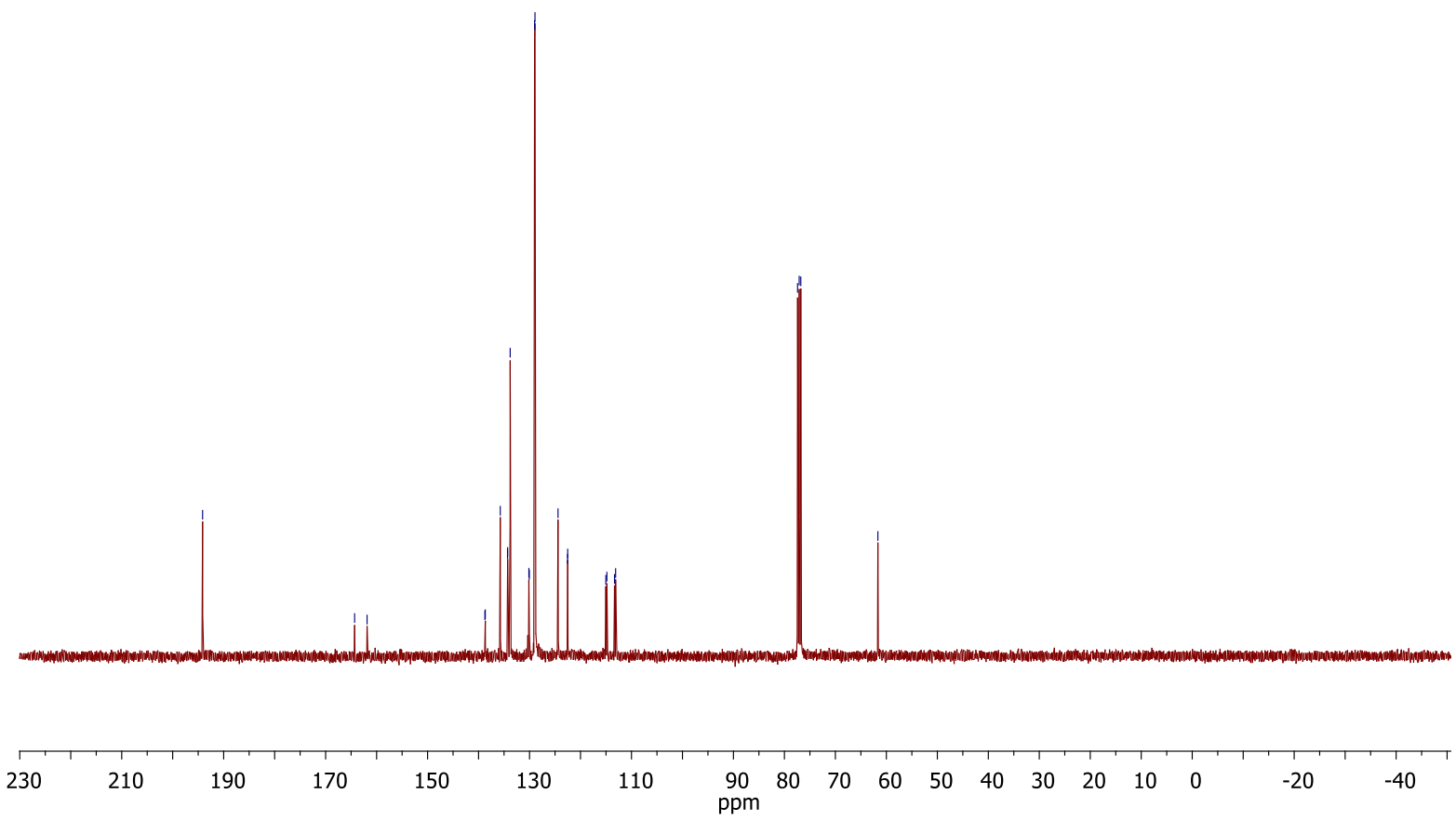

${ }^{13} \mathrm{C}$ NMR spectrum of $\mathbf{3 j a}\left(100.6 \mathrm{MHz}, \mathrm{CDCl}_{3}\right)$ 
<smiles>O=C(c1ccccc1)C(/C=C/c1ccsc1)c1ccccc1</smiles>

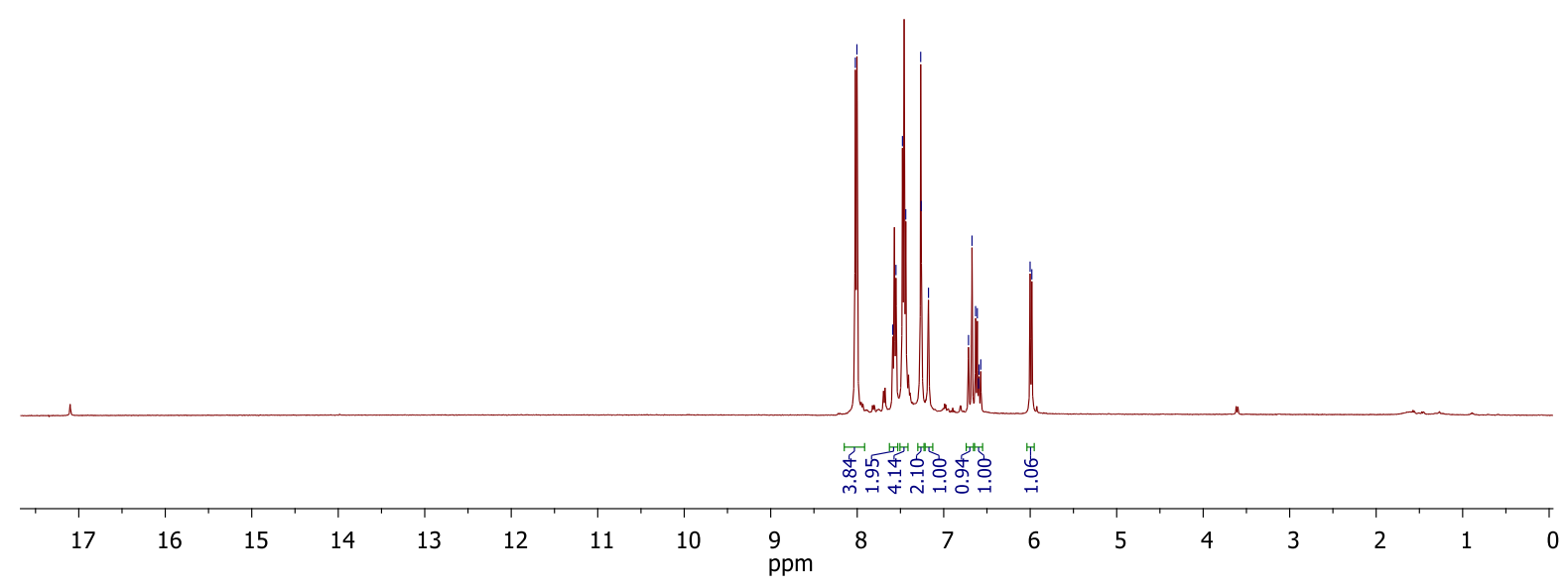

${ }^{1} \mathrm{H}$ NMR spectrum of $\mathbf{3 k a}\left(400.1 \mathrm{MHz}, \mathrm{CDCl}_{3}\right)$

\begin{tabular}{|c|c|c|}
\hline 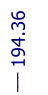 & 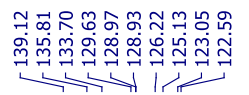 & 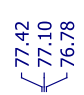 \\
\hline
\end{tabular}

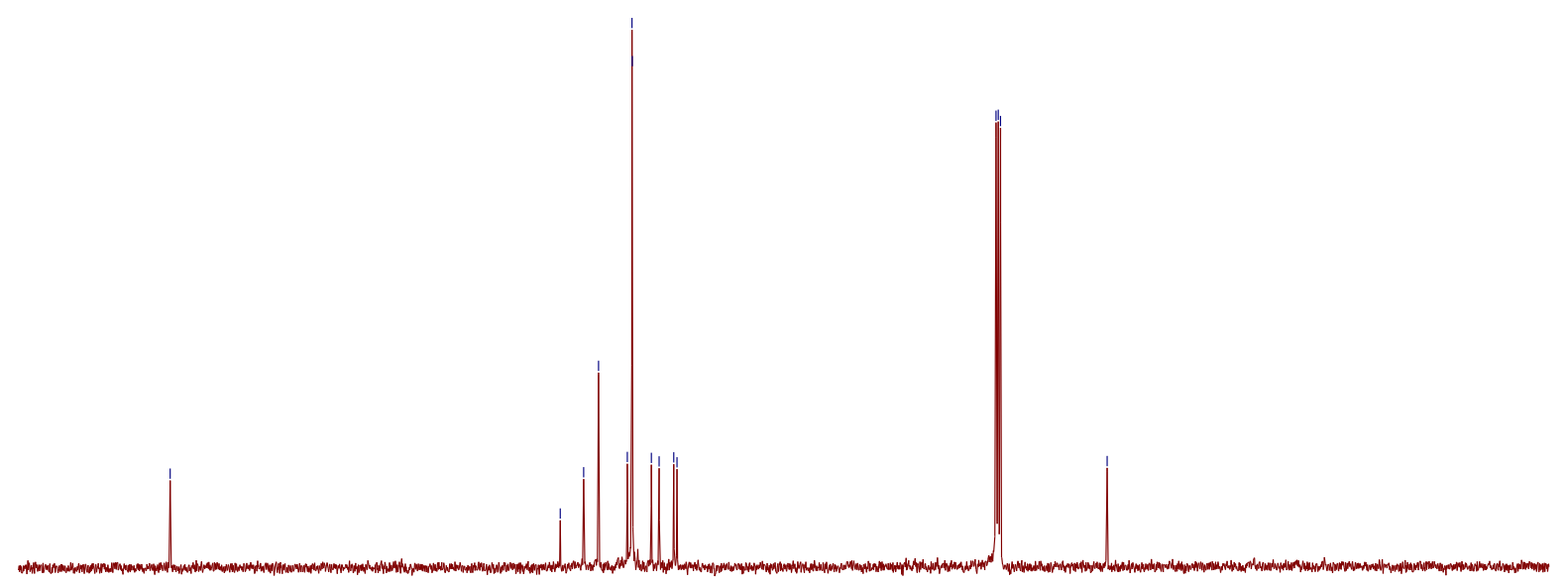

$\begin{array}{llllllllllllllllllllll}210 & 200 & 190 & 180 & 170 & 160 & 150 & 140 & 130 & 120 & \begin{array}{c}110 \\ \mathrm{ppm}\end{array} & 100 & 90 & 80 & 70 & 60 & 50 & 40 & 30 & 20 & 10 & 0\end{array}$

${ }^{13} \mathrm{C}$ NMR spectrum of $\mathbf{3 k a}\left(100.6 \mathrm{MHz}, \mathrm{CDCl}_{3}\right)$ 
${ }^{1} \mathrm{H}$ and ${ }^{13} \mathrm{C}$ NMR Spectra of Heterocycles 4, 5 and 6

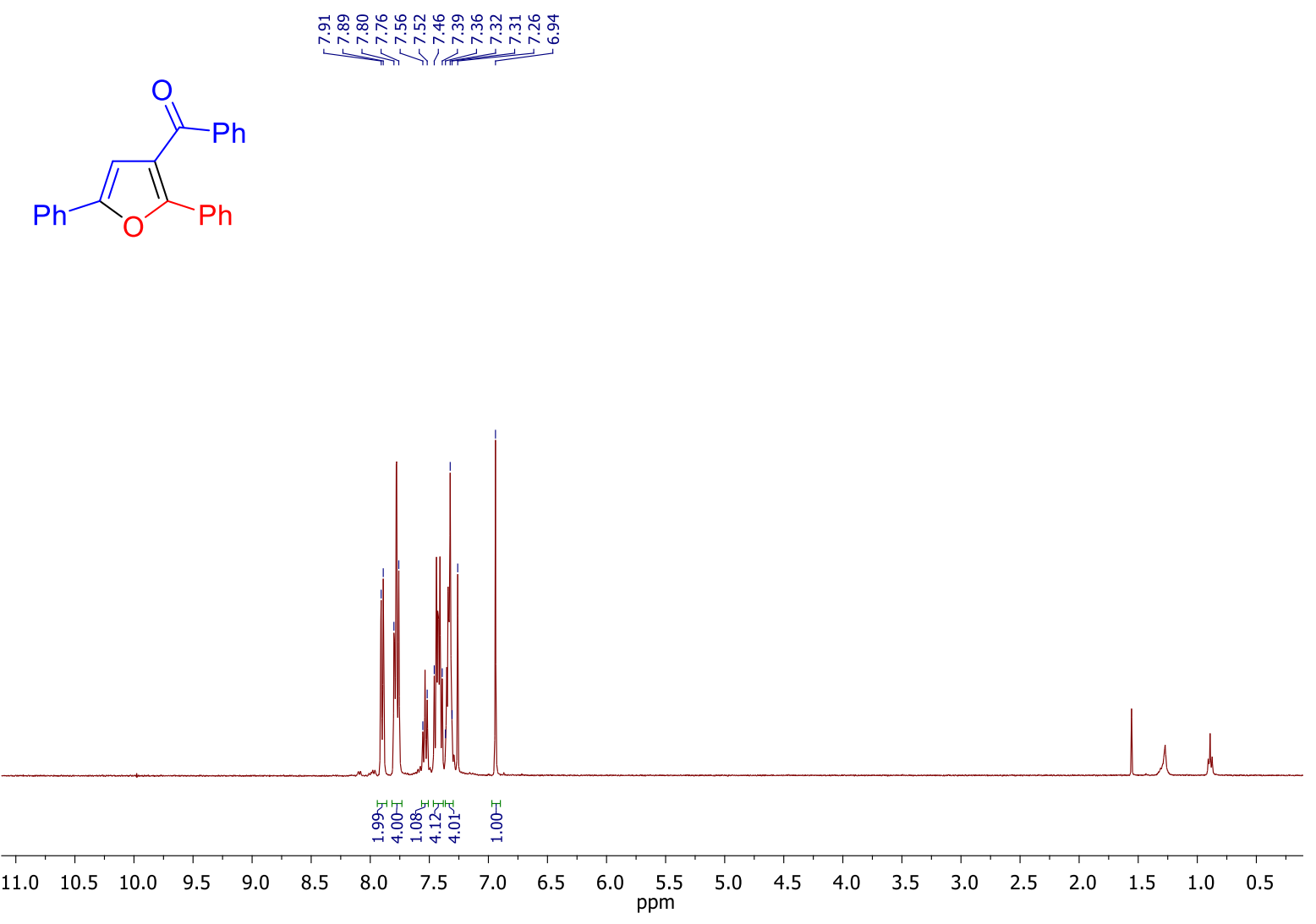

${ }^{1} \mathrm{H}$ NMR spectrum of $4\left(400.1 \mathrm{MHz}, \mathrm{CDCl}_{3}\right)$

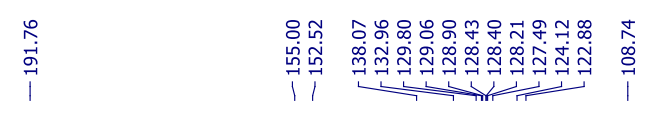

눈귱

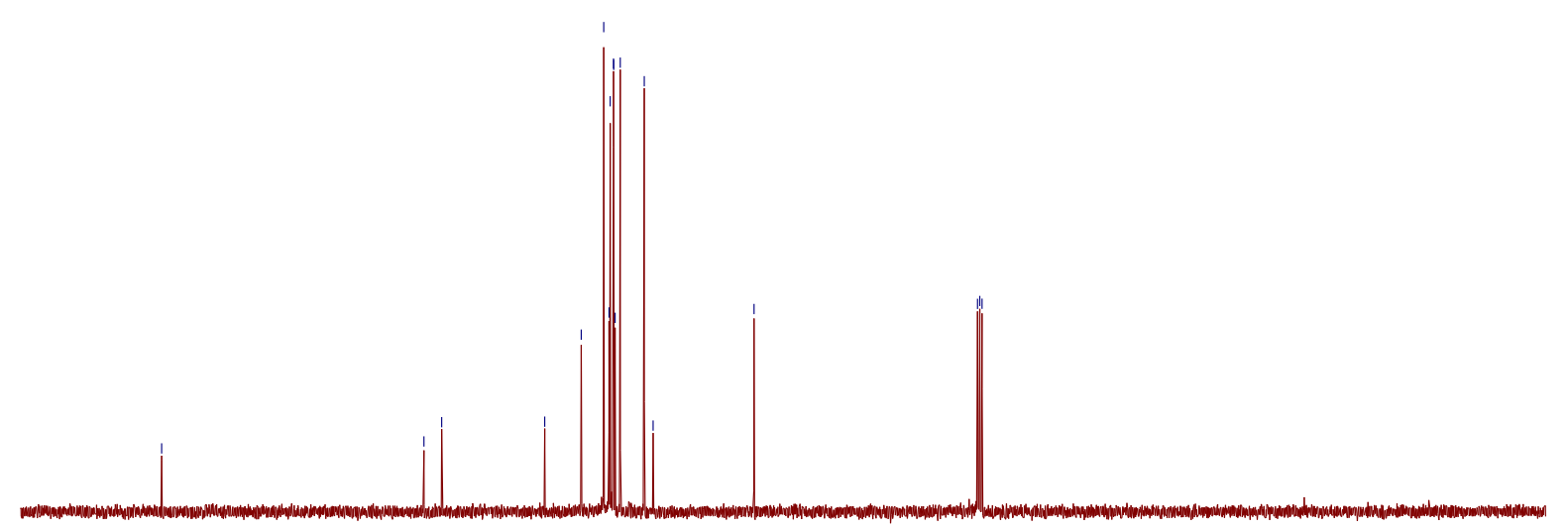

$\begin{array}{llllllllllllllllllllllllll}210 & 200 & 190 & 180 & 170 & 160 & 150 & 140 & 130 & 120 & \begin{array}{c}110 \\ \mathrm{ppm}\end{array} & 100 & 90 & 80 & 70 & 60 & 50 & 40 & 30 & 20 & 10 & 0\end{array}$

${ }^{13} \mathrm{C}$ NMR spectrum of $4\left(100.6 \mathrm{MHz}, \mathrm{CDCl}_{3}\right)$ 


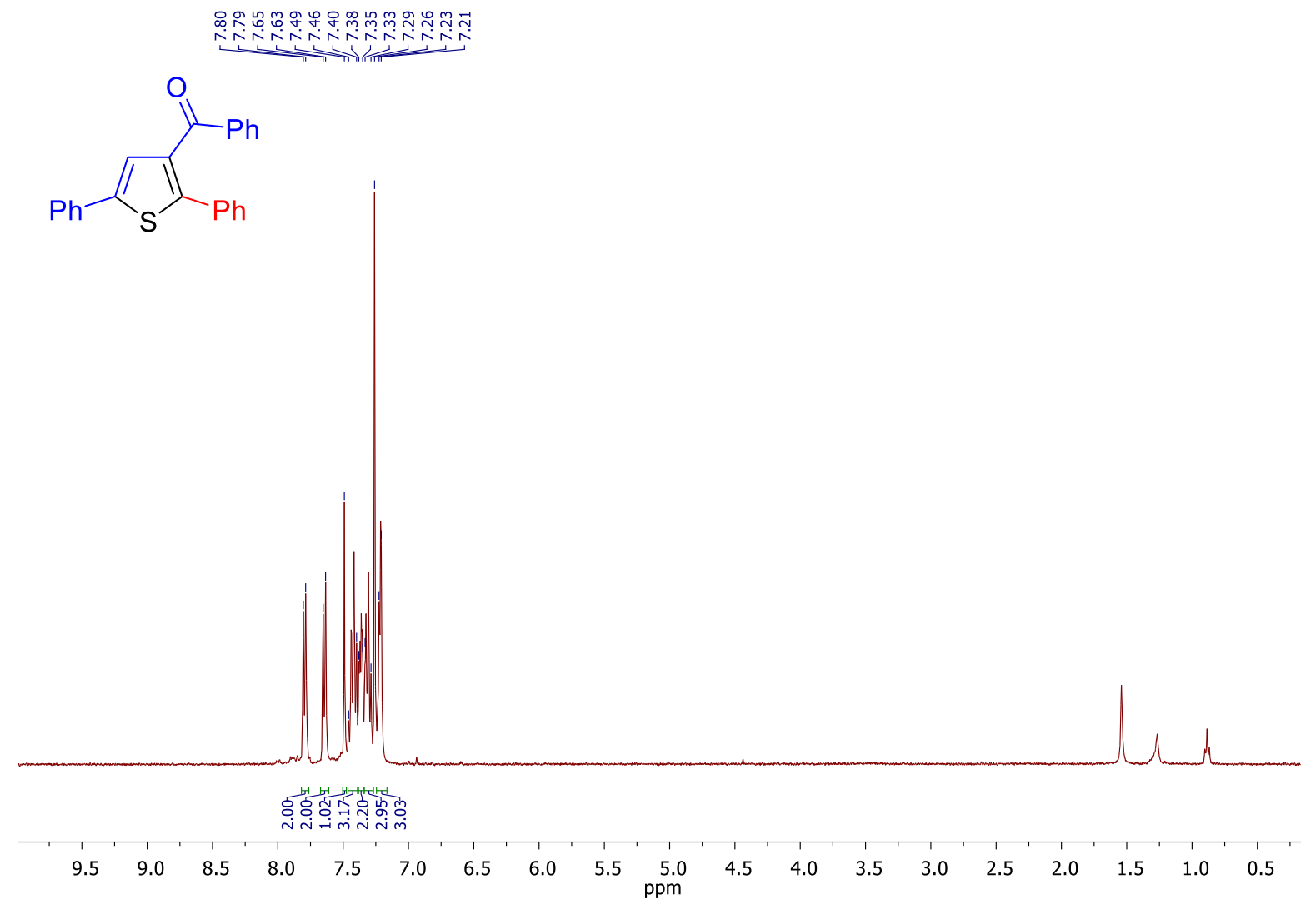

${ }^{1} \mathrm{H}$ NMR spectrum of $5\left(400.1 \mathrm{MHz}, \mathrm{CDCl}_{3}\right)$

\begin{tabular}{|c|c|}
\hline & 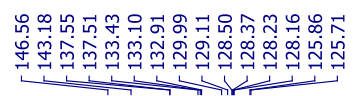 \\
\hline
\end{tabular}

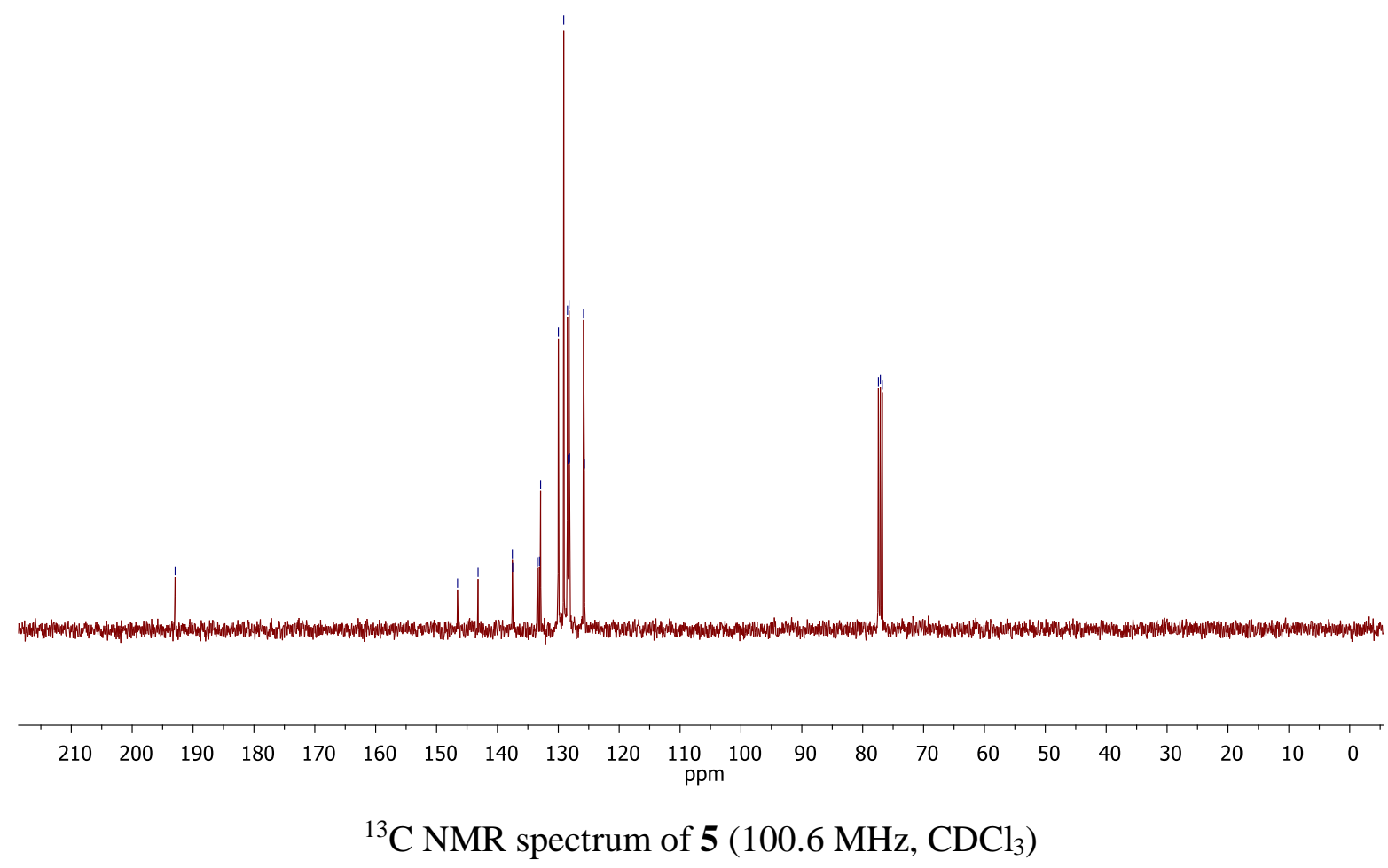




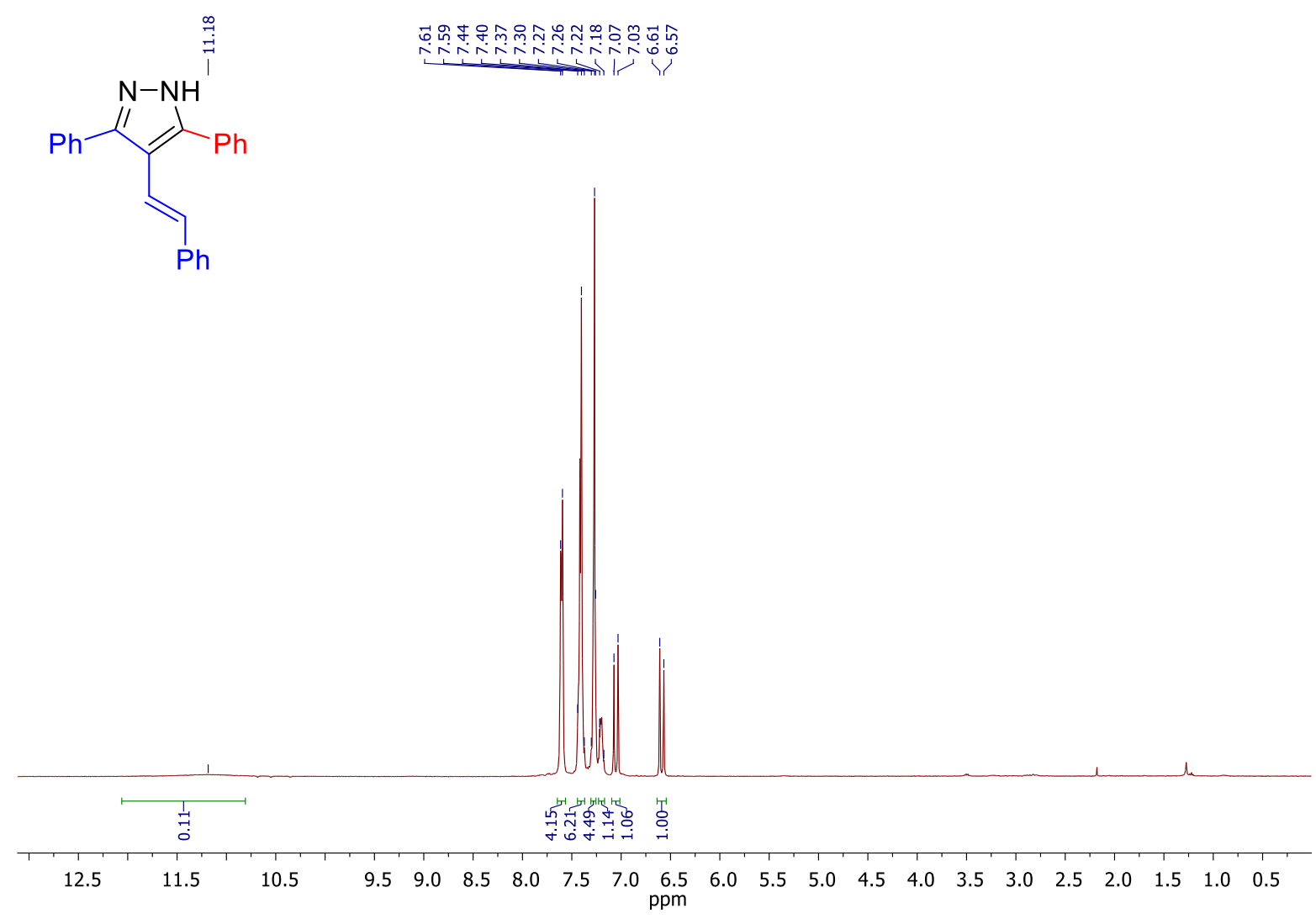

${ }^{1} \mathrm{H}$ NMR spectrum of $6\left(400.1 \mathrm{MHz}, \mathrm{CDCl}_{3}\right)$

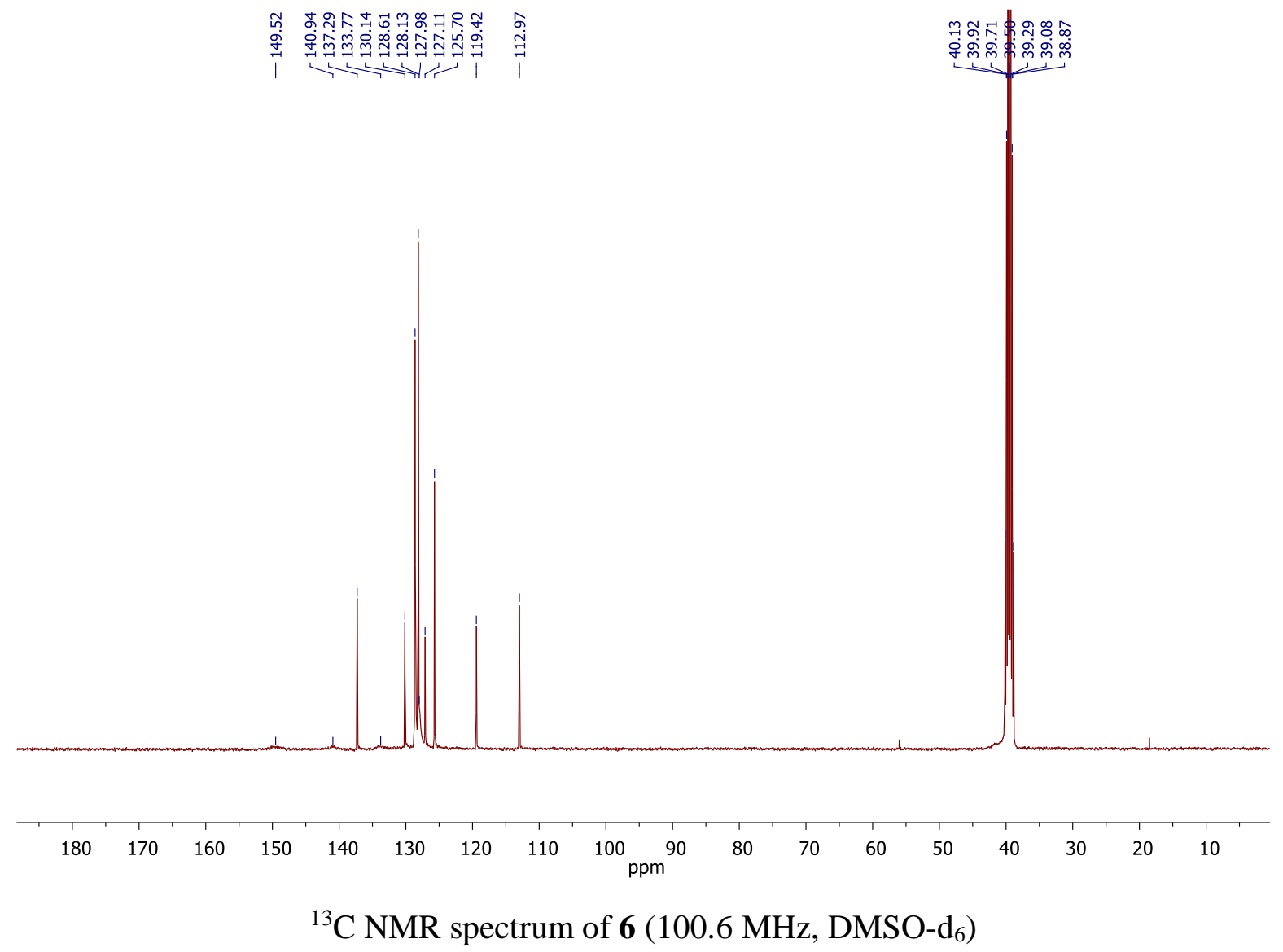


HRMS data for compounds 1c, 3-6

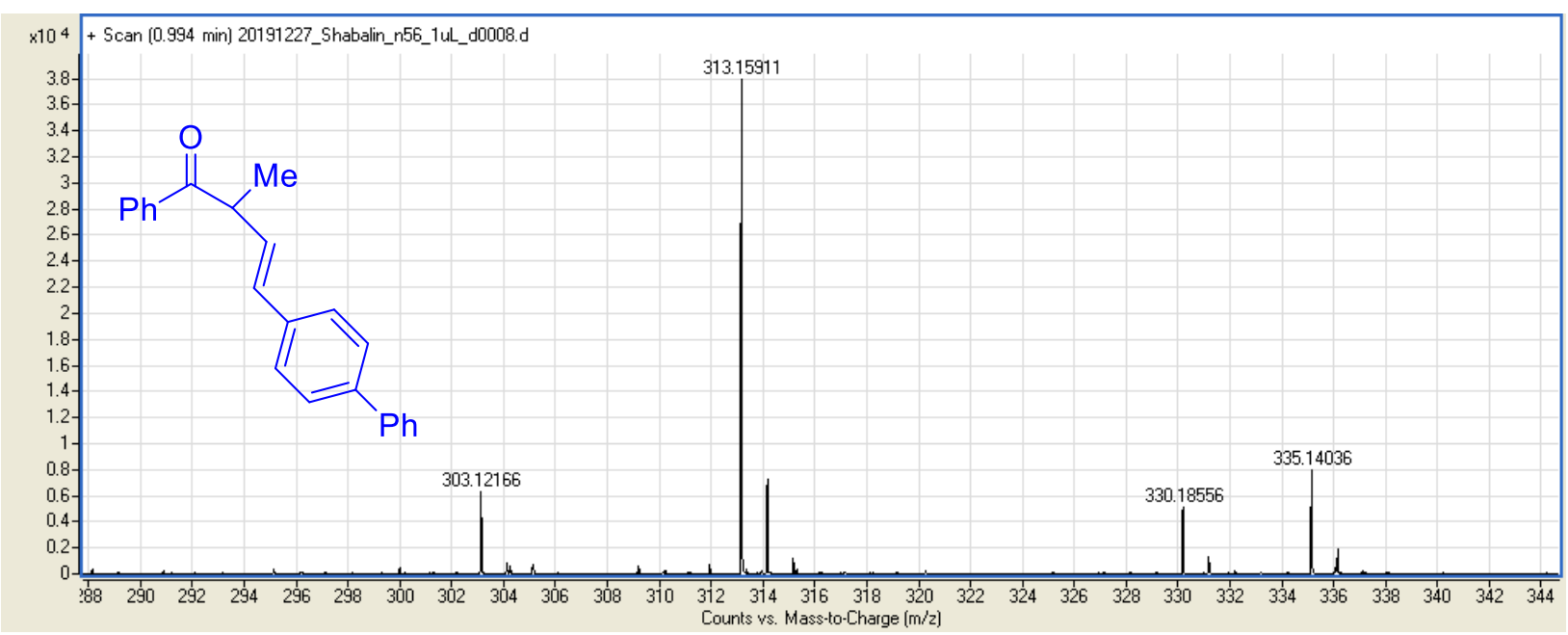

HRMS spectrum of 1c

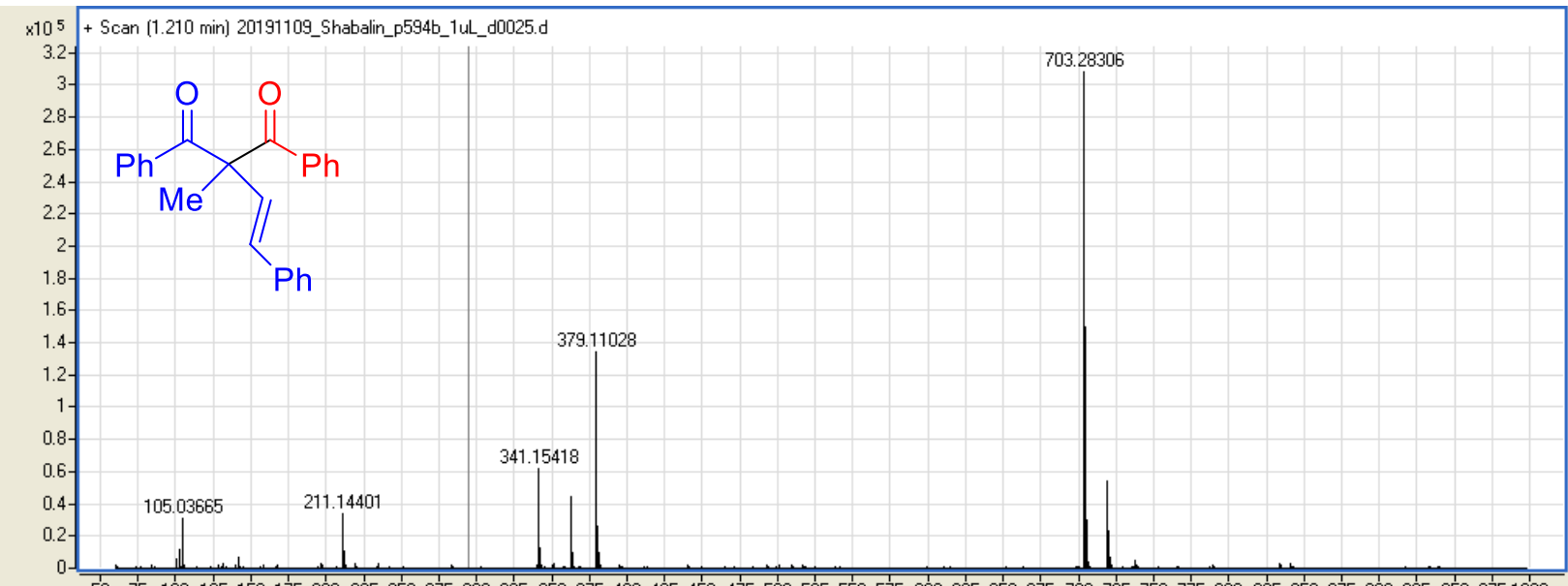

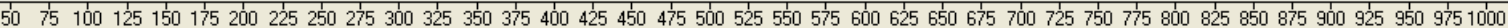
Counts vs. Mass-to-Charge $(\mathrm{m} / \mathrm{z})$

HRMS spectrum of $\mathbf{3 a a}$

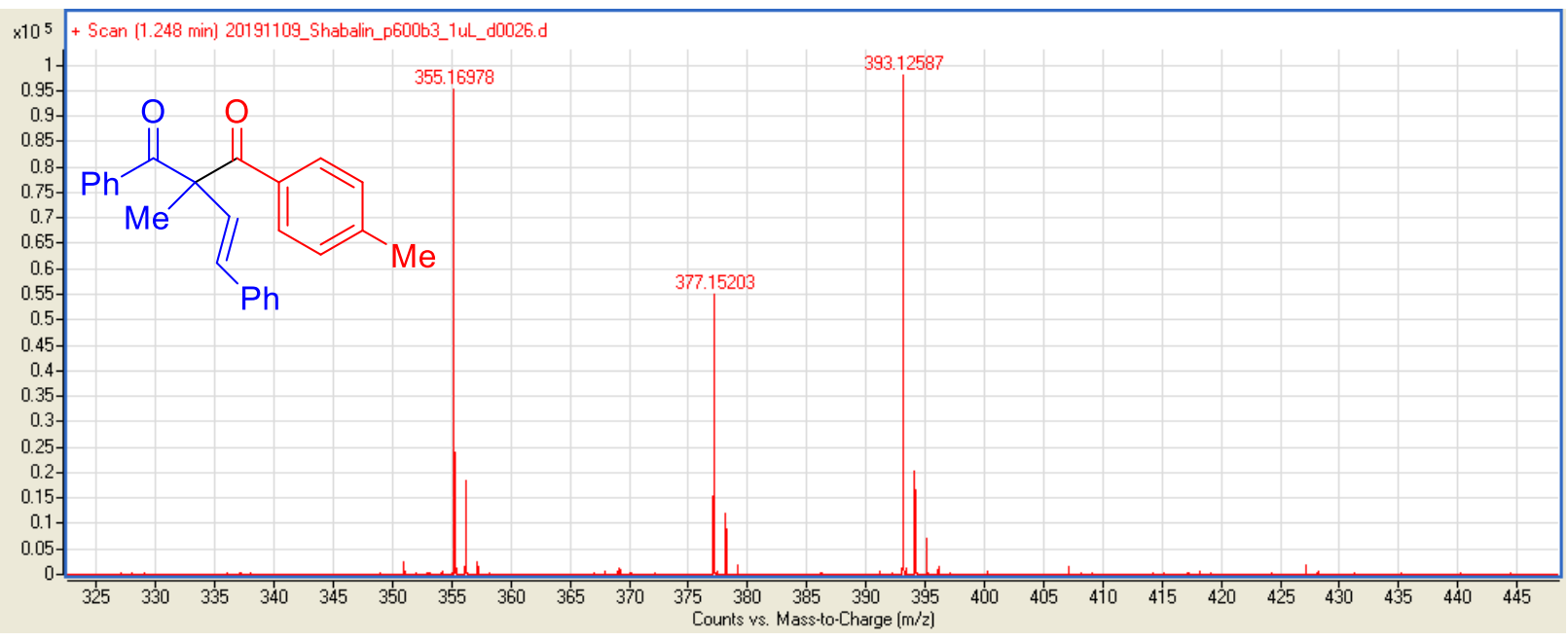

HRMS spectrum of $\mathbf{3 a b}$ 


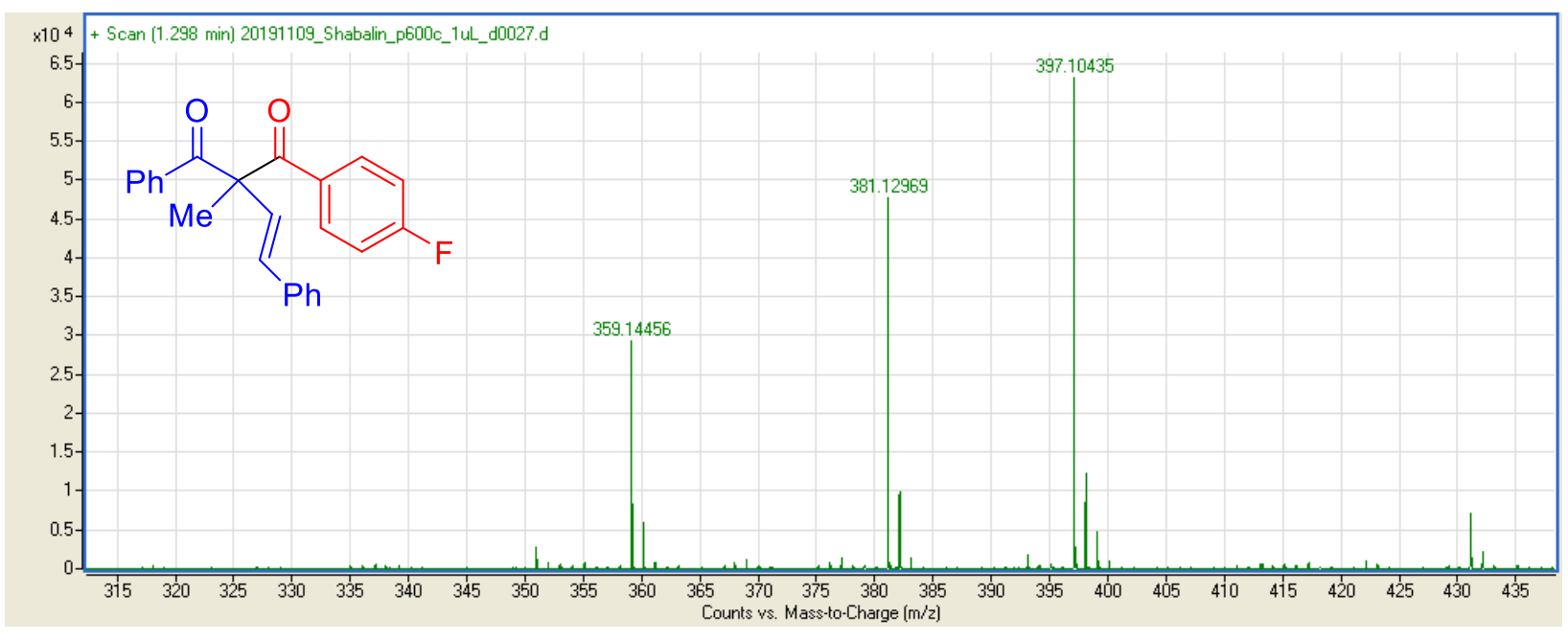

HRMS spectrum of 3ac

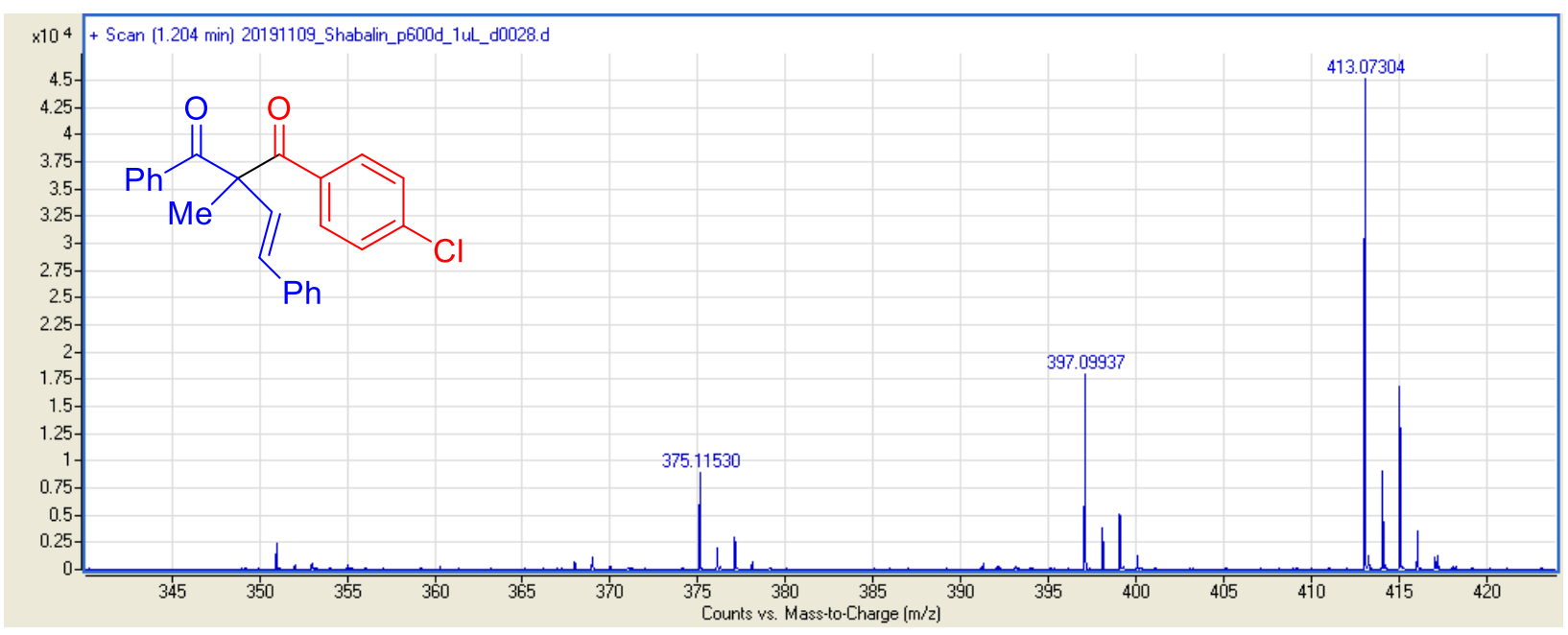

HRMS spectrum of $\mathbf{3 a d}$

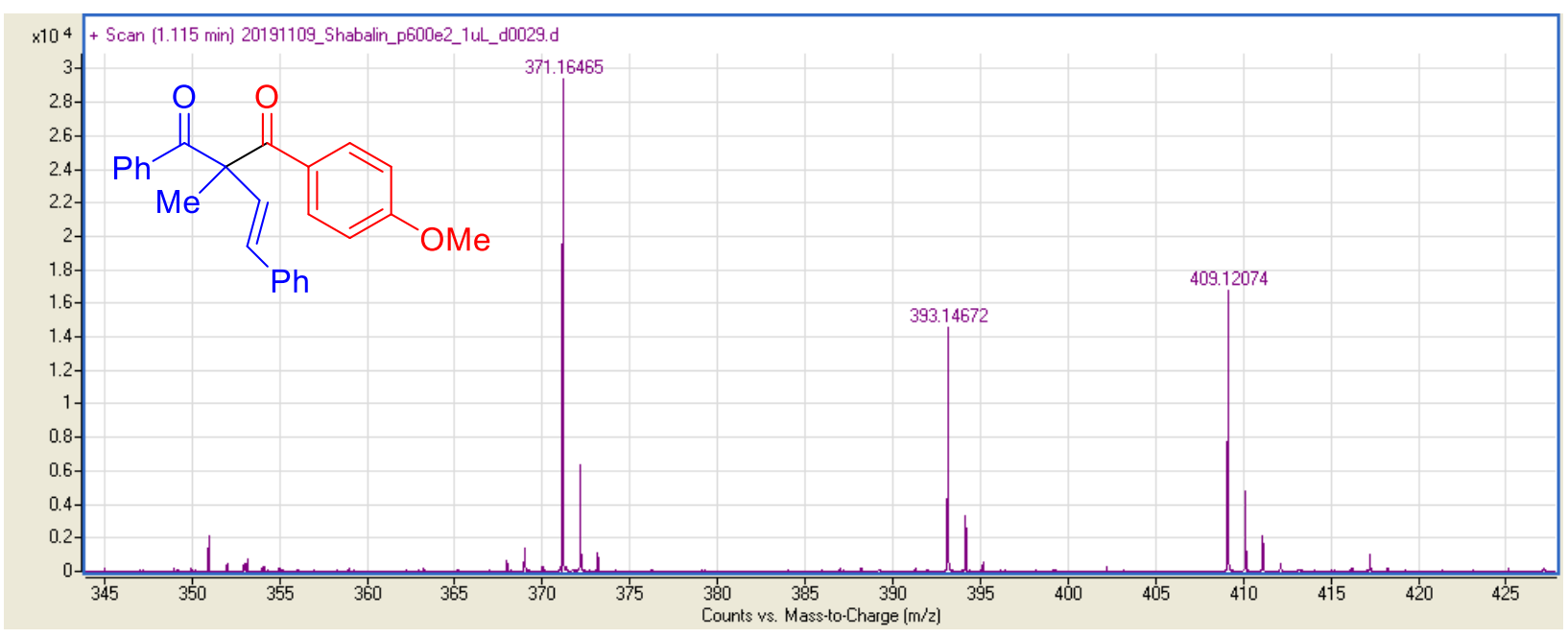

HRMS spectrum of $\mathbf{3 a e}$ 


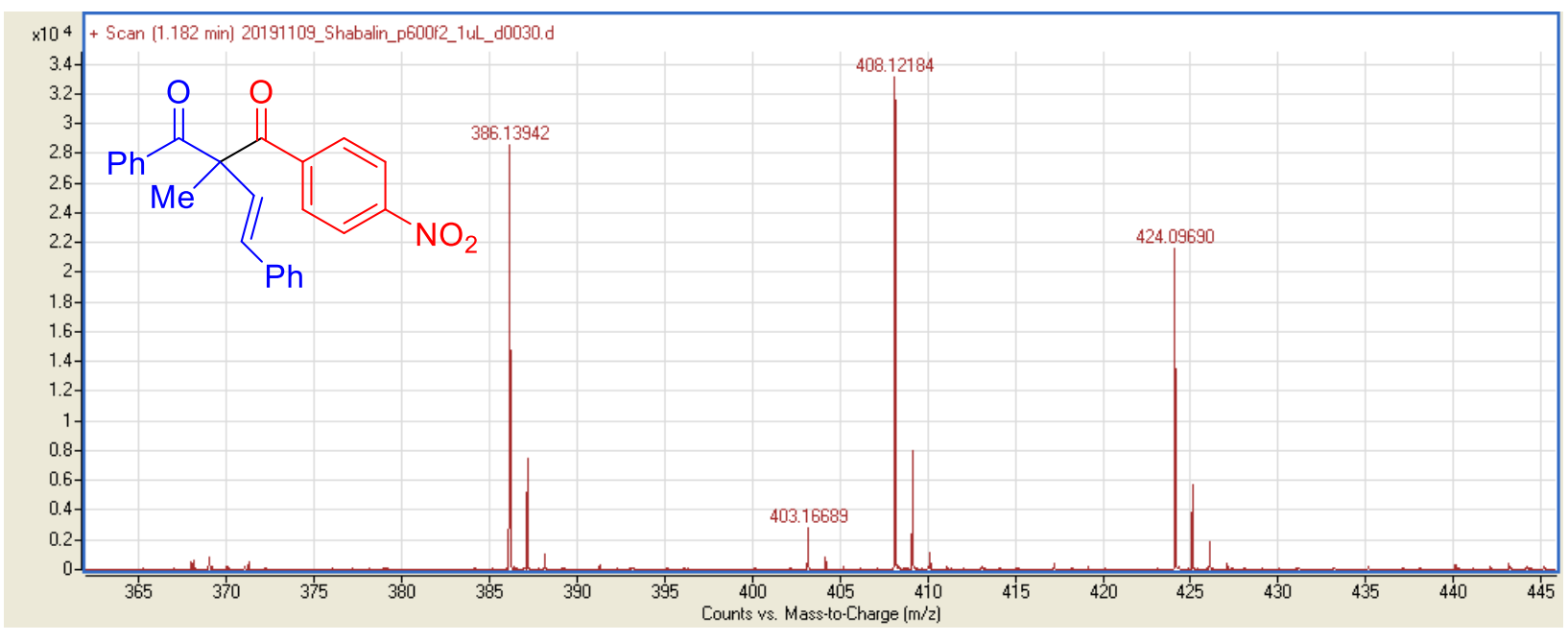

HRMS spectrum of 3af

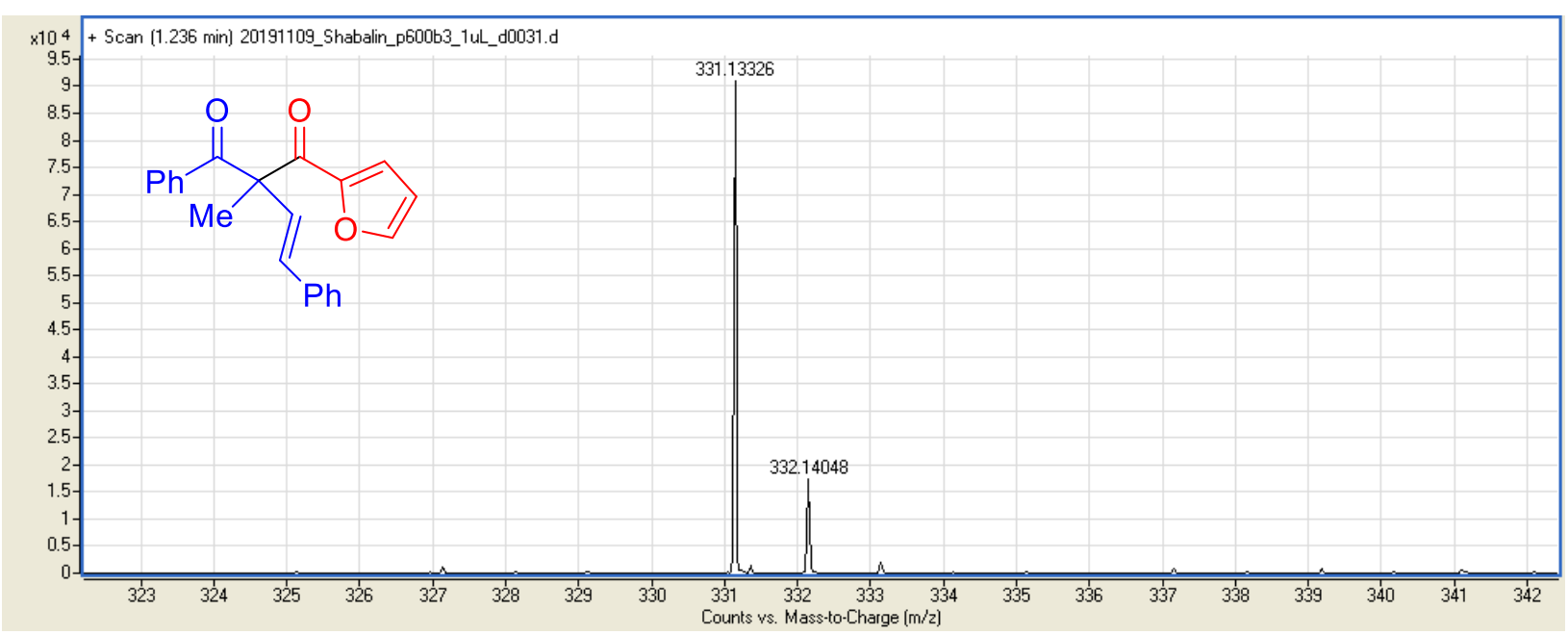

HRMS spectrum of $\mathbf{3 a g}$

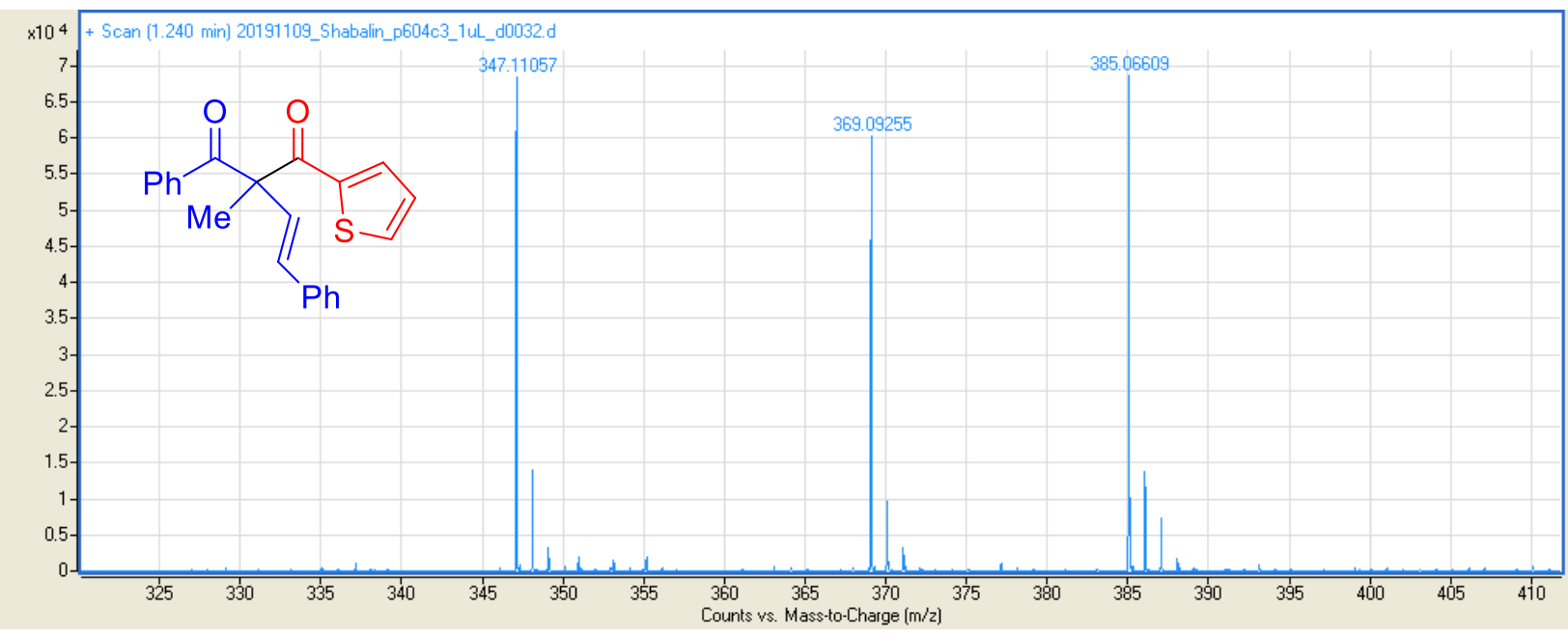

HRMS spectrum of 3ah 


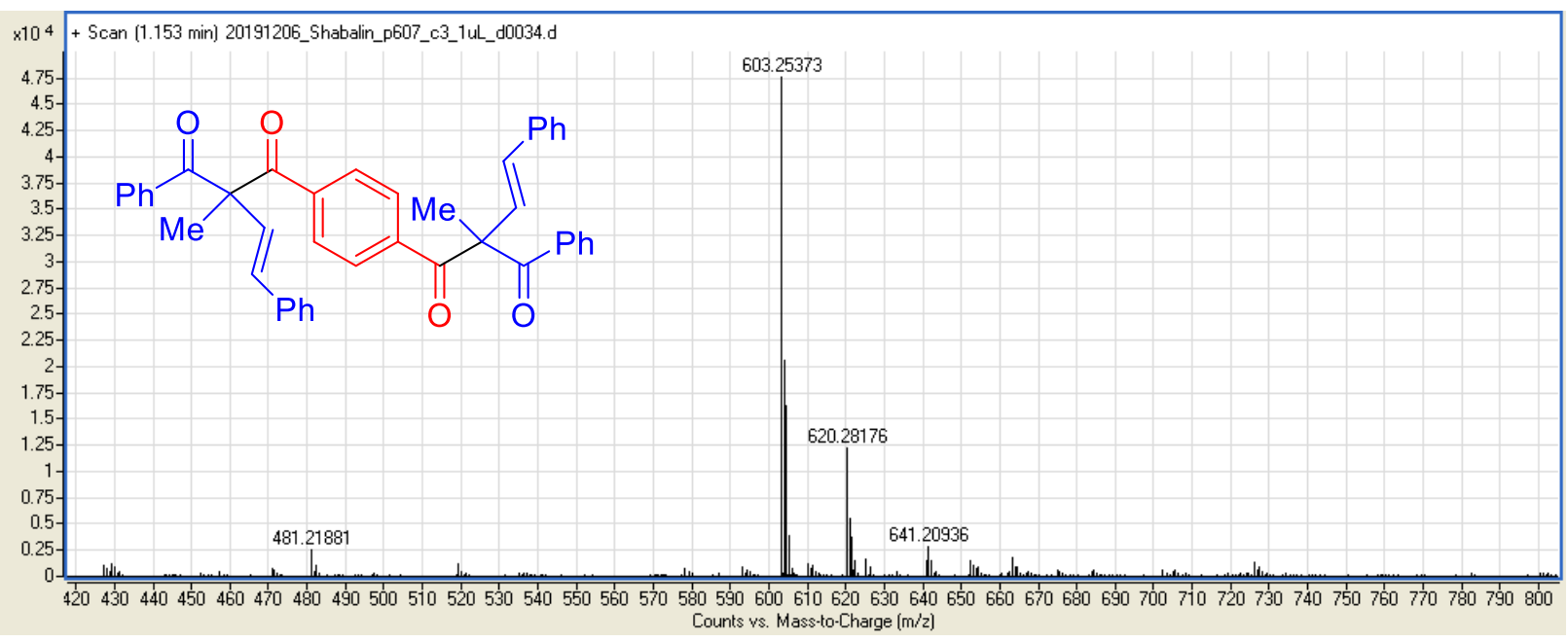

HRMS spectrum of 3ai

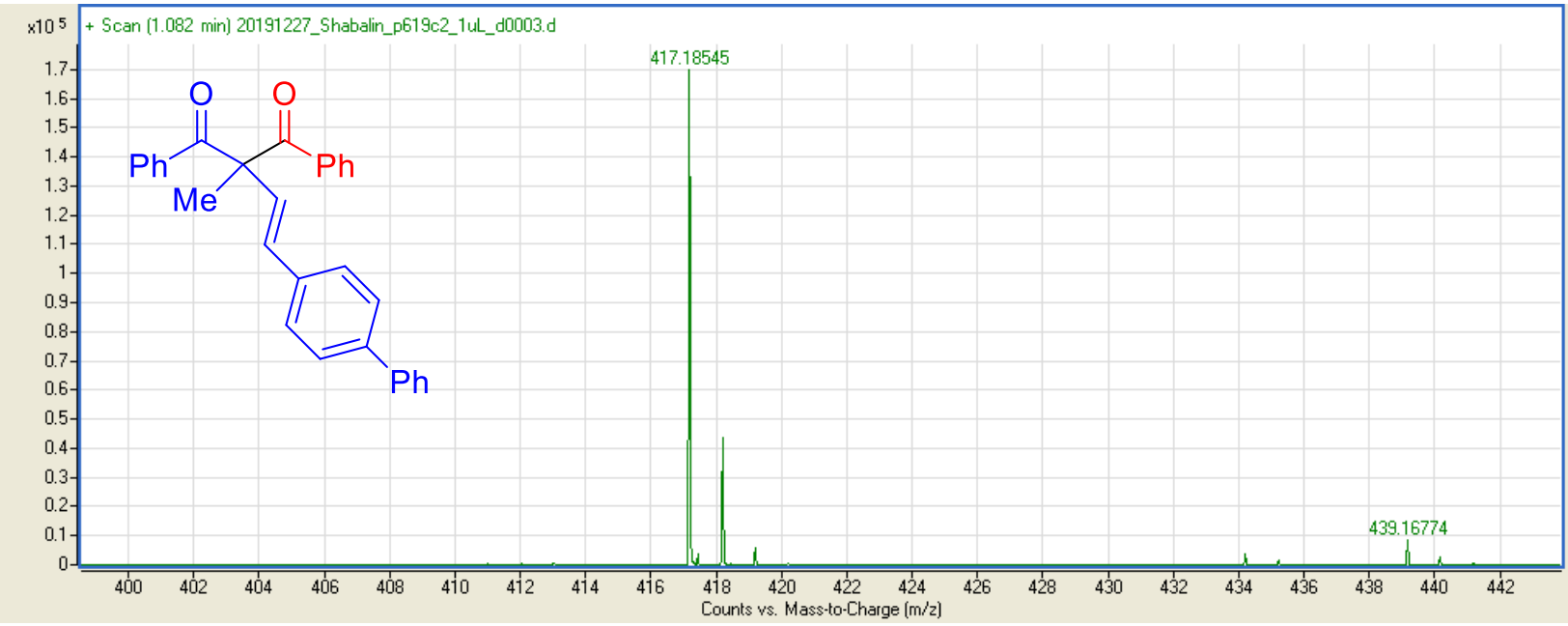

HRMS spectrum of 3ca

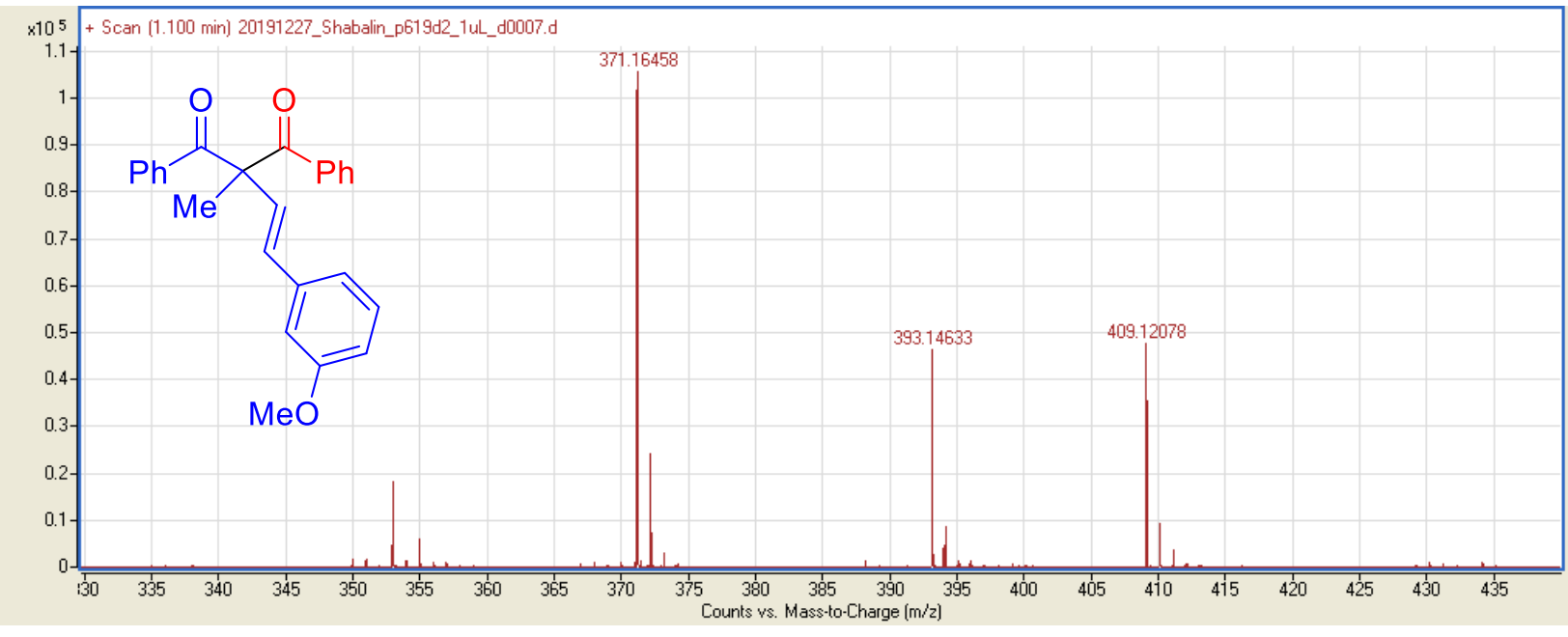

HRMS spectrum of 3da 


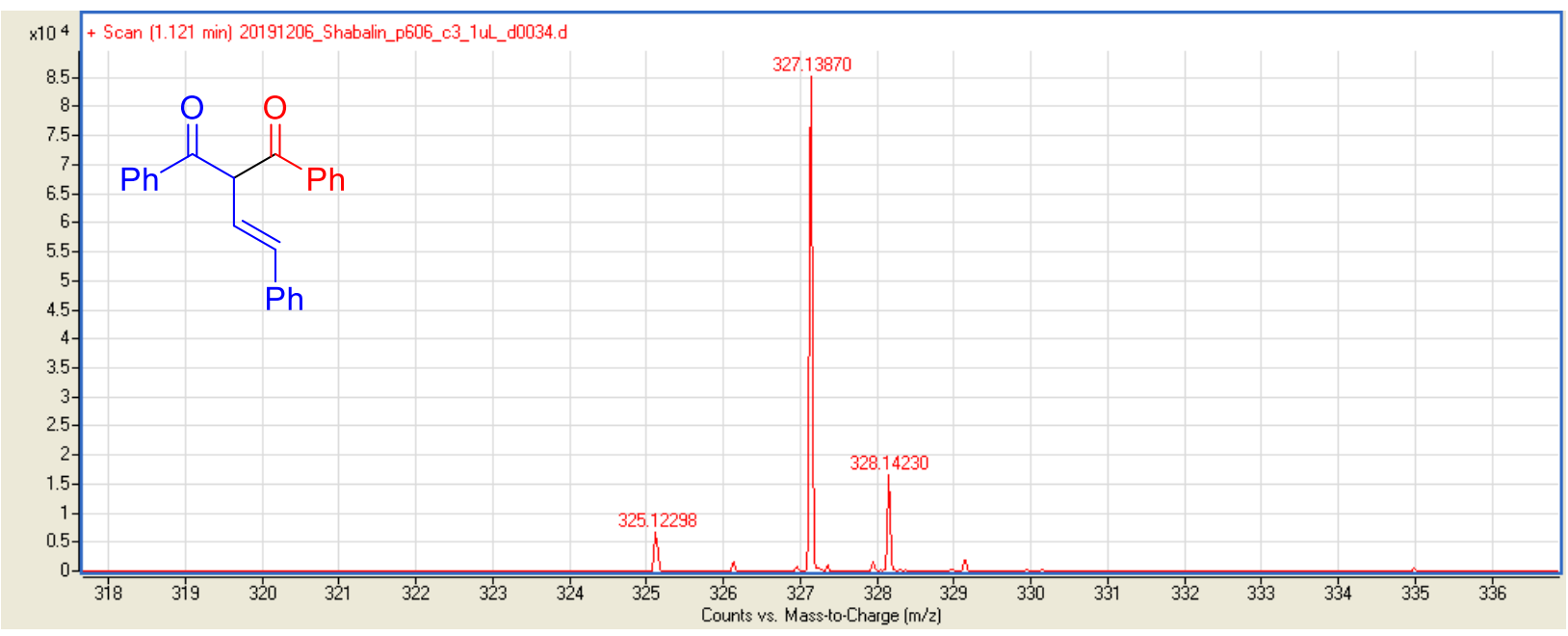

HRMS spectrum of 3ea

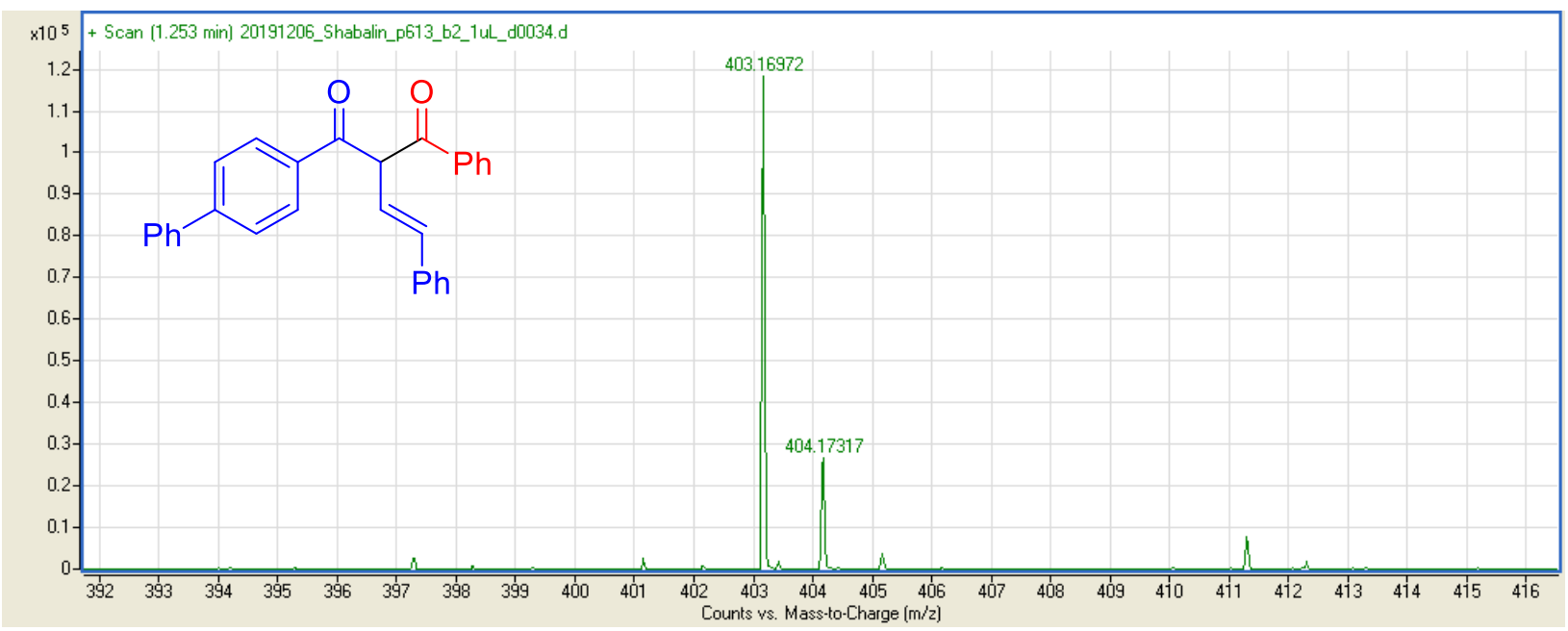

HRMS spectrum of $\mathbf{3 f a}$

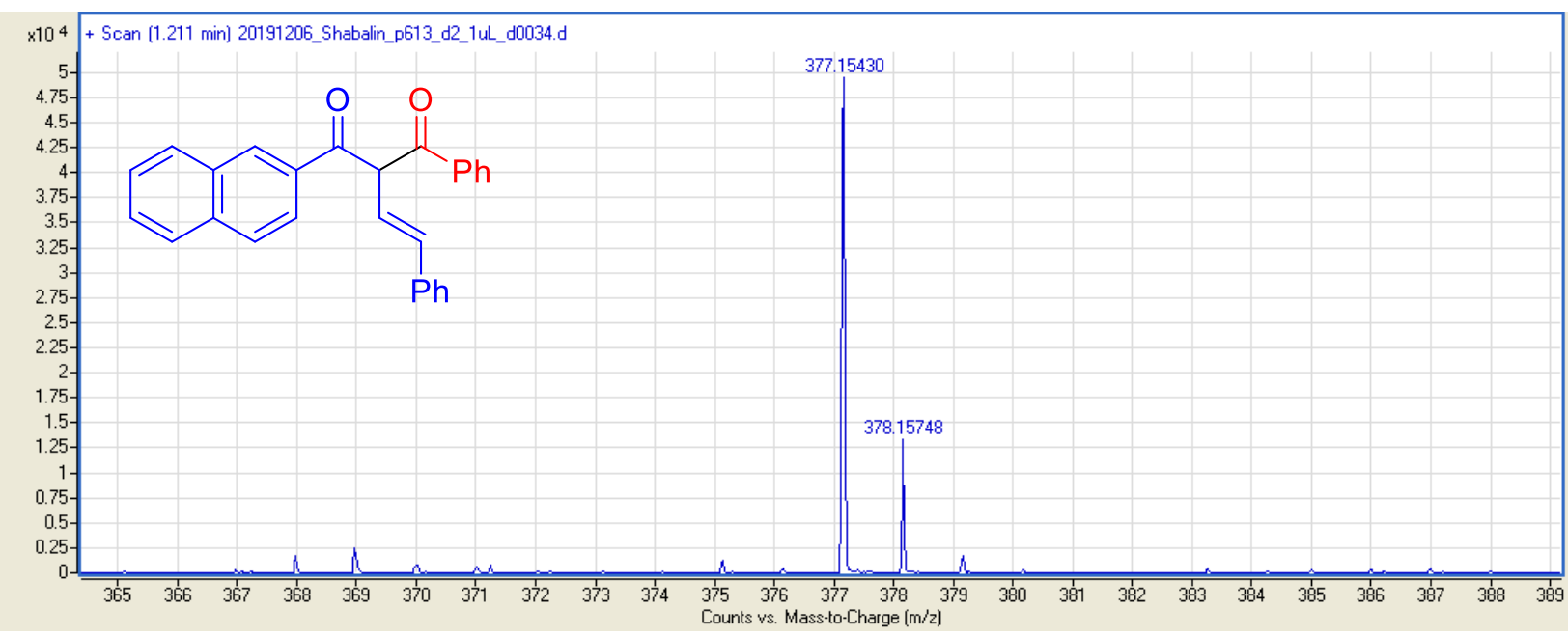

HRMS spectrum of $\mathbf{3 g a}$ 


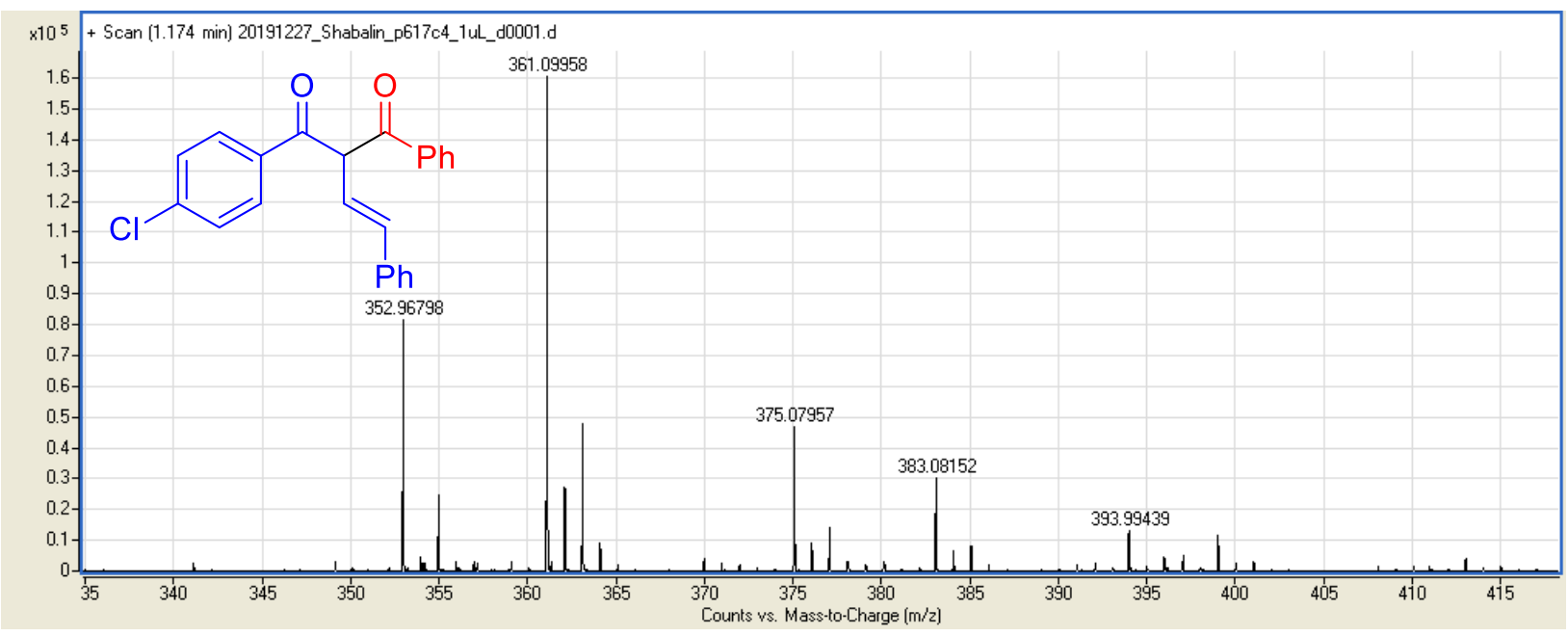

HRMS spectrum of 3 ha

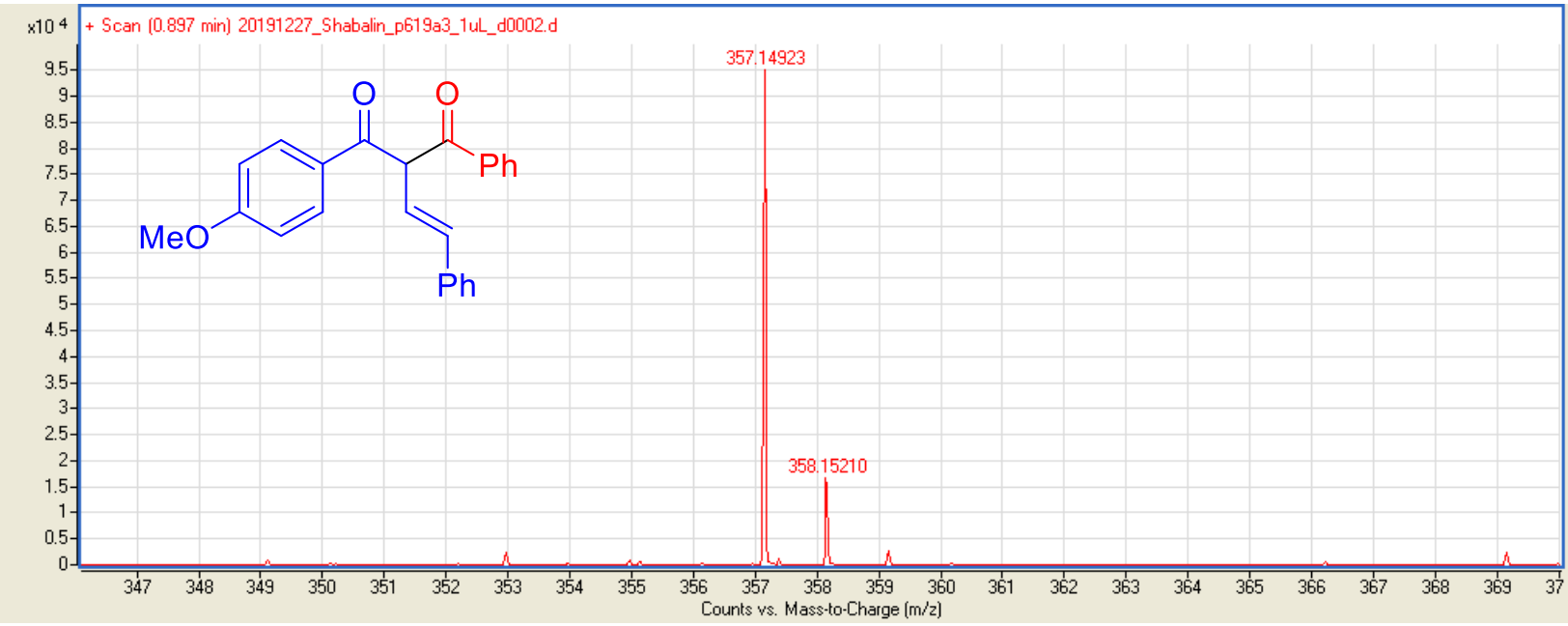

HRMS spectrum of 3 ia

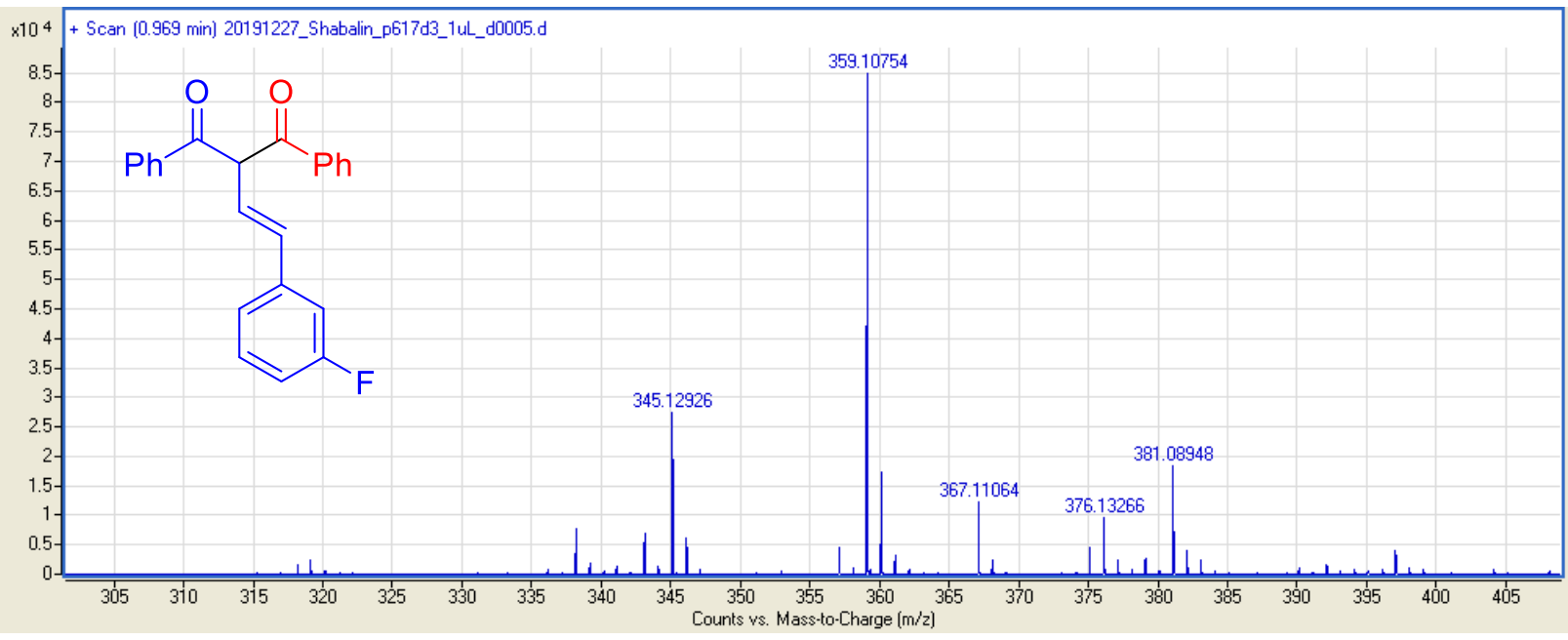

HRMS spectrum of $\mathbf{3 j a}$ 


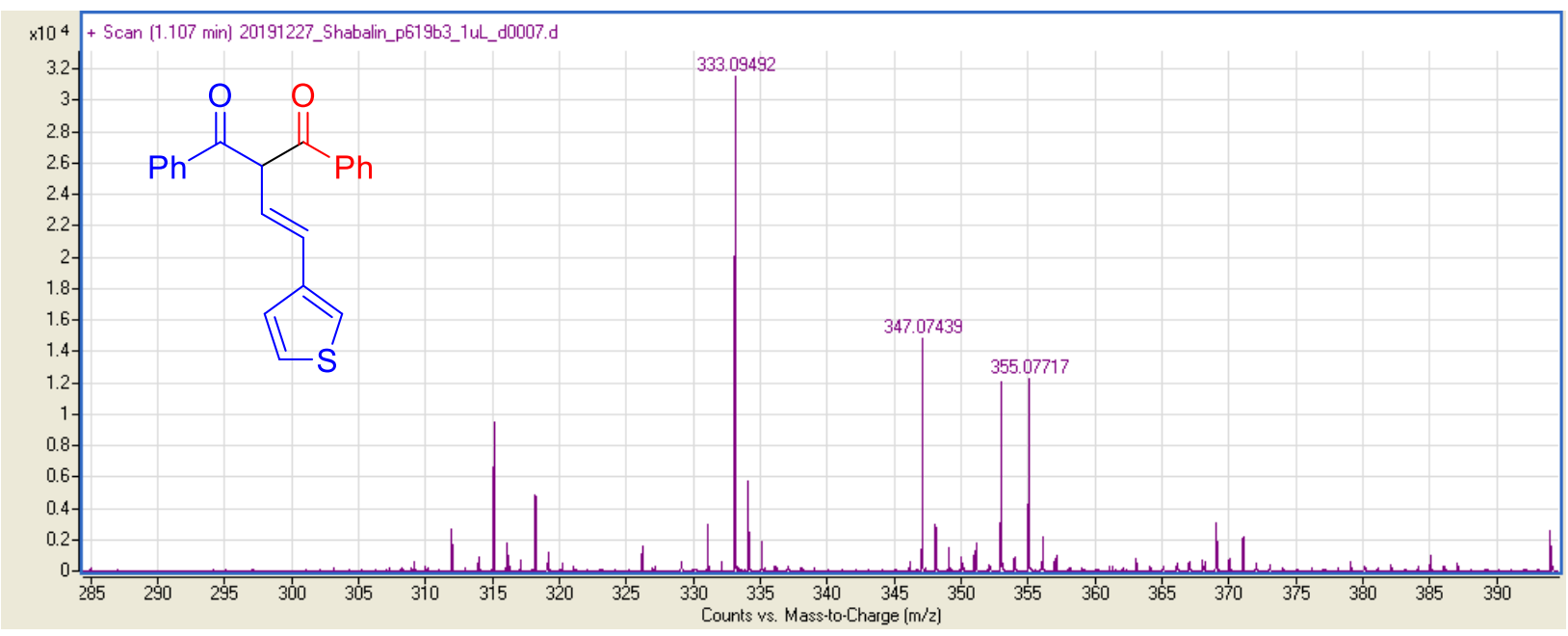

HRMS spectrum of 3ka

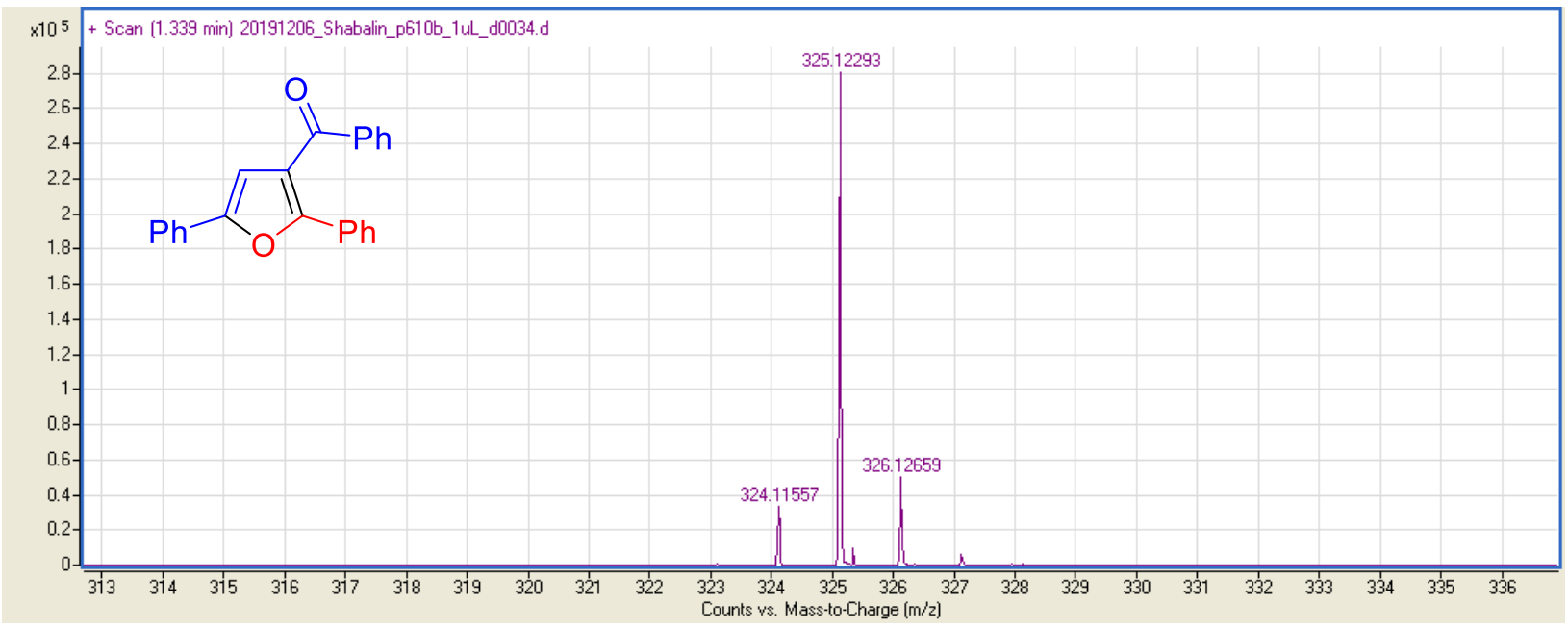

HRMS spectrum of $\mathbf{4}$

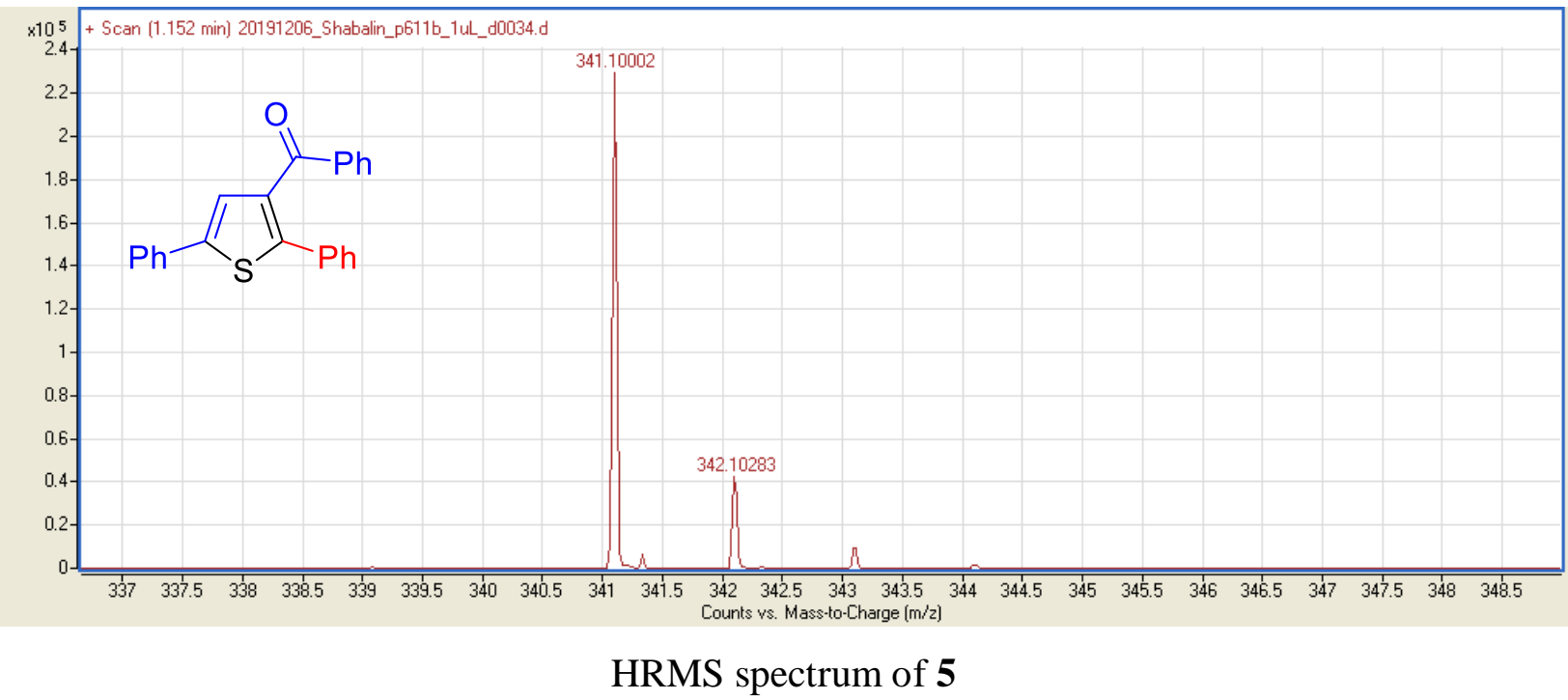




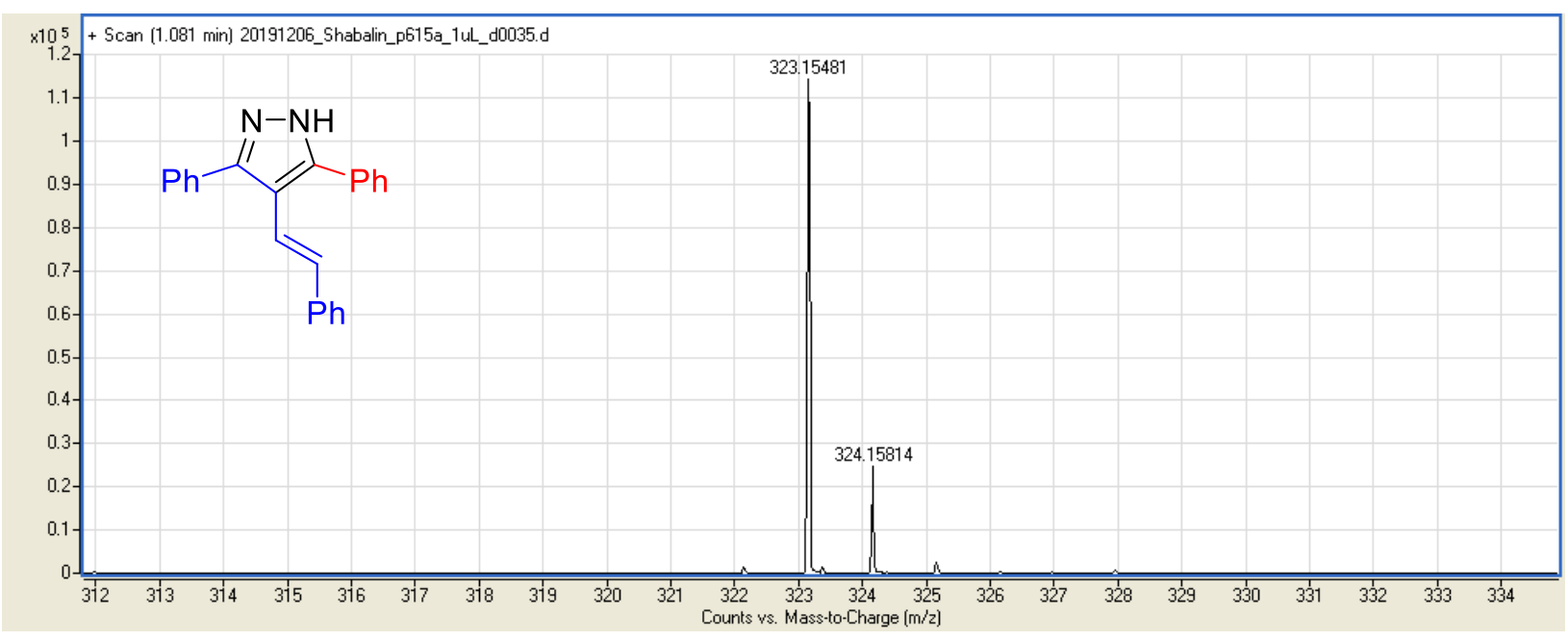

HRMS spectrum of $\mathbf{6}$ 